\title{
Understanding poverty-related diseases in Cameroon from a salutogenic perspective
}

\section{Valerie Makoge}




\section{Thesis committee}

\section{Promotor}

Prof. Dr M.A. Koelen

Professor of Health and Society

Wageningen University \& Research

\section{Co-promotors}

Dr H. Maat

Assistant professor, Knowledge, Technology and Innovation

Wageningen University \& Research

Dr H.W. Vaandrager

Associate professor, Health and Society

Wageningen University \& Research

\section{Other members}

Prof. Dr J.W.M. van Dijk, Wageningen University \& Research

Prof. B.B. Lindström, Norwegian University of Science and Technology, Norway

Prof. Dr P. Richards, Wageningen University \& Research

Dr M.E. Ormond, Wageningen University \& Research

This research was conducted under the auspices of the Wageningen School of Social Sciences (WASS) 


\section{Understanding \\ poverty-related diseases \\ in Cameroon \\ from a \\ salutogenic perspective}

\section{Valerie Makoge}

\section{Thesis}

submitted in fulfilment of the requirements for the degree of doctor at Wageningen University by the authority of the Rector Magnificus, Prof. Dr A.P.J. Mol in the presence of the Thesis Committee appointed by the Academic Board to be defended in public on the $7^{\text {th }}$ of July 2017

at $11 \mathrm{am}$ in the Aula. 
Valerie Makoge

Understanding poverty-related diseases in Cameroon from a salutogenic perspective.

207 pages.

PhD thesis, Wageningen University, Wageningen, the Netherlands (2017) With references, with summary in English

ISBN: 978-94-6343-451-5

DOI: $10.18174 / 416389$ 
To Alex, Astera-Lainey, Bonny, Siny Jr and Siny Sr 
Abstract 


\section{Abstract}

Poverty-related diseases (PRDs) assume poverty as a determinant in catching disease and an obstacle for cure and recovery. In Cameroon, over $48 \%$ of the population lives below the poverty line. This dissertation starts from the premise that the relation between poverty and disease is mediated by a person's capacity to cope with the challenges posed by the natural and social environment. The central problem addressed is that in (inter)national health promotion, disease eradication is overemphasized whereas strengthening the capacity of people to cope with harsh conditions is disregarded. Research efforts show a similar division in emphasis, resulting in a limited understanding of the way people deal with health challenges in conditions of poverty. This dissertation is based on the salutogenic model of health that emphasizes the combined effects of (natural) disease conditions, mental conditions and social factors as determinants of health. This implies an emphasis on health as a positive strategy to deal with stressors and also an emphasis on the agency of people to respond to challenges that hamper their health and wellbeing. The study is carried out among two different groups of people in Cameroon. These are workers including dependents of workers of the Cameroon Development Corporation (CDC) and students from the universities of Buea and Yaoundé. The overall aim of this dissertation is to understand how conditions of poverty impact the health of people and how they manage these challenges. Specifically, the study aims to unravel the interlink-ages between poverty and health by creating a deeper understanding of the social and material dynamics which enable people's capacity to preserve health, anticipate health risks, and mitigate or recover from stressors such as PRDs. The main research question addressed is: What factors underlie the maintenance of good health and overcoming stressors in the face of PRDs in Cameroon?

Different research methods were used to collect data. Interviews were carried out with respondents from both groups addressing PRDs, other stressors and coping strategies. General surveys were carried out to identify perceptions as well as health behaviour patterns across the two groups. Standardized surveys were carried out to measure individual factors such as sense of coherence, resilience, self-efficacy, subjective well-being and self-rated health. Results presented in different empirical chapters of the thesis each respond to a specific research question. In Chapters 2 and 3 are presented surveys with 272 students and 237 camp-dwellers respectively. Perceptions, attributed causes of, and responses towards PRDs are explored as well as motivations for given responses to health challenges. In chapter 4 , a qualitative study with 21 camp-dwellers and 21 students is presented in which the dynamics of health-seeking behavior is highlighted. In this chapter also, factors which are influential in seeking formal healthcare are indicated. Chapter 5 elaborates on what people experience as stressors and the mechanisms they put in place to cope with the stressors. In this chapter, not only is the diversity of stressors outlined for both groups, but also presented are the 
different identified coping mechanisms put in place by respondents. Chapter 6 which is the last empirical chapter presents coping with PRDs through an analysis of individual, demographic and environmental factors.

Based on the studies carried out, this thesis concludes that the two groups investigated are very aware of what PRDs are and can differentiate them from common diseases. Major PRDs listed by the two groups of respondents were malaria, cholera and diarrhoea. This classification is different from what is considered major PRDs by (inter)national health bodies such as the World Health Organization and the Ministry of Public Health in Cameroon. Also, organizations such as CDC and Universities, offer limited contributions towards better health for camp-dwellers and students respectively. This is experienced relative to the living conditions, quality of the healthcare system and poor work or study conditions. That notwithstanding, people play an active role in maintaining their health through diverse coping mechanisms. Coping was most strongly related to enabling individual factors such as sense of coherence and subjective health, perceptions of effective strategies to respond to diseases as well as social factors such as the meaningful activities in the social groups to which they belong. The results presented in this thesis are intended to contribute to sustainable and effective response strategies towards PRDs. 



\section{Table of Contents}

\section{Abstract}

Abstract

\section{Chapter 1}

\section{General Introduction}

Introduction

Poverty

Poverty-related diseases

Efforts to control PRDs - problem description

Theoretical framework - the salutogenic model of health

Research objective

The study area

Camps

Campuses

Thesis overview

References

Poverty related diseases (PRDs): Unravelling complexities in disease responses in Cameroon

$\begin{array}{ll}\text { Abstract } & 25 \\ \text { Background } & 26 \\ \text { Methods } & 28 \\ \text { Results } & 31 \\ \text { Discussion } & 36 \\ \text { Study limitations } & 39 \\ \text { Conclusion } & 40 \\ \text { List of abbreviations } & 40 \\ \text { Acknowledgements } & 41 \\ \text { References } & 41\end{array}$

Poverty and Health among Plantation Labourers in Cameroon: An Application of the Health Belief Model

$\begin{array}{lr}\text { Abstract } & 47 \\ \text { Introduction } & 48 \\ \text { Methods } & 49 \\ \text { Results } & 52\end{array}$


$\begin{array}{ll}\text { Discussion } & 58\end{array}$

$\begin{array}{ll}\text { Study limitations } & 61\end{array}$

Conclusion $\quad 62$

References 63

Chapter $4 \quad 68$

Health-Seeking Behaviour towards Poverty-Related Disease (PRDs):

A Qualitative Study of People Living in Camps and on Campuses in Cameroon

$\begin{array}{lr}\text { Abstract } & 69 \\ \text { Introduction } & 70 \\ \text { Methods } & 72 \\ \text { Results } & 75 \\ \text { Discussion } & 83 \\ \text { Methodological reflection } & 86 \\ \text { Conclusion } & 87 \\ \text { References } & 88\end{array}$

Chapter 5

Health dynamics in camps and campuses: stressors and coping strategies for well-being among labourers and students in Cameroon

$\begin{array}{ll}\text { Abstract } & 93\end{array}$

Introduction $\quad 94$

Methods $\quad 96$

Results 99

$\begin{array}{lr}\text { Discussion and Conclusion } & 119\end{array}$

$\begin{array}{ll}\text { Recommendations } & 123\end{array}$

$\begin{array}{ll}\text { References } & 124\end{array}$

Chapter $6 \quad 128$

Poverty-related diseases: factors that predict coping in two Cameroonian settings

$\begin{array}{lc}\text { Abstract } & 129 \\ \text { Introduction } & 130 \\ \text { Methods } & 131 \\ \text { Results } & 136 \\ \text { Discussion } & 146 \\ \text { Limitations } & 148 \\ \text { Conclusion } & 148 \\ \text { References } & 150\end{array}$ 
Chapter 7

\section{General discussion and conclusion}

Introduction

Summary of the main findings: answering the specific research questions

Bringing it all together: including people's perceptions and capacities for dealing with health challenges

The salutogenic model of health in the case of PRDs: the added value of our study

Methodological considerations

Recommendations for future research and policy

References

Summary

Acknowledgements

About the author

List of publications 


\section{Chapter1 \\ General Introduction}




\section{Introduction}

Ever since the formulation of the Millennium Development Goals (MDG) in the year 2000, the trio, malaria, HIV and tuberculosis (TB) have been prominent on the international agenda [1]. These diseases have become emblematic of the way in which poverty affects health in a negative way, as illustrated by the term poverty-related diseases (PRDs) [2]. PRDs are diseases for which poverty is attributed as a reason for acquiring the disease as well as a hindrance to its effective management and cure $[3,4]$. The effects of diseases associated with poverty are felt most strongly by the poor. This is because many factors increase health risks and thwart recovery for the poor more than for other groups. Most prominent among these factors are poor nutrition, stress, strenuous work in harsh working conditions, as well as inadequate, inaccessible or sometimes non-existent healthcare [5]. Given the importance of PRDs in terms of their debilitating effects, their widespread nature and their consequence on development, many attempts have been made to combat them. Most of these efforts have underlined identifying the causes of the diseases as a strategy while overlooking the social determinants of health [6]. Although the former approach is important and has had measurable success, the PRD problem still remains on the international agenda.

This dissertation starts from the premise that the relationship between poverty and health is mediated by people's capacity to cope with the challenges posed by their natural and social environments. It therefore focuses on understanding the dynamics - in conditions of poverty - that determine people's capacity to pursue health. In this dissertation, people are shown as active participants in matters concerning their health and wellbeing and therefore a focal point to be included in any interventions to promote health in people living in conditions of poverty. The study was carried out in Cameroon among two different groups: workers of the Cameroon Development Corporation (CDC) and their dependents, and students from the universities of Buea and Yaoundé. Both groups live in conditions of poverty, and both have to deal with PRDs in addition to the other stressors that they face, depending on their specific setting. Including camp dwellers and university students offers an opportunity to present findings across different contexts.

In this chapter, we start by presenting a picture of poverty in the world in general and in Cameroon in particular, after which we elaborate on PRDs, the dominant strategies that have been used in responding to them and why there is a need for another approach. We then expatiate on the salutogenic model of health and follow with a presentation of the main objectives and research questions, an overview of the study sites, research methods used and finally a general outline of the thesis. 


\section{Poverty}

It has been estimated that more than 767 million people globally live in poverty, i.e. live on less than US\$ 1.90 a day [7]. It has also been appraised that more than half of the world's extremely poor are found in Sub-Saharan Africa (SSA) [7], making it the region with the highest number of extremely poor people (369 million) in the world [7] and also the highest prevalence of hunger, resulting from poverty. In SSA, one in four people is undernourished [8]. Whereas progress in poverty reduction has been witnessed in countries in Asia, poverty has instead increased in SSA countries [7]. This is partly due to conflicts, human rights abuse, environmental challenges and population growth [7,9]. These figures position poverty as a significant public health issue in the world in general and in SSA in particular, with many organisations making it the primary focus of their work. For example, the World Bank has as its mission statement 'Our Dream is a World Free of Poverty' [10].

Cameroon is an SSA country, falling into the category of the poorest nations in the world, with $48 \%$ of its population living below the poverty line [11]. The statistics in a United Nations Development Programme publication are even starker: $17.8 \%$ are living near poverty, $27.1 \%$ are living in severe poverty and $27.6 \%$ are living below the income poverty line [12]. Reports on Cameroon show that looking at income poverty only will not reveal a comprehensive understanding of the poverty situation in Cameroon, as many people with income above the poverty line are still living in conditions of deprivation with respect to education, living conditions and health [12].

Given the complex nature of poverty, many definitions and classifications exist. Webster's dictionary defines poverty as lacking material possessions or money, or simply not having basic needs such as clothes to wear, food or accommodation [13]. Health organisations such as the World Health Organisation (WHO) take the definition a step further, highlighting the risks and deficiencies characteristic of poor people as well as poor people's incapacities [14]. The United Nations (UN) relates poverty to the inability to have choices and opportunities, having no power and no security, and labels poverty as a 'violation of human dignity' [15]. According to the UN, poor people are characteristically those who lack the power to make decisions and the basic necessities for subsistence, and this therefore affects their health.

Poor health has been closely linked to poverty [16]. The WHO [2] reports that up to $45 \%$ of the disease burden in poor countries is associated with poverty. The poor are said to be exposed to considerable environmental and individual risks, resulting in increased incidence of diseases [14]. The effect of poverty on health contributes towards what is known as the cycle of poverty, whereby poverty leads to poor management of diseases, reduced ability to work, with a consequent heavy stress on family income and status leading to a poverty 
trap for the family, which could trickle down for generations [17]. The inextricable linkages between poverty and health have been noted by several international and national health bodies and have given rise to the PRD term. Poverty contributes to conditions that cause PRDs and subsequently also prevents access to healthcare.

\section{Poverty-related diseases}

PRDs are diseases in which poverty is considered to be a cause for contracting a disease as well as an obstacle to cure and recovery $[2,3,4,17]$. Major PRDs reported by the WHO, the European Commission and other governing bodies are the infectious diseases HIV/AIDS, malaria and TB. The annual global health toll of PRDs approaches six million people [18]. The incidence of PRDs is a reflection of people's quality of life and wellbeing. PRDs are typically attributed to poor hygiene conditions, poor access to clean water, lack of education, inappropriate nutrition and housing. According to Stillwagon [19], the housing and working conditions of many people in the world promote parasitic and infectious diseases at endemic or epidemic levels. It should be noted that PRDs comprise diseases that can be prevented or avoided with doable management strategies. For example, improvements in social and material livelihood conditions would enhance prevention of, and recovery from, PRDs. Malaria, a case in point here, can be prevented by combining indoor residual spraying with insecticides, use of mosquito nets, and cleaning up of hiding and breeding spots [20,21]. Despite advances in malaria control, it is still a public health problem, with 214 million cases occurring in the world in 2015, with about 472,000 deaths, reported mainly in SSA [12].

The heavy burden posed by PRDs on the world has made it an international fight and has kept them on the global political agenda of international bodies such as the UN. The UN's MDGs of 2000 and its sustainable development goals (SDGs) of 2016 are points of reference here [1]. In 2000, the sixth MDG was to eradicate HIV, TB and malaria. This goal was not achieved in the 15 year timespan. In 2015, the UN member states adopted a set of new goals known as the SDGs to be achieved by 2030. Once again, the third SDG relates to poverty and the major PRDs: HIV, TB and malaria. Seemingly, poverty and major related diseases have remained fixed points on the global agenda and the focus of many global initiatives because the goals to eradicate them have so far been hard to achieve. 


\section{Efforts to control PRDs - problem description}

Given the importance and global interest of PRDs, many interventions have been put in place with the goal of eradicating them or reducing them to a minimum [1].

So far, the focus and the funding in the fight against PRDs have been mainly on prevalence studies, the development of new drugs, insecticides and more effective diagnostic techniques, and the identification of vaccine candidates, learning from previous successes related to other infectious diseases such as chicken pox and poliomyelitis [22,23]. Actually, some authors argue that vaccines are the only measure to effectively beat infectious diseases $[23,24]$. Clearly, progress has been made in implementing existing technologies, such as mass treatment of PRDs, resulting in reductions in the global prevalence of malaria, TB and HIV/AIDS [25]. However, even though a lot of effort has been put into reducing PRDs to a minimum, they still remain a problem. Given the current approach, the dominant focus is rather biomedical (pathogenic), that is: disease specific, studying the risk factors and searching for medical and technological solutions.

Cameroon has also been involved in the fight against PRDs in a disease-specific way. It has health initiatives that address specific PRDs, such as the Cameroon Coalition against Malaria (CCAM), the Commité Nationale de Lutte contre le SIDA (CNLS) against HIV/AIDS and the Programme National de Lutte Contre la Tuberculose (PNLT) against TB. Research initiatives focus on malaria prevalence [26], epidemiology in general [27], drug efficacy [28], efficacy of impregnated bed nets against Anopheles spp. [21,29,30], or vector and parasite resistance [31]. With regard to $\mathrm{TB}$, research has focused on prevalence [32], epidemiology [33], drug sensitivity and molecular diversity [34], and ways to improve detection of TB from sputum culture [35]. Finally, with regard to HIV, research has focused on transmission [36,37], identification of rare HIV groups [38] and also co-infection with TB [39,40]. These initiatives work independently of one another but in collaboration with the Ministry of Public Health and are focused on improving and implementing widespread diagnostic techniques for these three diseases, as well as the care of those affected by them. That notwithstanding, there is no integrated national program in place to fight PRDs.

Complementary approaches are necessary. Several authors have argued that health policies and public health institutions have oversimplified or ignored social determinants of health in the design and implementation of health programs $[6,41,42]$. These determinants represent economic and social conditions that influence differences observed in people's health status [6]. Linkages between living conditions and health are widely acknowledged but commonly framed in terms of (deprived) access to goods and health services by (poor) individuals. Frameworks used to describe infectious diseases have obscured their origin in 
poverty and social inequalities $[43,44]$. There is a clear need for an integrated approach to critical health issues such as PRDs in developing countries [45,46]. Integrated health policies, programs and organisations require a better understanding of the complex relations between social determinants of health, material conditions, institutional factors and the effects of socio-economic and health policies [6]. Hence, it is important to explicitly examine the broader social determinants of health.

Another omission in research on PRDs is the way in which people themselves perceive and deal with PRDs. Despite the stressors experienced by people living in poor conditions, many people are able to maintain their quality of life, health and wellbeing [46]. That is to say, measures put in place by people themselves to cope with deprivations and diseases have very often been ignored. It can be argued that this capacity to cope mediates between disease and poverty.

In summary, the dominant approach towards PRDs so far has been disease-focused and has ignored the social determinants of health and people's agency in avoiding, resisting and overcoming health threats and diseases. In (inter)national health promotion, disease eradication is overemphasized, whereas strengthening people's capacity to cope with harsh conditions is disregarded. This approach, also referred to as the biomedical or the pathogenic model of health, has been only partially successful in eradicating PRDs or reducing them to a minimum. So far, a major challenge for research has been to incorporate context-specific conditions and to develop general insights that allow for effective policies by regional, local, public and private organisations. The role of biomedical science has been, and still is, important, but in our opinion progress can be made by adding a complementary approach, based in social science.

We argue that, even though it is vitally important to prevent and treat diseases related to poverty, it is also imperative to acknowledge the social determinants of health [6]. We therefore argue in favour of a complementary approach to PRDs that will add to the dominant pathogenic approach, elements such as social determinants, people's perceptions and capacities. Including these elements offers an opportunity to get a clearer picture of PRDs not only to enable a more integrated fight against the diseases but also to empower people to live the lives they want to live, in other words, live in optimal wellbeing [47]. In such an approach, PRDs are considered not only as a list of diseases put forward by international and national health bodies, but also as a phenomenon experienced by people living in conditions of poverty. Paying attention to people's capacities highlights them as active participants in matters concerning their health and wellbeing. The research presented in this thesis took up that challenge by looking at how people living in conditions of poverty and disease in Cameroon perceive and deal with PRDs. The central problem addressed in this thesis is the lack of an 
integrated understanding of health dynamics in poor communities in Cameroon, resulting in a proliferation of PRDs.

\section{Theoretical framework - the salutogenic model of health}

The overall importance of mental and social conditions and factors in the natural environment is conceptualised in the salutogenic model of health $(\mathrm{SMH})$, first developed by Antonovsky $[48,49]$. This approach situates health as a result of a multifactorial and context-dependent process $[48,49]$. The salutogenic approach is relatively new and has so far been used mostly in the Western context [50-54]. Few studies have used this approach in Africa [55]. By focusing on people's perceptions of PRDs and how they cope with them, this thesis aims to reveal a series of new insights and challenges about understanding health and development.

The SMH studies health and determinants of health in the human frame of reference [57]. It shifts from the pathogenic approach, which emphasises risk, ill-health and disease. Its primary goal is to answer the question of what creates health rather than what causes disease. It places emphasis on the generation of health and the things and qualities that make people move towards improved or better health [58]. Antonovsky viewed health as a continuum (see Fig 1.1). Health is not a state but a movement along that continuum. This continuum, also referred to as the ease-dis(ease) continuum has at one end 'total absence of health' and at the other end 'total health' [59]. According to Antonovsky, people, due to the presence of stressors in their lives, are always moving along this continuum. A stressor is a demand made on a person by his external or internal environment for which he lacks an immediate and readily available response [60]. People experience stressors every day in their lives. They are neither pathogenic nor salutogenic. The way people experience stressors depends on their capacities to deal with them. Coping successfully with stressors will enable a person to maintain his/her health or move towards the ease end of the continuum. On the other hand, failure to successfully handle stressors may lead to breakdown or a movement towards the dis-ease end of the continuum $[56,58,60]$.

The SMH therefore highlights the processes through which people move towards the ease end on the continuum in the context of their daily lives and experiences $[48,60]$. In SSA countries in general and in Cameroon in particular, poverty - a stressor in itself - can add to other stressful experiences people have. Poverty can therefore be described as a condition with a relatively high exposure to stressors. Understanding the relationship between poverty and health in the SMH requires an understanding of the way people deal with stressors rela 


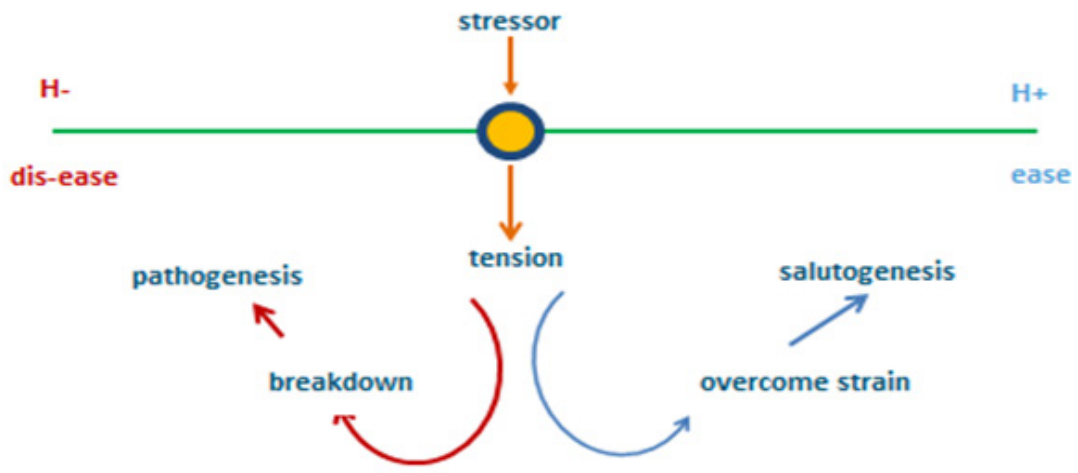

Figure 1.1: Ease - dis(ease) continuum of the salutogenic model of health Source: The Hitchhiker's Guide [56]

ted to poverty and PRDs in order to move towards optimum health. Therefore, the presence of PRDs can cause tension in people's lives that will have negative consequences on health and wellbeing. Dealing successfully with the demands imposed by poverty and related diseases will result in moving towards better health (the ease end of the continuum). Failure to deal successfully with the demands caused by PRDs will result in physical or mental anguish, i.e. a movement towards the dis-ease end of the continuum. Poverty and related diseases can be dealt with successfully when resources are available as well as when the motivation and the understanding to employ the available resources are present [56].

The SMH has two pivotal concepts: Generalised Resistance Resources (GRRs) and Sense of Coherence (SOC). Both are essential for coping with stressors and creating health [57].

Antonovsky in his book Health, Stress and Coping defined GRRs as 'physical, biochemical, artefactual-material, cognitive, emotional, valuative-attitudinal, interpersonal-relational, macrosociocultural characteristics of an individual, primary group, subculture, society, that are effective in avoiding or combatting a wide variety of stressors' [60, p.103]. GRRs arise from cultural, social and environmental living conditions, early childhood upbringing and socialisation experiences [61]. GRRs can be material or immaterial attributes found within people or in their immediate or remote environments [56]. Examples of GRRs are genetic 
and constitutional qualities, knowledge, intelligence, emotion, control, social support, cultural stability, but also material resources such as money. GRRs give prerequisites for life's experiences, which in turn maintain and strengthen positive developments in health [56]. If people have the ability to identify such resources in themselves or in their immediate surroundings and at their disposal, there is a better chance of their dealing successfully with life's challenges. GRRs open up the possibility for people to construct coherent life experiences [62].

What is important is having not only GRRs but also the ability to recognise, use and re-use the resources in a way that promotes health. This is the meaning of the second salutogenic key concept: SOC. SOC is defined as 'a global orientation that expresses the extent to which one has a pervasive, enduring though dynamic feeling of confidence that (1) the stimuli from one's internal and external environments in the course of living are structured, predictable, and explicable i.e. comprehensibility; (2) the resources are available to one to meet the demands posed by these stimuli i.e. meaningfulness; and (3) these demands are challenges, worthy of investment and engagement i.e. manageability' [59, p.19]. A strong SOC implies flexibility to be able to use different strategies or find different ways to solve problems. Therefore, SOC accurately reflects a person's capacity to respond to stressful situations [63]. According to Eriksson and Lindström [63], having a strong SOC enables the identification, use and re-use of resources for the intended purpose, in this case, to combat stressors such as PRDs. This latter implies that SOC and GRRs are interrelated. GRRs give prerequisites for the development of the SOC, and simultaneously people with a higher SOC are better able to identify resources and apply them in stressful situations to combat the stressors, because they see the world as more comprehensible, manageable and meaningful [64]. When people are under the threat of various stressors to physical or mental health, for example those related to conditions of poverty, or when facing PRDs, a strong SOC enables them to use GRRs to cope with these stressors and not to succumb to disease [59].

Studies in relation to poverty and health typically argue that people in low income countries like Cameroon lack the financial, material or mental means to prevent disease and do not have access to quality healthcare, and that this results in reduced health and increased disease incidence among the poor $[2,5,65]$. Most research on PRDs works from this perspective, focusing on limiting factors [66,67], and little attention is paid to people's coping mechanisms. Without ignoring the importance of limited means, we argue - from an SMH perspective - that people living in conditions of poverty can find ways to deal with those threats. In our opinion, the SMH offers a platform for researchers, organisations and other health providers to understand how people and societies deal with PRDs, the resources at their disposal, the resources that they identify and use, and their capacities to cope with PRD challenges in order to help them move towards optimal wellbeing [68]. With our study, we hope to shed light on what people do to manage their health despite the difficulties they face. 


\section{Research objective}

The overall aim of this thesis is to understand how conditions of poverty impact people's health and how they manage these challenges. Specifically, the study aims to unravel the interlinkages between poverty and health by creating a deeper understanding of the social and material dynamics that enable people's capacity to preserve health, anticipate health risks, and mitigate or recover from stressors such as PRDs. The study aims to contribute to sustainable and effective response strategies towards PRDs.

\section{Main research question}

The main research question addressed is: What factors underlie the maintenance of good health and overcoming stressors in the face of poverty-related diseases in Cameroon?

\section{Specific research questions}

1. What factors underlie people's perceptions of PRDs and how do these influence the way people respond to diseases?

2. What are the health challenges faced by camp dwellers and university students and how do they respond to those challenges?

3. How are stressors experienced by camp dwellers and university students and what mechanisms do they use to cope with stressors?

4. Which factors influence effective coping with health challenges in the settings?

The research questions are answered by means of a research design that includes different methods. Four cross-sectional studies were conducted in two phases between 2013 and 2014 in Cameroon. During these studies, the PRD phenomenon was explored using interviews and surveys developed by combining theoretical insights with results from preliminary exploratory interviews and observations within the context of camp dwellers' and students' settings. The interview method provided data on the basis of which meanings and deeper understanding of people's experiences were unravelled [69]. The survey method consisted of various components and allowed for statistical analysis of the attributes of the camp dwellers and students with respect to PRDs [70]. Applying a mixed methods research approach made it possible to complement and mutually validate findings and present a more coherent and complete picture of the way PRDs are experienced and dealt with in the two settings [71-73]. 
The overall study started with an exploratory phase to collect basic information, i.e. a rapid health appraisal. First, to analyze the health system in Cameroon, policy documents were read. Next, observations were conducted in the camps and the universities to get initial data on health facilities and conditions. In the qualitative studies, interviews were held with respondents in both settings. Background information, socio-economic determinants, stressors, resources, coping strategies and mechanisms in relation to health and other stressors were obtained at this stage. The respondents were asked about PRDs, health and healthcare services, factors hindering their health and wellbeing, and also to rate their health. The interviewing ended when no new information was being obtained with additional interviews [74]. The quantitative studies consisted of a survey. Survey instruments included both unstandardized and standardized questionnaires. Here also, the respondents' general background characteristics were obtained. These included a.o. biographical data (sex, age, marital status, income), household characteristics (number of people living in the house, number of rooms), hygiene (bodily care and toilet facilities), food and feeding practices, and health-seeking behavior patterns. The standardized questionnaires included the English version of the SOC-13 validated questionnaire, the self-efficacy questionnaire, the resilience questionnaire, the subjective wellbeing life scale (SWLS) questionnaire and the single item self-rated health questionnaire. More detailed descriptions of the research design and methods are provided in the chapters.

\section{The study area}

Cameroon is a country in Central Africa. It is a bordered to the southwest by the Gulf of Guinea, to the northwest by Nigeria, to the south by Gabon, the Republic of Congo and Equatorial Guinea, and by the Central African Republic and Chad in the east. It has an area of over $475000 \mathrm{~km}^{2}$ [75]. It is a country with great diversity, in geography, climate and culture and is commonly referred to as Africa in miniature. Cameroon has 10 regions with about 24 million inhabitants. It is a bilingual country having English and French as its official languages, with French being the most commonly used. This study was carried out in the Southwest and Centre regions of Cameroon. Fig 1.2 shows where this study was carried out. 


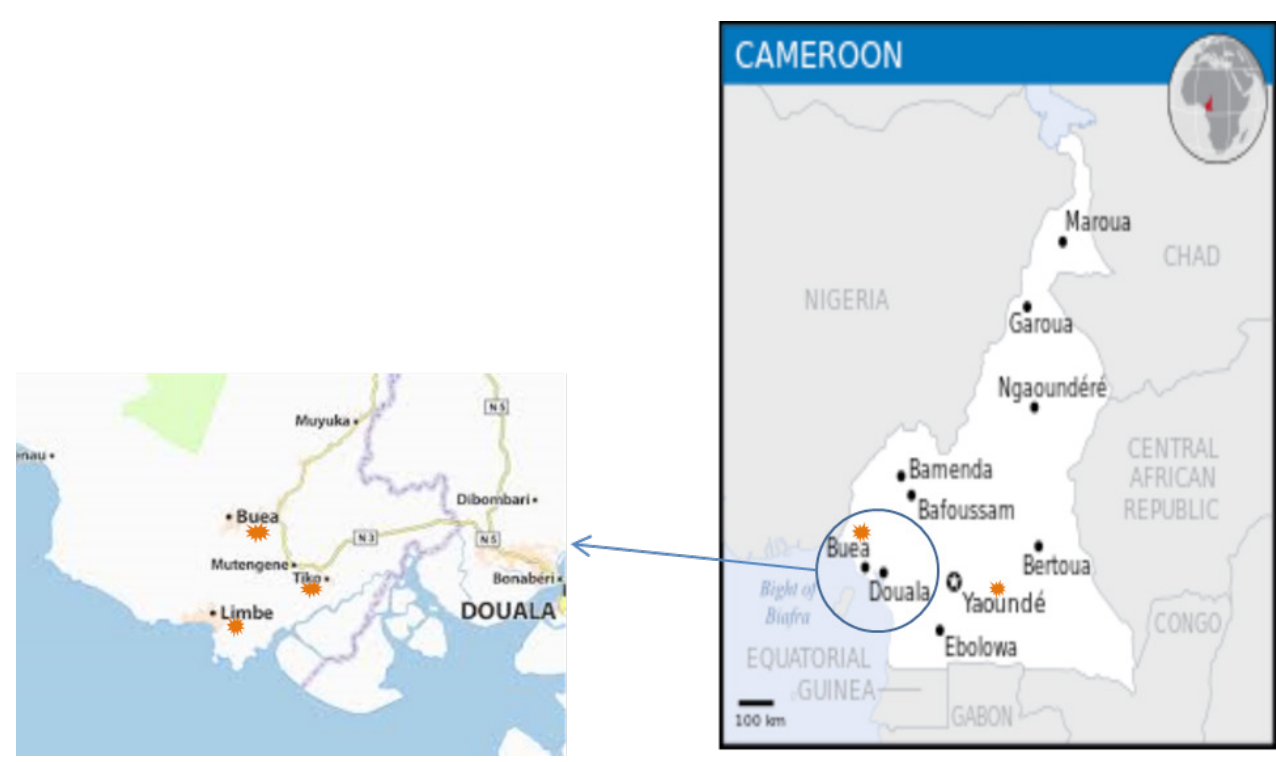

Figure 1.2: Map of Cameroon and study sites

Source: Maps by United Nations Office for the Coordination of Humanitarian Affairs SVG locator maps of Cameroon (location map scheme) (Cameroon - Location Map (2013) - CMR - UNOCHA.svg)

Two settings were included in this study. One setting was the camps belonging to the Cameroon Development Corporation (CDC) and the other was two state universities, the University of Buea and the University of Yaoundé I to which we refer to as campuses. Both settings were selected because they are home to people from different parts of Cameroon settled in the settings for work or studies, respectively, and also because differences in the socio-demographic characteristics of the camp and campus respondents offered an opportunity to see how people with such differences experienced and managed PRDs. A more detailed description of the settings is given below. We highlight the healthcare services in both settings to show their differences and give background to the studies presented in the empirical chapters.

\section{Camps}

Cameroon Development Corporation (CDC) is an agro-industrial organisation created in 1947 [76] and now fully owned by the state of Cameroon by order of a presidential decree ( $\left.\mathrm{N}^{\circ} 2016 / 031\right)$ in January 2016. CDC covers over forty-two thousand hectares of land which span from the Southwest region to the Littoral region. The CDC headquarters is in Limbe $\left(4.0225^{\circ} \mathrm{N}, 9.1954^{\circ} \mathrm{E}\right)$. CDC has three plantation groups: rubber, oil palm and banana. Its 


\section{CDC ADMINISTRATIVE STRUCTURE}

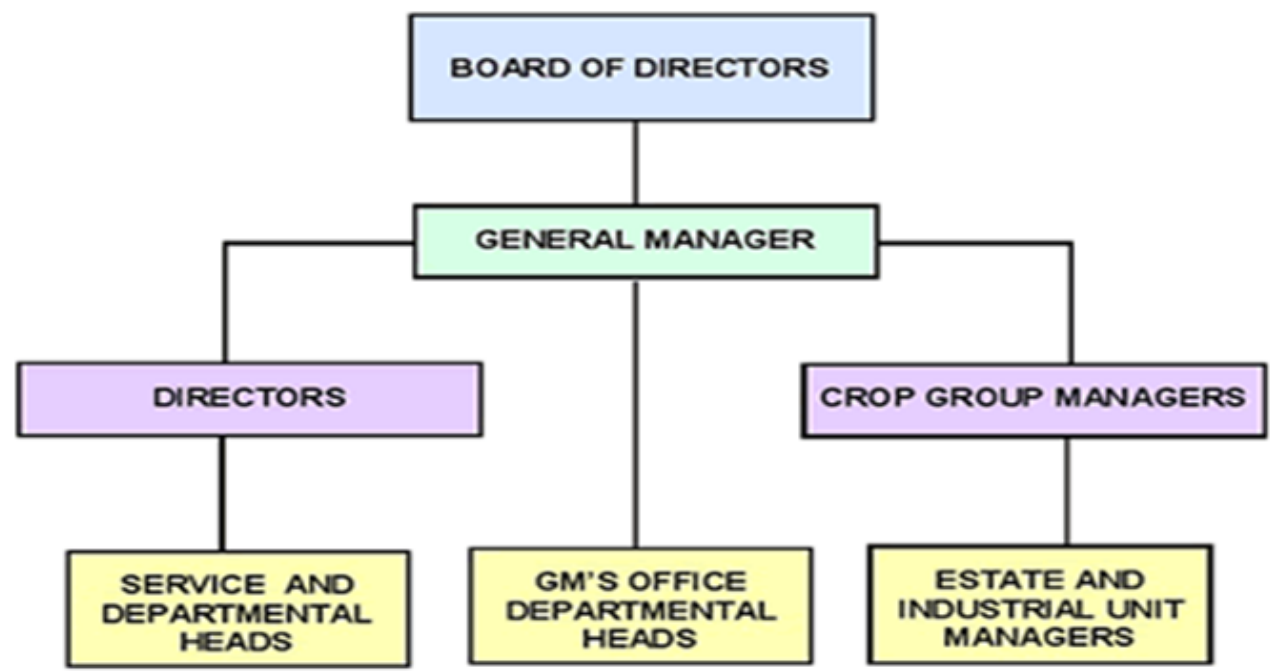

Figure 1.3: Administrative structure of CDC

Source: CDC website

products - semi-finished rubber, palm oil, palm-kernel oil and banana - are used for both export and local use. CDC is one of the largest employers in Cameroon, second only to the government of Cameroon. It employs over 20,000 people, about 18,000 of whom are permanent workers. CDC's administrative structure is shown in Fig 1.3.

At the head of CDC is the 12-member board of directors. The general manager of CDC oversees the daily running of CDC in collaboration with the directors and crop group managers. Each crop group has estates run by estate managers. In the rubber group, there are 11 estates, in the palm group there are seven. A conglomeration of fields and camps make up an estate. CDC has camps in many places in the Southwest region of Cameroon. These camps were built in the 1970s to house people working on the different plantations. Usually, people in the camps are of low socio-economic status. A great number of camp dwellers have a low level of education. The general housing conditions lack basic necessities. Houses in the camps are usually in blocks placed in several parallel rows. Families are allocated either one or two rooms; in exceptional cases a house has three rooms. Unmarried camp dwellers are given a single room. If a worker marries or has children, an application can be made for an additional room, but this takes time. There is a shortage of rooms in many CDC camps. Because of this, camp dwellers convert their kitchen into an extra room and then cook outside. 
Toilets in the camps are shared, with some camps having more households per toilet facility than others. There are three types of toilet structure in the CDC camps: aqua-privy toilets, pits toilets and water system toilets. The water system toilets are found in central camps, as camps located close to a town are called. An example of a central camp is Limbe camp, which was part of this study. In Limbe camp, water system toilets are placed in strategic positions in the camp. There are separate bathroom buildings (with toilets and shower areas) for males and females. CDC workers are employed as guards to monitor and ensure the proper use of the toilets and bathing space. Camps without water or with an unreliable water supply have pit toilets, at least two in a camp. Toilet sharing has been indicated by camps dwellers as a factor that exposes them to more infection risks.

One of the benefits of working for $\mathrm{CDC}$ is access to 'free' medical care. A very small monthly deduction from the workers' salary qualifies the workers and their families to go the CDC clinics and hospital and have free consultation and medication from the pharmacy. There is a nurse station called an AID post in each camp. These are first aid posts for treating minor ailments. Also, in these AID posts, patients with more complex ailments are assessed for symptoms so that their information can be available when they reach the clinics to speed up the process through which they have to go before receiving treatment. CDC clinics are found in the estates, with each estate having a clinic. In the estates, cars (also called ambulances) are used to transport the sick from the camps to the clinics on Mondays, Wednesdays and Fridays. Previously, clinics in the estates were manned by nurses, but today, two or three estates have been joined to form a medical zone with a medical doctor in charge. This means that a medical officer is in charge of all clinics in the medical zone. Doctors are therefore present daily at certain stations while consultations are going on in the different clinics in their medical zones. The cases that cannot be handled by the nurses are sent to the doctors, who are usually in the middle clinic of a medical zone for easy access.

\section{Campuses}

Cameroon has eight state universities. The role of universities is to provide an all-embracing and safe environment where students can be stimulated to achieve their potential. The University of Buea (UB) $\left(4.1537^{\circ} \mathrm{N}, 9.2920^{\circ} \mathrm{E}\right)$ is located in the Southwest region in Cameroon, and the University of Yaoundé I (UNIYAO) $\left(3.8574^{\circ} \mathrm{N}, 11.5014^{\circ} \mathrm{E}\right)$ is located in Cameroon's Centre region. UB is one of two universities that use English as the main language of instruction in Cameroon (Anglo-Saxon university). It was created in 1993 [77]. UNIYAO is a bilingual university with a population of about thirty-three thousand students [78]. UB is located in the Molyko neighbourhood in Buea, and UNIYAO is located in the Ngoa-Ekelle 
neighbourhood in Yaoundé. Most students of both universities live in the neighbourhoods where the university is located. The houses in which they live are privately owned, and students have to negotiate the rental terms themselves with the landlords. University students live mostly in single rooms, some self-contained and others with shared facilities. Students are typically young people who are exposed to a relatively new situation in which they have to care for their own livelihood on campus, socialize in the academic community and fulfill the requirements of the curriculum. Part of taking care of themselves involves taking care of their health. Healthcare services for the students are more complex in nature than those available in the camps. On each campus, there is a health unit or dispensary to carry out medical tests required by the university before student enrolment and also to attend to emergencies that occur in the university before transfer to appropriate services. These dispensaries are not in place as healthcare services for the students. Around the student neighbourhoods there are many small pharmacies. There are also street vendors who sell their merchandise from small stalls built on wheelbarrows. Furthermore, there are small clinics (both legal and illegal), some of which are part of the student building itself. A small clinic typically consists of two tiny $(2 \times 2 \mathrm{~m})$ rooms. One of the rooms is further divided into two by a curtain to create more rooms for different activities of the practice, such as the laboratory or the consultation rooms. These small healthcare centers are part of, or close to, the student residential areas, usually within $100 \mathrm{~m}$. A consultation fee is charged. Larger pharmacies, further away from the student neighbourhoods, are usually reached by taxi. There is teaching hospital (CUSS) in the University of Yaoundé. It is part of the university's medical school and is not cheaper than other hospitals, which are further away from the campus. In the hospitals (even in CUSS), patients (students or non-students) have to pay a consultation fee. In the student neighbourhoods however, the small pharmacies or street vendors give free consultations.

\section{Thesis overview}

This thesis is divided into seven chapters (Table 1.1). The first chapter is a general introduction to the thesis, followed by five empirical chapters and finally the general discussion chapter in which evidence from the empirical chapters is brought together in an explanatory piece. The empirical chapters have been either submitted to, or published in, peer-reviewed scientific journals. Each of the empirical chapters, Chapters 2 to 6 , addresses one of the specific research questions. The empirical chapters are not presented in the order in which the data were collected but rather in a way that best fits the answering of the research questions. 
Table 1.1: Outline of chapters, research approach and methods of data collection

\begin{tabular}{|c|c|c|c|c|}
\hline Section & Chapter & & $\begin{array}{l}\text { Res e a r ch } \\
\text { approach }\end{array}$ & Methods \\
\hline I & 1. & Introduction & Theoretical & Literature review \\
\hline \multirow[t]{3}{*}{ II } & 2. & $\begin{array}{l}\text { Poverty and health among } \\
\text { plantation labourers in Ca- } \\
\text { meroon: an application of } \\
\text { the health belief model }\end{array}$ & Quantitative & $\begin{array}{l}\text { Questionnaire-ba- } \\
\text { sed survey among } \\
\text { camp dwellers }\end{array}$ \\
\hline & 3. & $\begin{array}{l}\text { Poverty-related diseases: } \\
\text { unravelling complexities in } \\
\text { disease responses in Came- } \\
\text { roon }\end{array}$ & Quantitative & $\begin{array}{l}\text { Questionnaire-ba- } \\
\text { sed survey among } \\
\text { students }\end{array}$ \\
\hline & 4. & $\begin{array}{l}\text { Health-seeking behaviour } \\
\text { towards poverty-related di- } \\
\text { sease (PRDs): a qualitative } \\
\text { study of people living in } \\
\text { camps and on campuses in } \\
\text { Cameroon }\end{array}$ & Qualitative & $\begin{array}{l}\text { Literature review, } \\
\text { observations, se- } \\
\mathrm{mi} \text {-structured } \\
\text { interviews with } \\
\text { camp dwellers and } \\
\text { students }\end{array}$ \\
\hline \multirow[t]{2}{*}{ research } & 5. & $\begin{array}{l}\text { Health in the midst of stres- } \\
\text { sors: a salutogenic approach }\end{array}$ & Qualitative & $\begin{array}{l}\text { Literature review, } \\
\text { observations, se- } \\
\mathrm{mi} \text {-structured } \\
\text { interviews with } \\
\text { camp dwellers and } \\
\text { students }\end{array}$ \\
\hline & 6. & $\begin{array}{l}\text { Poverty-related diseases: } \\
\text { factors that predict coping in } \\
\text { two Cameroonian settings }\end{array}$ & Quantitative & $\begin{array}{l}\text { Questionnaire-ba- } \\
\text { sed survey among } \\
\text { camp dwellers and } \\
\text { students }\end{array}$ \\
\hline $\begin{array}{l}\text { Bringing it } \\
\text { all together }\end{array}$ & 7. & $\begin{array}{l}\text { Synthesis, discussion and } \\
\text { conclusion }\end{array}$ & & $\begin{array}{l}\text { Literature review } \\
\text { for supporting and } \\
\text { contrasting argu- } \\
\text { ments }\end{array}$ \\
\hline
\end{tabular}

Chapters 2 and 3 (research question 1) use the health belief model to explore respondents' perspectives on PRDs. In these chapters, respondents' perceptions and attributed causes and responses to PRDs are explored, as well as respondents' motivations for dealing with health challenges in the way that they do. In Chapter 4 (research question 2), the dynamics in 
play in the way respondents seek health are explored. Factors that influence respondents' decisions to seek health are indicated. Chapter 5 (research question 3) elaborates on what people experience as stressors and how they draw on resources to cope with the identified stressors and learn from their experiences in a way that helps them to feel more in control of their circumstances. Chapter 6 (research question 4) uses a series of standardised tests to uncover the factors that predict coping in the two settings. In this chapter, coping with PRDs is investigated through an analysis of individual, demographic and environmental factors. Finally, Chapter 7 consists of a summary and a discussion of the main findings, an appraisal of the research and the highlighting of potential policy implications. 


\section{References}

1. Sachs JD. From millennium development goals to sustainable development goals. The Lancet. 2012;379: 2206-2211.

2. WHO. Global report for research on infectious diseases of poverty. Geneva: World Health Organisation; 2012.

3. Stevens P. Diseases of poverty and the 10/90 gap. IPN Working Papers on Intellectual Property, Innovation and Health. London, UK: World Health Organisation; 2004.

4. Singh AR, Singh SA. Diseases of poverty and lifestyle, well-being and human development. Mens Sana Monographs. 2008;6: 187-225.

5. Burtscher D, Burza S. Health-seeking behaviour and community perceptions of childhood undernutrition and a community management of acute malnutrition (CMAM) programme in rural Bihar, India: a qualitative study. Public Health Nutr. 2015;18(17): 3234-3243. https://doi.org/10.1017/S1368980015000440

6. Marmot M. Social determinants of health inequalities. The Lancet. 2005;365: 10991104.

7. World Bank. Poverty and shared prosperity: taking on inequality. Washington DC: World Bank; 2016.

8. WFP. Hunger statistics. World Food Programme. Rome: United Nations; 2017.

9. WHES. World hunger and poverty facts and statistics. Washington DC: WHES; 2015.

10. World Bank. The World Bank annual report. Washington DC: The World Bank; 2013.

11. Heifer International. State of the African farmer; 2014. Available from: https://www. heifer.org/ending-hunger/our-work/countries/africa/cameroon.html

12. UNDP. Work for human development. Briefing note for countries on the $2015 \mathrm{hu}-$ man development report Cameroon. United Nations Development Programme; 2015. Available from: http://hdr.undp.org/sites/all/themes/hdr_theme/country-notes/CMR. pdf 
13. Webster. Poverty. Springfield MA: Merriam Webster; 2017.

14. WHO. Poverty. Geneva: World Health Organisation; 2017.

15. UN. Indicators of poverty and hunger. New York: United Nations; 2011.

16. Murray S. Poverty and health. CMAJ. 2006;174: 923-923.

17. Bhutta ZA, Sommerfeld J, Lassi ZS, Salam RA, Das JK. Global burden, distribution, and interventions for infectious diseases of poverty. Infect Dis Poverty. 2014;3: 21. doi: $10.1186 / 2049-9957-3-21$

18. WHO. Housing and health. Geneva: World Health Organisation; 2010.

19. Stillwagon E. The ecology of poverty: nutrition, parasites and vulnerability to HIV/ AIDS. In: Gillespie S, editor. AIDS, poverty, and hunger: challenges and responses. Washington DC: International Food Policy Research Institute; 2005, pp. 167-180.

20. Muheki C, McIntyre D, Barnes KI. Artemisinin-based combination therapy reduces expenditure on malaria treatment in KwaZulu Natal, South Africa. Trop Med Int Health. 2004;9: 959-966.

21. Antonio-Nkondjio C, Demanou M, Etang J, Bouchite B. Impact of cyfluthrin (Solfac EW050) impregnated bed nets on malaria transmission in the city of Mbandjock: lessons for the nationwide distribution of long-lasting insecticidal nets (LLINs) in Cameroon. Parasit Vectors. 2013;6: 10. doi: 10.1186/1756-3305-6-10

22. Lång H, Quaglio G, Olesen OF. Tuberculosis research in the European Union: Past achievements and future challenges. Tuberculosis. 2010;90: 1-6.

23. Olesen OF, Hoeveler A. How can the industrial world help to implement new vaccines against poverty-related diseases? In: Kaufmann Stefan HE, Lambert P-H, editors. The grand challenge for the future. Springer (online); 2005, pp. 37-52.

24. Radošević K, Rodriguez A, Lemckert A, Goudsmit J. Heterologous prime-boost vaccinations for poverty-related diseases: advantages and future prospects. Expert Rev Vaccines 2009;8: 577-592.

25. Hotez PJ (2017) Developing and financing neglected disease vaccines in our new era 
of "blue marble health" and the anthropocene epoch. Vaccine. doi: 10.1016/j.vaccine.2017.02.002.

26. Ntonifor NH, Veyufambom S. Assessing the effective use of mosquito nets in the prevention of malaria in some parts of Mezam division, Northwest Region Cameroon. Malar J. 2016;15: 390. doi: 10.1186/s12936-016-1419-y

27. Mbenda HGN, Awasthi G, Singh PK, Gouado I, Das A. Does malaria epidemiology project Cameroon as 'Africa in miniature'? J Biosci. 2014;39: 727-738.

28. Whegang SY, Tahar R, Foumane VN, Soula G, Gwét H, et al. Efficacy of non-artemisinin-and artemisinin-based combination therapies for uncomplicated falciparum malaria in Cameroon. Malar J. 2010;9: 56. doi: 10.1186/1475-2875-9-56

29. Chouaïbou M, Etang J, Brévault T, Nwane P, Hinzoumbé CK, et al. Dynamics of insecticide resistance in the malaria vector Anopheles gambiae sl from an area of extensive cotton cultivation in Northern Cameroon. Trop Med Int Health. 2008;13: 476-486.

30. Chouaibou M, Simard F, Chandre F, Etang J, Darriet F, et al. Efficacy of bifenthrin-impregnated bednets against Anopheles funestus and pyrethroid-resistant Anopheles gambiae in North Cameroon. Malar J. 2006;5: 77. doi: 10.1186/1475-2875-5-77

31. Menze BD, Riveron JM, Ibrahim SS, Irving H, Antonio-Nkondjio C, et al. Multiple insecticide resistance in the malaria vector Anopheles funestus from Northern Cameroon is mediated by metabolic resistance alongside potential target site insensitivity mutations. PloS One. 2016;11: e0163261.

32. Kuaban C, Bame R, Mouangue L, Djella S, Yomgni C. Non conversion of sputum smears in new smear positive pulmonary tuberculosis patients in Yaounde, Cameroon. East Afr Med J. 2009;86(5): 219-225.

33. Noeske J, Nana Yakam A, Foe A. Epidemiology of tuberculosis in Cameroon as mirrored in notification data, 2006-2014. Int J Tuberc Lung Dis. 2016;20: 1489-1494.

34. Titanji V, Assam J. Drug sensitivity and molecular diversity of M. tuberculosis in Cameroon: a meta-analysis. J Vasc Med Surg. 2016;4: 266. doi: 10.4172/2329-6925.1000266

35. Pefura-Yone EW, Kengne AP, Kuaban C. Non-conversion of sputum culture among patients with smear positive pulmonary tuberculosis in Cameroon: a prospective cohort 
study. BMC Infect Dis. 2014;14: 1-6.

36. Park JN, Papworth E, Kassegne S, Moukam L, Billong SC, et al. HIV prevalence and factors associated with HIV infection among men who have sex with men in Cameroon. J Int AIDS Soc. 2013;16. doi: 10.7448/IAS.16.4.18752

37. Nguefack HLN, Gwet H, Desmonde S, Oukem-Boyer OOM, Nkenfou C, et al. Estimating mother-to-child HIV transmission rates in Cameroon in 2011: a computer simulation approach. BMC Infect Dis. 2016;16: 11. doi: 10.1186/s12879-016-1336-2

38. Rodgers MA, Vallari AS, Harris B, Yamaguchi J, Holzmayer V, et al. Identification of rare HIV-1 Group N, HBV AE, and HTLV-3 strains in rural South Cameroon. Virol. 2017;504: 141-151.

39. Agbor AA, Bigna JJR, Billong SC, Tejiokem MC, Ekali GL, et al. Factors associated with death during tuberculosis treatment of patients co-infected with HIV at the Yaoundé Central Hospital, Cameroon: an 8-year hospital-based retrospective cohort study (2006-2013). PloS One. 2014;9: e115211.

40. Nsagha DS, Pokam BT, Assob JCN, Njunda AL, Kibu OD, et al. HAART, DOTS and renal disease of patients co-infected with HIV/AIDS and TB in the South West Region of Cameroon. BMC Public Health. 2015;15: 1040.

41. Tones K, Green J. Health promotion: planning and strategies. London: Sage; 2004.

42. Green LW, Kreuter MW. Health program planning: an educational and ecological approach. New York: McGraw-Hill; 2005.

43. Farmer P. Social inequalities and emerging infectious diseases. Emerg Infect Dis. 1996; 2(4):259-269.

44. Quinn SC, Kumar S. Health inequalities and infectious disease epidemics: a challenge for global health security. Biosecur Bioterror. 2014;12: 263-273.

45. Niehof A, Rugalema G, Gillespie S. Aids and rural livelihoods: dynamics and diversity in sub-Saharan Africa. London: Earthscan; 2010.

46. Rau B. Too poor to be sick: linkages between agriculture and health. HIV/AIDS Programme Working Paper. Rome: FAO; 2006. 
47. Becker CM, Glascoff MA, Felts WM. Salutogenesis 30 years later: where do we go from here? Int Electron J Health Educ. 2010;13: 25-32.

48. Antonovsky A. The salutogenic model as a theory to guide health promotion. Health Promot Int. 1996;11: 11-18.

49. Koelen MA, van den Ban AW. Health education and health promotion. Wageningen NL: Wageningen Academic Publishers; 2004.

50. Lindström B, Eriksson M. The salutogenic approach to the making of HiAP/healthy public policy: illustrated by a case study. Glob Health Promot. 2009;16: 17-28.

51. Eriksson M, Lindström B. Bringing it all together: the salutogenic response to some of the most pertinent public health dilemmas. In: Morgan A, Ziglio E, Davies M, editors. Health assets in a global context. New York: Springer; 2010, pp. 339-351.

52. Super S, Verschuren WM, Zantinge EM, Wagemakers MAE, Picavet HSJ. A weak sense of coherence is associated with a higher mortality risk. J Epidemiol Community Health. 2014;68(5): 411-417.

53. Thedin Jakobsson B. What makes teenagers continue? A salutogenic approach to understanding youth participation in Swedish club sports. Phys Educ Sport Pedagogy. 2014;19: 239-252.

54. Roy P, Tremblay G, Robertson S, Houle J. "Do it all by myself”: a salutogenic approach of masculine health practice among farming men coping with stress. Am J Mens Health. $2015 ; 1557988315619677$.

55. Morris-Paxton AA, Van Lingen JM, Elkonin D. Wellness and academic outcomes among disadvantaged students in South Africa: an exploratory study. Health Educ J. 2016;0017896916650707.

56. Lindström B, Eriksson J. The hitchhiker's guide to salutogensis: salutogenic pathways to health promotion. Helsinki: Folkhalsan Research Centre; 2010.

57. Eriksson M, Lindström B, Lilja J. A sense of coherence and health. Salutogenesis in a societal context: Åland, a special case? J Epidemiol Community Health. 2007;61: 684-688.

58. Dardet CA, Tomas AB, Boonekamp G, Breton E, Contu P, et al. Twenty-five years of 
capacity building: the ETC 'Healthy Learning' process. Wageningen NL: European Training Consortium in Public Health and Health Promotion and the Wageningen University, Health and Society Group; 2016.

59. Antonovsky A. Unraveling the mystery of health: how people manage stress and stay well. San Francisco CA: Jossey-Bass; 1987.

60. Antonovsky A. Health, stress, and coping. San Francisco CA: Jossey-Bass; 1979.

61. Mittelmark MB, Sagy S, Eriksson M, Bauer GF, Pelikan JM, et al. The handbook of salutogenesis. Heidelberg: Springer Open; 2017. doi 10: 978-973.

62. Koelen Maria LB. Health promotion philosophy and theory. In: Dardet CA et al., editors. Twenty-five years of capacity building: the ETC 'Healthy Learning' process. Wageningen NL: European Training Consortium in Public Health and Health Promotion and the Wageningen University, Health and Society Group; 2016, pp. 21-37.

63. Eriksson M, Lindström B. Life is more than survival: exploring links between Antonovsky's salutogenic theory and the concept of resilience. In: Gow KM, Celinski M, editors. Wayfinding through life's challenges: coping and survival. New York: Nova Science; 2011, pp. 31-46.

64. Wainwright NW, Surtees PG, Welch AA, Luben RN, Khaw K-T, et al. Healthy lifestyle choices: could sense of coherence aid health promotion? J Epidemiol Community Health. 2007;61: 871-876.

65. Ahmed SM, Adams AM, Chowdhury M, Bhuiya A. Changing health-seeking behaviour in Matlab, Bangladesh: do development interventions matter? Health Policy Plan. 2003;18: 306-315.

66. Halperin D, Allen A. Is poverty the root cause of African AIDS? AIDS Anal Afr. 2001; 11: 1-3.

67. Lozano R, Naghavi M, Foreman K, Lim S, Shibuya K, et al. Global and regional mortality from 235 causes of death for 20 age groups in 1990 and 2010: a systematic analysis for the Global Burden of Disease Study 2010. The Lancet. 2012;380: 2095-2128.

68. Becker CM, Rhynders P. It's time to make the profession of health about health. Scand J Public Health. 2013;41: 1-3. 
69. Baxter P, Jack S. Qualitative case study methodology: study design and implementation for novice researchers. Qual Rep. 2008;4: 544-559.

70. Fowler Jr FJ. Survey research methods. Thousand Oaks CA: Sage; 2013.

71. Sale JEM, Lohfeld LH, Brazil K. Revisiting the quantitative-qualitative debate: implications for mixed-methods research. Qual Quant. 2002;36: 43-53.

72. Johnson RB, Onwuegbuzie AJ. Mixed methods research: a research paradigm whose time has come. Educ Research. 2004;33: 14-26.

73. Kelle U. Combining qualitative and quantitative methods in research practice: purposes and advantages. Qual Res Psychol. 2006;3: 293-311.

74. Strauss A, Corbin J. Basics of qualitative research: techniques and procedures for developing grounded theory. Thousand Oaks CA: Sage; 1998.

75. UN. Cameroon. World statistics pocket book. Geneva: United Nations; 2016, pp. 38-38.

76. Cameroon Development Corporation. Limbe Cameroon: Cameroon Development Corporation; 2009.

77. UB. About University of Buea. Buea Cameroon: University of Buea; 2014.

78. INS. Généralités sur le Cameroun. Yaoundé Cameroon: Institut Nationale de la Statistique de Cameroun; 2010. 


\section{Poverty related diseases (PRDs): Unravelling com- plexities in disease responses in Cameroon}

Valerie Makoge, Harro Maat, Lenneke Vaandrager, Maria Koelen

This chapter is published as: Poverty related diseases (PRDs): Unravelling complexities in disease responses in Cameroon. Tropical Medicine and Health (2017) 45:2 


\section{Abstract}

Background: In Cameroon, poverty-related diseases (PRDs) are a major public health concern. Research and policies addressing PRDs are based on a particular understanding of the interaction between poverty and disease, usually an association between poverty indicators and health indicators for a specific country or region. Such indicators are useful but fail to explain the nature of the linkages between poverty and disease or poverty and health. This paper presents results of a study among university students, unraveling how they perceive diseases, the linkages with poverty, their responses to diseases, and the motivations behind reported responses.

Based on the health belief model, this cross-sectional study was carried out among 272 students at the universities of Buea and Yaoundé in Cameroon. Data were collected using questionnaires containing items matching the research objectives. The questionnaires were self-completed.

Results: Malaria was considered as the most common disease perceived and also a major PRD. Contrary to official rankings of HIV/AIDS and TB, cholera and diarrhea were considered as other major PRDs. Also, typhoid fever was perceived to be more common and a PRD than HIV/AIDS and TB combined. The most prominently attributed cause for disease was (lack of) hygiene. In response, students deployed formal and/or informal healthcare strategies, depending on factors like available money, perceived severity of the disease, and disease type. Discrepancies were observed in respondents' response to diseases generally and to malaria in particular. Even though, overall, respondents pre-dominantly reported a formal healthcare response toward diseases in general, for malaria informal responses dominated. There was an overall strong awareness and (pro)activity among students for dealing with diseases.

Conclusion: Although the high use of informal facilities and medication for malaria may well be a reason why eradication is problematic, this seems to be a deliberate strategy linked to an awareness of the limitations of the formal health system. In any intervention intended to foster health, it is therefore vital to consider people's perceptions toward diseases and their response strategies. Our results give important leads to health promotion interventions to develop group-specific programs. 


\section{Background}

The eventual success of health-promoting interventions for infectious diseases in developing countries depends on a prior understanding of the complexities surrounding people's efforts to respond to illnesses. Poverty makes such efforts more complicated. The recognition of linkages between poverty and health has led to the term poverty-related diseases (PRDs). PRDs are diseases whereby poverty is a factor that increases the chances of getting the disease and hinders proper treatment and cure $[1,2]$. According to the World Health Organisation (WHO), the major PRDs are malaria, HIV/AIDS and tuberculosis [3]. Cameroon, located in Central Africa, is one of those nations in which PRDs are of significant public health concern. In Cameroon, for instance, everyone is at risk of malaria but the burden is felt more by the poor. Malaria accounts for most hospitalisations, and up to $40 \%$ of family income is reportedly spent on its prevention and treatment [4]. The prevalence of HIV in Cameroon is the highest in the sub-region of West and Central Africa, standing at 5.1\% [5]. Also, about 33,000 tuberculosis infections are recorded each year, with over 2,000 annual deaths [6] mostly in association with HIV $[7,8]$.

Research and policies addressing PRDs are based on a particular understanding of the interaction between poverty and disease, measured as an association between poverty indicators and health indicators for a specific country or region. Such indicators provide an adequate picture of the diseases most prevalent among the poor but do not further explain the nature of the linkages between poverty and disease or poverty and health $[1,9]$. Besides disease prevalence and income levels, living conditions influence vulnerability towards certain diseases and are thus also important for understanding PRDs [10].

Rather than approaching PRDs from statistics, we study people's own perspective on the connections between poverty and health. We investigated perceptions and responses to health issues among university students in Cameroon, a group that is well educated but has an income level that on average is close to the official poverty line of 1.25 US\$ a day (see Table 1). Common diseases in this group are similar to those in other groups in Cameroon, although some studies have reported a high prevalence of sexually transmitted infections (STIs) among students (e.g. $31 \%$ for gonorrhoea) due to a reduced awareness of preventive strategies [11]. Malaria has been reported to account for up to $65 \%$ of absences from schools $[4,12]$. Many factors influence a person's selective response to illness. The options available to acquire treatment or medication in Cameroon include government hospitals and healthcare centres, church-related hospitals and clinics, private doctors, private pharmacies (big and small), community health workers and street vendors [13]. The use of informal healthcare providers in Cameroon is common $[14,15]$. Acquiring care from formal healthcare services is not always an obvious first step in Cameroon where most healthcare is an out-of-pocket expense $[16,17]$. 
The aim of our study was to get a deeper understanding of the complexities surrounding responses towards diseases among university students in Cameroon. Such understanding is essential for the design and assessment of interventions geared at promoting health $[18,19]$ among poor groups in society.

We used the health belief model (HBM) [20] to understand students' response to diseases. The health belief model is a model commonly used in health education and health promotion that aims to predict and understand health behaviours of people in terms of belief patterns they may have [20-23]. According to the HBM, people's response to diseases is guided by two main beliefs: a belief in a health threat (presence of disease) and a belief in the effectiveness of deploying a response strategy [20,22]. Because PRDs are primarily infectious diseases, the first belief implies a perceived susceptibility to infection and a perception that this infection could be harmful. The second belief in the context of our study implies a belief that both formal and informal health facilities and medication can be used to respond to diseases and that these actions will be effective [22]. Figure 2.1 shows how we operationalise disease responses in the HBM.

The specific objectives of our study were to assess the perceptions of university students in Cameroon about common diseases and diseases related to poverty, to find out how they respond to diseases, to ascertain the motivations for their responses and finally to identify the determinants (perceived benefits and barriers) for the participants' use of the healthcare services.

\section{Operationalisation of disease responses in the health belief model}

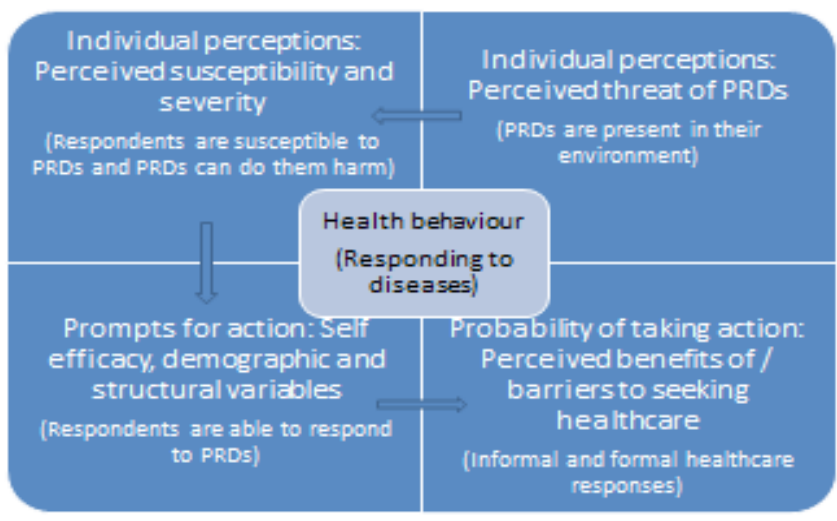

Figure 2.1: Operationalisation of disease responses in the HBM 


\section{Methods}

\section{Survey design and respondents:}

Our study was part of a larger project that had as objective to create an understanding of the social and material dynamics that enable the capacity to preserve health, anticipate health risks, and mitigate or recover from stressors such as PRDs in Cameroon. This study took place between 2013 and 2014 and was carried out in the Southwest and Centre regions of Cameroon.

Respondents were selected among students at the University of Buea (UB), located in the Southwest region, $4.1537^{\circ} \mathrm{N}, 9.2920^{\circ} \mathrm{E}$, and the University of Yaoundé (UNIYAO), located in the Centre region $3.8574^{\circ} \mathrm{N}, 11.5014^{\circ} \mathrm{E}$ of Cameroon. UB, founded in 1995, has a population of about 12,000 students [24]. UNIYAO, the oldest university in Cameroon, was founded in 1962 and has a population of about 33,000 students [25]. Every year, over one thousand students seek entry into the universities of Buea or Yaoundé. Potential students originate from different regions of Cameroon, have either an anglophone or a francophone culture and settle into these settings for studies. Entry into UB is on a competitive basis following results of the general certificate examination (GCE A'L), whereas entry into UNIYAO is not based on competition. Both universities are state-owned and are top-ranked universities in Cameroon. University students were selected for this study because, despite having education and career opportunities that are better than for most people, during their study, most students live in deprived conditions and face financial challengers. Their experiences and disease response strategies are important for understanding the complexities that exist between poverty and health.

University students reside in what we refer to as campus settings. Most university students live in rented rooms in neighbourhoods close to the university because on-campus rooms are too few to cater for the high demand. Student residences vary in size and can have as few as five rooms, whereas others have up to 40 rooms. For our study, the neighbourhoods visited were the Ngoa-Ekelle in Yaoundé and the Molyko in Buea situated within a few hundred metres of the university and each housing hundreds of students. These neighbourhoods are quite similar, both bustling with commercial activities that centre around students' needs such as photocopying and printing stalls, small restaurants, bars, small pharmacies and cyber cafés. Respondents were following various study programmes offered by the university. The universities offer no free healthcare services to the students, who therefore have to seek healthcare off-campus at personal expense.

\section{Survey instrument}

From initial observations and preliminary conversations with students, we obtained an ima- 
ge of the key issues and conditions affecting students' health, from which we designed a questionnaire in line with the health belief model [20]. The questionnaire was comprised of closed questions with yes/no answer options and questions with pre-defined answer categories, with the possibility for multiple responses in some questions.

\section{Individual perceptions}

The construct of a perceived threat of disease is characterised by a perceived vulnerability and a perceived severity of disease. These factors have been shown to influence how people respond to diseases $[20,22]$. Perceiving diseases as a threat means recognising their presence and their ability to affect a person. This factor was included to pinpoint specific diseases affecting the health and well-being of university students and was measured by asking students to identify what diseases they perceive as common and what diseases they associate with poverty. In addition to the WHO-listed top three PRDs, other diseases such as cholera, diarrhoea, typhoid fever and meningitis were included in this question.

Perceived vulnerability was constructed as the perception of the risk of contracting diseases. Questions focused on factors reported in the literature as having a direct impact on health and increasing vulnerability to diseases, such as food availability, balanced diet, good and permanent water, and sanitation challenges $[26,27]$.

Perceived severity, which implies the perception that PRDs could cause harm to respondents, was not specified in the questionnaire because other studies have established this aspect with regard to malaria and HIV in Cameroon [4, 28-30].

\section{Prompts to action}

A prompt to action refers to the recognition that actions can be taken to respond to diseases faced by university students. Questions asked included: "How would you normally respond to diseases in general?" and "How would you normally respond to malaria?" The additional question about malaria gives further insights into students' responses to PRDs. Because prevalence, morbidity and mortality due to malaria are high in Cameroon [31, 32], all students are likely to have experience in dealing with it.

\section{Probability of taking action}

Converting prompts to action into real action depends on the perceived benefits and barriers relating to the effectiveness of the intended action [20]. We included several options for ac- 
tion in the questionnaire, covering both formal and informal medical facilities. An example of a question asked is: "What determines whether you seek formal or hospital healthcare?"

Socio-demographic variables like age, sex and other variables shown to influence how people respond to diseases [33] were also obtained in this study.

\section{Procedure}

The questionnaires were pre-tested amongst students at the Catholic University in the Southwest region to ensure that the questions were understandable. Consequent to the pre-test, minor amendments were made relating to the comprehensibility of the questions.

The questionnaires were self-administered. The respondent sampling method followed that previously described by Moyou-Somo et al. [32] whereby, for a population of less than 1,000 inhabitants, one out of every two houses is selected for the research. The first building selected was the one closest to the main road and from this we moved inwards into the neighbourhood. In our study, we considered the student's room as a house. The first author and trained assistants went into each student building, explained the study and requested participation. The questionnaires were left with the students and picked up later in the day. In total, 300 questionnaires were distributed, and 272 respondents completed and returned the questionnaire, giving a response rate of $90 \%$.

\section{Data analysis}

The data were analysed using SPSS Statistics version 22 (SPSS Inc. IBM). Before analysis, data from pre-coded questionnaires were entered into SPSS and checked for errors by the first author and an assistant. Chi-square and ANOVA tests were used to analyse differences between the universities as well as in the factors included in the survey, such as response strategies towards diseases in general and towards malaria in particular. We performed logistic regression analysis to explain trends seen in people's response to malaria. Included in the model were socio-demographic factors (age, sex and income). We also calculated the odds ratio of factors shown to have an influence on people's health, such as food, water and sanitation challenges experienced by people, and seeking formal healthcare for malaria; $\mathrm{p}$ values $<0.05$ were considered to be significant.

\section{Ethics approval and consent to participate}

This study was approved by the Wageningen University review board. The aim of the study was carefully explained to all respondents. Respondents signed an informed consent form before participating in the study. 


\section{Results}

\section{Respondents' characteristics}

As shown in Table 2.1, 272 students (39\% males and 61\% females) participated in the survey, $98.9 \%$ of whom were single. The income of most university students was less than 20,000 FCFA (less than 34.7 US\$) per month. Respondents from the two universities showed no significant differences in background variables such as sex, marital status and income. However, the mean age of students at UB was slightly lower than that of students at UNIYAO (23 and 24.5respectively; F (1,264), p < 0.001). Further analysis revealed that age did not play a significant role in respondents' response to diseases; therefore, all respondents are treated as one group.

Table 2.1: Background characteristics of student respondents from UB and UNIYAO

\begin{tabular}{|c|c|c|c|c|}
\hline & & $\begin{array}{c}\mathrm{UB} \\
(\mathrm{N}=161)\end{array}$ & $\begin{array}{l}\text { UNIYAO } \\
(\mathrm{N}=111)\end{array}$ & \\
\hline & $\%$ & $\%$ & & $p$-value \\
\hline \multirow[t]{2}{*}{ Sex } & male & 43.5 & 32.4 & \\
\hline & & & & 0.66 \\
\hline female & female & 56.5 & 67.6 & \\
\hline \multirow[t]{2}{*}{ Participants' age in ranges } & $<25$ & 77.4 & 52.3 & $<0.05$ \\
\hline & 25 or older & 22.6 & 47.7 & \\
\hline \multirow[t]{2}{*}{ Single people (vs married) } & married & 0.6 & 1.8 & 0.363 \\
\hline & single & 99.4 & 98.2 & \\
\hline \multirow{4}{*}{$\begin{array}{l}\text { Participants' income level } \\
\text { (per month) }\end{array}$} & $<20,000$ FCFA & 42.5 & 44.0 & 0.820 \\
\hline & $20-50,000$ FCFA & 36.6 & 39.4 & \\
\hline & $50-100,000$ FCFA & 11.8 & 10.1 & \\
\hline & $>100,000 \mathrm{FCFA}$ & 9.2 & 6.4 & \\
\hline
\end{tabular}




\section{Respondents' belief in diseases as a threat and perceived vulnera- bility towards PRDs}

The three diseases most commonly identified by respondents were malaria: $91.1 \%$, typhoid: 35.7\% and HIV/AIDS: $16 \%$. The three major PRDs perceived were malaria, cholera and diarrhoea. WHO-listed PRDs, such as HIV/AIDS and TB, had lower ratings (Table 2.2).

The presence of diseases was mostly attributed to (lack of) hygiene (53.2\%). Poor hygiene conditions increase respondents' vulnerability to diseases. For example, many respondents had toilets in their rooms for personal use (61.7\%), but another group used pit toilets that they shared with neighbours, with a consequent increased infection risk. Other attributed causes were poverty (31.3\%), climatic conditions (29.8\%) and lack of knowledge (23.8\%).

Table 2.2: Respondents' classification of common diseases and PRDs

\begin{tabular}{lll}
\hline Diseases & \multicolumn{2}{l}{ Respondents' classification (\%) } \\
\cline { 2 - 3 } & Common diseases & PRDs \\
\hline Malaria & 91.1 & 36.4 \\
Cholera & 6.7 & 34.4 \\
Diarrhoea & 13.8 & 31.2 \\
Typhoid fever & 35.7 & 28.1 \\
HIV/AIDS & 16 & 20.2 \\
STIs & 10.8 & 9.9 \\
TB & 2.6 & 5.9 \\
Meningitis & 1.5 & na \\
\hline
\end{tabular}

${ }^{\star}$ More than one response was possible. na $=$ not asked

\section{Prompts to action: disease responses}

Table 2.3 shows a picture of the different ways in which students respond to diseases relative to socio-demographic characteristics. It can be seen that, irrespective of socio-demographic characteristics, most people reported that they would use the formal healthcare facilities as their general response to health challenges. 
Table 2.3: Variation of health-seeking practices in relation to socio-demographic differences

\begin{tabular}{|c|c|c|c|c|}
\hline \multirow[t]{2}{*}{ Socio-demographic variables } & \multicolumn{4}{|c|}{ Response to diseases in general $(\mathrm{N}=272)$} \\
\hline & & Formal \% & Informal \% & Both \% \\
\hline \multirow[t]{2}{*}{ Female } & male & 71.1 & 23.7 & 5.2 \\
\hline & female & 70.0 & 23.8 & 6.3 \\
\hline \multirow[t]{2}{*}{ Participants' age in ranges } & $<25$ & 73.1 & 22.2 & 4.8 \\
\hline & 25 or older & 65.5 & 26.2 & 8.3 \\
\hline \multirow[t]{2}{*}{ Marital status } & married & 100 & 0.0 & 0.0 \\
\hline & single & 70.4 & 24.1 & 5.5 \\
\hline Participants' income level & $<20$ & 66.7 & 30.5 & 2.9 \\
\hline \multirow[t]{3}{*}{ in thousand FCFA } & $20-50$ & 75.0 & 17.7 & 7.3 \\
\hline & $50-100$ & 65.4 & 26.9 & 7.7 \\
\hline & $>100$ & 71.4 & 19.0 & 9.5 \\
\hline
\end{tabular}

Note: Figures may not add up to exactly $100 \%$ because of rounded values.

\section{Response to malaria}

The picture of using the formal healthcare system as a general response to diseases $(70.4 \%)$ changes for malaria. Table 2.4 shows these discrepancies. In the case of malaria, the use of informal treatment and medication was the dominant response (86\%), with only about $6 \%$ of respondents reporting that they would employ formal healthcare services.

Table 2.4: Discrepancies in disease responses towards malaria and other diseases

\begin{tabular}{llll}
\hline & Formal & Informal & Both \\
\hline Health-seeking practices in general & $70.4 \%$ & $23.7 \%$ & $5.8 \%$ \\
Health-seeking practices in the case of malaria & $6.4 \%$ & $86.1 \%$ & $7.5 \%$ \\
\hline
\end{tabular}

In an effort to explain these discrepancies, we investigated predictors of seeking formal healthcare as well as the odds of water, sanitation and food challenges influencing the way people respond to malaria. Table 2.5 provides descriptive information regarding the presence or absence of challenges and the selected response to malaria. Logistic analysis regression (results shown in Table 2.6) did not reveal any socio-demographic factors to be predictors of seeking formal healthcare for malaria. Also, none of those experiencing sanitation, food and water challenges showed increased or decreased odds of seeking formal healthcare in the case of malaria attacks (see Table 2.7). 
Table 2.5: Variation in sanitation, food and water challenges with respect to malaria responses

\section{Sanitation, food and water challenges}

Does participant share toilet with yes other houses?

no

Are there water cuts in the neigh- yes bourhood?

no

Does participant eat or drink herbs yes and other parts of plants to prevent or cure disease?

no

Is food readily available for the par- yes ticipant?

No/sometimes

Does participant cook his/her Yes/sometimes meals?

no

Does participant consider his/her Yes/sometimes diet to be balanced?

$$
\text { no }
$$

Are there days when participant yes misses one or more meals?

Response to malaria

\begin{tabular}{lll}
\hline Formal \% & Informal \% & Both \% \\
\hline 3.8 & 33.2 & 3.8
\end{tabular}

2.6

52.3

3.8

5.7

54.0

0.8

32.1

1.9

6.0

43.4

7.2

0.4

42.6

0.4

3.4

35.7

3.8

3.0

50.4

3.8

5.3

74.8

6.8

1.1

11.3

0.8

3.0

49.1

5.2

3.4

37.1

2.2

6.4

77.4

6.8

no

8.6

0.8

Note: Values on table may not add up to exactly $100 \%$ because of rounded values.

Table 2.6: Logistic regression model with seeking formal healthcare in the event of malaria as dependent variable

\begin{tabular}{lllll}
\hline Variables & B & S.E. & Sig. & $\operatorname{Exp(B)}$ \\
\hline Age & .098 & .075 & .191 & 1.103 \\
Sex & -.614 & .533 & .249 & .541 \\
Income & -.161 & .311 & .604 & .851 \\
Nagelkerke R2 & & & & 0.041
\end{tabular}


Table 2.7: Odds ratios and $95 \%$ confidence interval for seeking formal healthcare in the presence of threats

\begin{tabular}{lll}
\hline Predictor variables (threats) & OR $(\mathbf{9 5} \% \mathbf{C I})$ & P value \\
\hline Toilet sharing & $1.076(.616-1.879)$ & 0.798 \\
Water cuts & $.818(.456-1.466)$ & 0.499 \\
Drink/eat herbs & $.591(.334-1.043)$ & 0.068 \\
Food availability & $1.135(.651-1.979)$ & 0.655 \\
Food cooking & $1.714(.795-3.699)$ & 0.166 \\
Balanced meal & $1.399(.808-2.421)$ & 0.230 \\
Food miss day & $.873(.334-2.284)$ & 0.782 \\
\hline
\end{tabular}

\section{Top informal healthcare responses towards malaria}

Small pharmacies (any small shop selling some medication) were reportedly the most common way in which respondents dealt with malaria (52.2\%). Self-medication practices (20.6\%) were also commonly used. Medicinal plants, usually a combination of different plants, were used for self-medication, with $56.7 \%$ of respondents reportedly using a combination of plants to prevent or treat malaria. Common medicinal plants used were: fever grass, pawpaw leaves, aloe vera, mango and guava leaves. Using street vendors as informal healthcare providers was the third most commonly reported practice (18.8\%).

\section{Probability of taking action: determinants for seeking informal and formal healthcare}

Formal healthcare was often sought after self-medication failed (33.2\%) or when illness was severe (22.9\%). Having money was the most important factor enabling people to make use of official medical facilities. Other important factors were perceived severity of the disease and duration of the illness (Table 2.8). 
Table 2.8: Determinants in favour of using formal healthcare facilities

\begin{tabular}{ll}
\hline Determinants & \% (N) \\
\hline Money & $53.9(144)$ \\
Severity of illness & $40.8(109)$ \\
Duration of illness & $20.2(54)$ \\
Fear & $7.5(20)$ \\
Unavailability of drugs & $6.7(18)$ \\
Attitude of hospital staff & $4.1(11)$ \\
Time & $2.6(7)$ \\
Distance to healthcare service & $1.5(4)$ \\
\hline
\end{tabular}

Note: Multiple responses were possible.

\section{Discussion}

The aim of this study was to get a deeper understanding of the complexities regarding the way in which university students respond to diseases present in their environment. Before we delved into how students respond to PRDs, it was important to identify what students consider to be PRDs. Our results show that university students perceive malaria as the top common disease and PRD. Typhoid fever is considered a common disease but was not ranked highly as a PRD, whereas cholera, which was not perceived as very common, was classified as a major PRD. Although our study does not provide a clear explanation for this ranking, it is likely that respondents' ideas of interconnections between hygiene, health and extreme poverty carry a symbolic meaning of the kind of situation they strongly reject [34]. In other words, cholera, and the scare it generates, represents poor social well-being culminating in poor health. This suggests that people's capacity to maintain personal hygiene and ensuring a liveable environment are two sides of the same coin. The fight against PRDs therefore should focus strongly on facilitating good hygiene practices. Overall, official health authorities and international agencies may underestimate people's perception of health and hygiene and their capacity to adapt to changing circumstances such as outbreaks of infectious diseases [35]. We show this in our study by highlighting people's role in responding to diseases that affect them and by underlining the importance of taking this response into account in the design of interventions whose goal is to foster health.

It is noteworthy that respondents' classification of major PRDs differed from that used by health bodies such as the United Nations, WHO, the European Commission [36] and Ca- 
meroon's ministry of public health [5]. The United Nations, for instance, listed the major PRDs as malaria, HIV/AIDS and TB in millennium development goal 6 to be eradicated in an allocated 15-year time-span. This was not achieved and these diseases are now included in the third sustainable development goal (SDG 3), to be achieved by 2030 [37]. Emphasis on achieving such goals highlights the importance of problems faced by people living in conditions of poverty. Studies such as the one presented here provide insights into the complexities of the interactions between poverty and health - insights that are useful for both governmental and non-governmental organisations and international health bodies in the formulation of policy to improve people's health and well-being and provide information needed for the design and implementation of adequate interventions to promote human health.

As expected, the classification of malaria as a major PRD and a public health concern was uncontested by our respondents, and this is confirmed by other studies in Cameroon [31, 38], Nigeria [39], Ethiopia [40], Kenya [41] and Uganda [42]. The other two WHO-listed PRDs differed in importance in our respondents' perspective. HIV/AIDS was perceived as the third most common disease by $16 \%$ of respondents, but it was not ranked among the top three PRDs. This is probably because students are at an age and life-stage in which they take a more adventurous and active approach to sexuality [43-45] and therefore may not necessarily link HIV/AIDS to poverty. Our study showed that less than $3 \%$ of respondents perceived TB as being common and only about $6 \%$ perceived it as a PRD. Actually, in the list of diseases given to respondents, TB appeared at the bottom end of both rankings. Apparently, students do not consider TB a common disease and do not associate it with poverty. Typhoid fever on the other hand was perceived as more common and also more a PRD than HIV/AIDS and TB combined (see Table 2). Our results reveal a chasm between world health bodies' official classifications and what people in conditions of poverty themselves perceive. Although people's perceptions are not infallible, health programmes are likely to be more effective if they match people's perception of disease risk with options for improving their health. We suggest that disease risks perceived by people living in conditions of poverty should be the focus of health-promoting agencies' in the fight against PRDs. Further research could look into other groups in society as well, and develop in-country differentiated health programmes.

By looking at PRDs from the respondents' viewpoint, we show that PRDs are not only a list of diseases but also entail people's perceptions of the interlinkages between poverty and health, a factor that we consider a relevant focus for the successful achievement of SDG 3.

By identifying common diseases and PRDs through the respondents' eyes, we reveal an interesting perspective on the major threats to students' health and well-being. For one thing, 
we ascertain factors that increase students' vulnerability to diseases. Some of these factors are under the students' control and others are not. On the one hand, poor hygiene conditions were perceived by respondents as the most pronounced reason for disease presence. This was rated even higher than poverty, even though both may be interlinked [1]. These conditions can be partly controlled by the students themselves, when they clean up their own surroundings to partially reduce the risk of malaria infection [46]. On the other hand, other factors, for example poor housing conditions as observed in the neighbourhoods, are beyond the students' control as they have to take what is available due to the shortage of accommodation possibilities.

Our respondents also attributed disease presence to climatic conditions, lack of knowledge and poor education. Other studies carried out in UB confirmed, for example, that the high prevalence of STIs was linked to students' lack of knowledge on ways to protect themselves [11]. This underlines the need for group-specific health education interventions.

Moreover, our study revealed that the way students respond to disease was not always clearcut; rather, it was influenced by disease genre. The response to malaria differed from the response to diseases in general. The general response to diseases was indicated as being mostly through formal healthcare facilities (70\%). Money was reported as an important indicator for deploying this response strategy. However, our results show different strategies in spending scarce money. Even when the costs of hospital consultation, laboratory examination and buying medication from hospitals can be covered, the decision to do so can be postponed, depending on other factors, most prominently the perceived severity of the disease. Other studies have reported a similar strategic use of available resources [47-50, 51]. Perceived severity is an obvious incentive for hospital-based action [22]. However, confounding factors could be the pain caused by the condition, duration of the illness, unavailability of medication at home, the failure of self-medication to alleviate symptoms, or fear instilled by the disease condition. These factors stand on the one hand as enablers of hospital-based responses and, on the other hand, as barriers to this route. Furthermore, these factors indicate the other processes that could occur between the onset of symptoms and the use of formal medical facilities.

Interestingly, our study showed that, in the case of malaria, students' response strategy was very different from that promulgated by health agencies and medical experts. Most respondents $(86 \%)$ reported using informal health services and medicine as a response to malaria. This indicates a belief that the informal health sector is beneficial and effective in the case of malaria. It is noteworthy, though, that malaria is well-perceived as a severe disease in Cameroon $[30,52]$ and that our respondents indicated that one of the determinants for seeking formal healthcare was the perceived severity of the disease. Students' response to malaria 
would therefore be expected to align with what they said was their general response to diseases. However, this was not the case. People obviously do not display a clear-cut logical pattern of response whereby they treat all diseases in the same way. Other factors may play a role in their decisions. These could be psychological or financial. Psychologically, perceptions are important. High perceived severity of disease, for example, is a reason reported for hospital care [53]. Financial factors too were indicated. In the case of malaria, respondents opted to use small pharmacies, self-medication practices (with medicinal plants) and street vendors. It is not clear from our study why informal healthcare options are chosen to respond to malaria. A possible explanation could be that malaria is very common $[4,28]$ and an integral part of everyday life. Its constant presence may reduce the perception that it is a life-threatening disease and numb people to its deleterious effects. A qualitative study among a sample of respondents living in these same settings under similar conditions indicated that proximity and money-saving characteristics of informal healthcare providers such as small pharmacies and street vendors made them more enticing options [54]. This has also been reported in other studies [55]. It should be noted that the reason for informal healthcare in the case of malaria could not be explained by socio-demographic characteristics, and the odds did not increase or decrease with challenges that people experienced in relation to sanitation, food and water.

The insights revealed in our study are worthy of consideration in the context of health promotion interventions, as they could throw more light on why malaria is persistent and still a number one problem in Cameroon just like in other parts of Sub-Saharan Africa. For instance, our respondents have shown strong awareness and (pro)activity in relation to malaria, but this may well be a reason why eradication is problematic. Aspects such as 1) self-diagnoses of malaria by people leading to 2) (im)proper self-medication practices without necessarily following treatment recommendations or appropriate treatment may have unfavourable outcomes. Also, a link may exist between using the informal sector (small pharmacies, street vendors) and the persistence of malaria, as well as the development of resistance to antimalarial drugs. Our findings therefore underline the need for integrated and all-encompassing strategies in the fight against malaria.

\section{Study limitations}

Our study was cross-sectional in nature. A cross-sectional study refers to a study in which data are collected from respondents at a specific point in time and over a short period. In this way, a cross-sectional study will give a picture of the study of interest at the time it is carried out [56]. Our study therefore may not have unraveled all the complexities that change with time in the settings. Even though the perceived severity of malaria is already established in 
Cameroon, it would have been interesting to see how respondents perceive the severity of all WHO-ranked major PRDs as well, especially TB, which they did not perceive as a major PRD. By using the health belief model as a framework for our study, we may have omitted some aspects that also play a role in the way people respond to disease, such as the role of significant others in the decision to respond to diseases in particular ways.

\section{Conclusion}

The aim of this study was to acquire a deeper understanding of the interaction between poverty and disease by investigating the health beliefs of university students in Cameroon. Our study showed that students are well aware of what constitutes common diseases and also display strong beliefs about what diseases can be attributed to poverty. Contrary to official rankings, students consider malaria, cholera, diarrhoea and typhoid fever as major PRDs. Moreover, the results revealed that students consider (lack of) hygiene as a more prominent cause of disease than poverty. Respondents also displayed strong beliefs about their capacity to respond to diseases. Our study found that they deploy both formal and informal response strategies towards diseases, depending on factors like having money to afford the services, perceived severity of the disease, disease genre or belief in the effectiveness of an action to bring relief from the burdens imposed by diseases. A remarkable finding of our study was that university students adopt a mostly informal response to malaria. A better understanding of the practices, surrounding beliefs and group-specific responses to malaria is essential for the effective management and control of the disease.

\section{List of abbreviations}

$\begin{array}{ll}\text { HIV } & \text { Human Immuno-deficiency virus } \\ \text { HBM } & \text { Health Belief Model } \\ \text { PRD } & \text { Poverty related disease } \\ \text { STI's } & \text { Sexually transmitted infections } \\ \text { SDG } & \text { Sustainable Development Goal } \\ \text { TB } & \text { Tuberculosis } \\ \text { UB } & \text { University of Buea' } \\ \text { UNIYAO } & \text { University of Yaounde } \\ \text { WHO } & \text { World Health Organisation } \\ 40 & \end{array}$




\section{Acknowledgements}

The authors would like to thank all the university students of Buea and Yaoundé who took part in this study. The authors would also like to thank Lette Hogeling for her assistance in the statistical analysis.

\section{References}

1. Stevens P. Diseases of poverty and the 10/90 Gap. London: International Policy Network; 2004. http://www.who.int/intellectualproperty/submissions/InternationalPolicyNetwork.pdf. Accessed 26 May 2016.

2. Singh AR, Singh SA. Diseases of poverty and lifestyle, well-being and human development. Mens Sana Monographs. 2008 Jan-Dec;6(1):187-225. doi: 10.4103/09731229.40567.

3. WHO. Global report for research on infectious diseases of poverty.World Health Organization. 2012. http://apps.who.int/iris/bitstream/10665/44850/1/9789241564489_eng. pdf. Accessed17 Sept 2015.

4. CCAM. About_malaria: For a malaria free Cameroon. A bilingual publication of the Cameroon Coalition Against Malaria. 2009;2(1):1-28.

5. MINSANTE. Profil des Estimations et Projections en Matière de VIH et SIDA au Cameroun 2010-2020. Yaoundé: Ministère de la Santé Publique; 2009. p. 17.

6. WHO. Towards universal access to diagnosis and treatment of multidrug-resistant and extensively drug-resistant tuberculosis by 2015: WHO progress report 2011. Geneva: World Health Organization; 2011. p. 119.

7. Cambanis A, Ramsay A, Yassin MA, Cuevas LE. Duration and associated factors of patient delay during tuberculosis screening in rural Cameroon. Trop Med Int Health. 2007;12(11):1309-14.

8. Pefura-Yone EW, Kengne AP, Kuaban C. Non-conversion of sputum culture among patients with smear positive pulmonary tuberculosis in Cameroon: a prospective cohort study. BMC Infect Dis. 2014;14(1):1-6.

9. Von Philipsborn P, Steinbeis F, Bender ME, Regmi S, Tinnemann P. Poverty-related and neglected diseases-an economic and epidemiological analysis of poverty relatedness and neglect in research and development. Glob Health Action. 2015;8. doi: http:// dx.doi.org/10.3402/gha.v8.25818. 
10. WHO. Housing and health. 2010. http://www.who.int/hia/housing/en/. Accessed 12 Sept. 2016.

11. Nkuo-Akenji T, Nkwesheu A, Nyasa R, Tallah E, Ndip R, Angwafo Iii F. Knowledge of HIV/AIDS, sexual behaviour and prevalence of sexually transmitted infections among female students of the University of Buea, Cameroon. Afr J AIDS Res. 2007;6(2):157-63.

12. DHS. The DHS Program - Cameroon: Standard DHS, 2011. Demographic Health Survey. Cameroon: Institut Nationale de la Statistique; 2011. pp. 188-204.

13. Kamgnia B. Use of health care services in Cameroon. Int J Appl Econom Quant Stud. 2006;3-2:53-64.

14. Hughes R, Chandler C, Mangham-Jefferies L, Mbacham W. Medicine sellers' perspectives on their role in providing health care in North-West Cameroon: a qualitative study. Health Pol Plan. 2013; doi: 10.1093/heapol/czs103.

15. Crabbe F, Carsauw H, Buve A, Laga M, Tchupo J, Trebucq A. Why do men with urethritis in Cameroon prefer to seek care in the informal health sector? Genitourin Med. 1996;72(3):220-2.

16. Jaja PT. Health-seeking behaviour of Port Harcourt city residents: a comparison between the upper and lower socio-economic classes. J Public Health Africa. 2013; doi: http://dx.doi.org/10.4081/jphia.2013.e9.

17. Kankeu HT, Ventelou B. Socioeconomic inequalities in informal payments for health care: an assessment of the 'Robin Hood' hypothesis in 33 African countries. Soc Sci Med. 2016;151:173-86.

18. Mackian S, Bedri N, Lovel H. Up the garden path and over the edge: where might health-seeking behaviour take us? Health Pol Plan. 2004;19(3):137-46.

19. Grundy J, Annear P. Health-seeking behaviour studies: a literature review of study design and methods with a focus on Cambodia. Melbourne, Australia: The Nossal Insitute for Global Health; 2010.

20. Janz NK, Becker MH. The health belief model: a decade later. Health Educ Behav. 1984;11(1):1-47.

21. Hochbaum G, Rosenstock I, Kegels S. Health belief model. United States Public Health Service; 1952.

22. Koelen MA, van den Ban AW. Health education and health promotion. Wageningen, NL: Wageningen Academic Publishers; 2004.

23. Green EC, Murphy E. Health belief model. The Wiley Blackwell encyclopedia of health, illness, behavior, and society. Chichester, UK: Wiley; 2014. 
24. University of Buea. About UB: University of Buea. 2014. http://www.ubuea.cm/about/. Accessed 15 Aug 2015.

25. Institut National de la Statistique. Annuaire Statistique du Cameroun 2010. Yaoundé: Institut National de la Statistique.

26. WHO. Guidelines for drinking-water quality: recommendations. Geneva: World Health Organization; 2004.

27. Mensah P, Yeboah-Manu D, Owusu-Darko K, Ablordey A. Street foods in Accra, Ghana: how safe are they? Bulletin of the World Health Organization. 2002;80(7):546-54.

28. MINSANTE. Plan Strategique Nationale de la lutte contre le paludisme au Cameroon 2007-2010. 2007. http://www.africanchildforum.org/clr/policy\%20per\%20country/cameroun/cameroon_malaria_2001-2006_fr.pdf. Accessed 8 Oct 2016.

29. Makoge V, Maat H, Edward N, Emery J. Knowledge, attitudes and practices towards malaria in Mbonge and Kumba Sub-divisions in Cameroon. Int J Trop Dis Health. 2016;15(2):1-13.

30. Kimbi HK, Nkesa SB, Ndamukong-Nyanga JL, Sumbele IU, Atashili J, Atanga MB. Knowledge and perceptions towards malaria prevention among vulnerable groups in the Buea Health District, Cameroon. BMC Public Health. 2014;14(1):1.

31. Ndo C, Menze-Djantio B, Antonio-Nkondjio C. Awareness, attitudes and prevention of malaria in the cities of Douala and Yaounde (Cameroon). Parasit Vectors. 2011; doi: 10.1186/1756-3305-4-181.

32. Moyou-Somo R, Essomba P, Songue E, Tchoubou NN, Ntambo A, Hiol HN, et al. A public private partnership to fight against malaria along the Chad-Cameroon pipeline corridor: I. Baseline data on socio-anthropological aspects, knowledge, attitudes and practices of the population concerning malaria. BMC Public Health. 2013;13(1).

33. Glanz K, Rimer BK, Viswanath K. Health behavior and health education: theory, research, and practice. San Francisco, CA: Jossey-Bass; 2008.

34. Douglas M. Rules and meanings: the anthropology of everyday knowledge. London: Routledge; 2002.

35. Richards P. Ebola: how a people's science helped end an epidemic. London: Zed; 2016.

36. Gryseels B, Zumla A, Troye-Blomberg M, Kieny MP, Quaglio G, Holtel A, et al. European Union conference on poverty-related diseases research. Lancet Infect Dis. 2009;9(6):334-7.

37. Sachs JD. From millennium development goals to sustainable development goals. Lancet. 2012;379(9832):2206-11. 
38. Nkuo Akenji TK, Ntonifor NN, Ching JK, Kimbi HK, Ndamukong KN, Anong DN, et al. Evaluating a malaria intervention strategy using knowledge, practices and coverage surveys in rural Bolifamba, southwest Cameroon. Trans R Soc Trop Med Hyg. 2005 May;99(5):325-32.

39. Audu O, Bako Ara I, Abdullahi Umar A, Nanben Omole V, Avidime S. Sociodemographic correlates of choice of health care services in six rural communities in North Central Nigeria. Adv Public Health. 2014; http://dx.doi.org/10.1155/2014/651086.

40. Jima D, Tesfaye G, Deressa W, Woyessa A, Kebede D, Alamirew D. Baseline survey for the implementation of insecticide treated mosquito nets in Malaria control in Ethiopia. Ethiop J Health Dev 2005;19(1):16-23.

41. Imbahale SS, Fillinger U, Githeko A, Mukabana WR, Takken W. An exploratory survey of malaria prevalence and people's knowledge, attitudes and practices of mosquito larval source management for malaria control in western Kenya. Acta Trop. 2010;115(3):24856.

42. Musoke D, Karani G, Ssempebwa JC, Musoke MB. Integrated approach to malaria prevention at household level in rural communities in Uganda: experiences from a pilot project. Malar J. 2013; doi: 10.1186/1475-2875-12-327.

43. Siegel DM, Klein DI, Roghmann KJ. Sexual behavior, contraception, and risk among college students. J Adolesc Health. 1999;25:336-43.

44. Atuyambe LM, Kibira SPS, Bukenya J, Muhumuza C, Apolot RR, Mulogo E. Understanding sexual and reproductive health needs of adolescents: evidence from a formative evaluation in Wakiso district, Uganda Adolescent Health. Reprod Health. 2015; doi: 10.1186/s12978-015-0026-7.

45. Sekirime WK, Tamale J, Lule JC, Wabwire-Mangen F. Knowledge, attitude and practice about sexually transmitted diseases among university students in Kampala. Afr Health Sci. 2001;1(1):16-22.

46. WHO. World malaria report 2013. http://www.who.int/malaria/publications/world_ malaria_report_2013/wmr2013_no_profiles.pdf?ua=1. Accessed 3 September 2015.

47. Adedokun BO, Morhason-Bello IO, Ojengbede OA, Okonkwo NS, Kolade C. Helpseeking behavior among women currently leaking urine in Nigeria: is it any different from the rest of the world? Patient Prefer Adher. 2012;6:815-19.

48. Abdulraheem IS, Parakoyi DB. Factors affecting mothers' healthcare-seeking behaviour for childhood illnesses in a rural Nigerian setting. Early Child Dev Care. 2009;179(5):671-83.

49. Burtscher D, Burza S. Health-seeking behaviour and community perceptions of childhood undernutrition and a community management of acute malnutrition (CMAM) 
programme in rural Bihar, India: a qualitative study. Public Health Nutr. 2015; doi: $10.1017 /$ S1368980015000440.

50. Ahmed SM, Adams AM, Chowdhury M, Bhuiya A. Changing health-seeking behaviour in Matlab, Bangladesh: do development interventions matter? Health Pol Plan. 2003;18(3):306-15.

51. Wang Q, Brenner S, Leppert G, Banda TH, Kalmus O, De Allegri M. Health seeking behaviour and the related household out-of-pocket expenditure for chronic non-communicable diseases in rural Malawi. Health Pol Plan. 2015;30(2):242-52.

52. Sumbele IUN, Samje M, Nkuo-Akenji T. A longitudinal study on anaemia in children with Plasmodium falciparum infection in the Mount Cameroon region: prevalence, risk factors and perceptions by caregivers. BMC Infect Dis. 2013;13(1):1.

53. Biswas P, Kabir ZN, Nilsson J, Zaman S. Dynamics of health care seeking behaviour of elderly people in rural Bangladesh. Inter. J. Ageing Later Life. 2006;1(1):69-89.

54. Makoge V, Maat H, Vaandrager L, Koelen M. Health seeking behaviour toward poverty-related diseases (PRDs): a qualitative study of people living in camps and on campuses in Cameroon. Research report. Wageningen, NL: Wageningen University, Health and Society, 2016.

55. Ondicho JM. Factors associated with use of herbal medicine among the residents of Gucha sub-county, Kenya. Thesis for Master of Science in Applied Epidemiology, Jomo Kenyatta University of Agriculture and Technology, Juja, Kenya; 2015.

56. Levin KA. Study design III: cross-sectional studies. Evid Based Dent. 2006 Mar $1 ; 7(1): 24-5$. 


\section{Chapter 3}

Poverty and health among plantation labourers in Cameroon: An application of the health belief model

Valerie Makoge, Harro Maat, Lenneke Vaandrager, Maria Koelen

This chapter is under review as Poverty and health among Plantation Labourers in Cameroon: Perceptions, Challenges and Coping strategies. PLOS Neglected Tropical Diseases. 


\section{Abstract}

Creating better access to good quality healthcare for the poor is a major challenge to development. In this study, we examined inter-linkages between poverty and disease, referred to as poverty-related diseases (PRDs), by investigating how Cameroon Development Corporation (CDC) camp dwellers respond to diseases that adversely affect their health and wellbeing. Living in plantation camps is associated with poverty, overcrowding, poor sanitation and the rapid spread of diseases.

In a survey of 237 CDC camp dwellers in Cameroon, we used the health belief model to understand the drivers (perceived threats, benefits and cues for treatment seeking) of reported responses. Using logistic regression analysis, we looked for trends in people's response to malaria. We calculated the odds ratio of factors shown to have an influence on people's health, such as food, water, sanitation challenges and seeking formal healthcare for malaria.

Malaria, cholera and diarrhoea were the major PRDs perceived by camp dwellers. We found a strong link between what respondents perceived as PRDS and hygiene conditions. Poverty for our respondents was more about living in poor hygiene conditions than lack of money. Respondents perceived health challenges as stemming from their immediate living environment. Moreover, people employed a variety of strategies to seek healthcare. Interestingly, even though respondents reported using formal healthcare services as a general response to illness $(84 \%)$, almost $90 \%$ stated that, in the case of malaria, they would use informal healthcare services.

Our study recommends that efforts to curb the devastating effects of PRDs should have a strong focus on perceptions (i.e. include diseases that people living in conditions of poverty perceive as PRDs) and on hygiene practices, emphasising how they can be improved. By providing insights into the inter-linkages between poverty and disease, our study offers relevant guidance for potentially successful health promotion interventions. 


\section{Introduction}

Creating better access to good quality healthcare for the poor is a major challenge to development [1]. Poverty is a condition that increases disease incidence for many people in developing countries [2]. The World Health Organisation (WHO) reports that up to $45 \%$ of disease cases in developing countries are a result of poverty [3]. The perceived relation between poverty and disease has resulted in the term poverty-related diseases (PRDs), which illustrates that poverty is a reason for disease presence and a limiting factor to its effective management and cure [4]. Behind the daunting statistics on PRDs lies a complex reality. In most situations, poverty implies that disease prevention and treatment are available erratically or partially, and this increases the challenge to effectively manage diseases $[4,5]$. A deeper understanding of the inter-linkages between poverty and disease is important for the proper design, implementation and evaluation of health promotion interventions, especially those aimed at PRDs.

The major PRDs reported by international organisations such as the WHO are malaria, HIV/AIDS and tuberculosis [3]. These diseases together are responsible for $18 \%$ of the disease burden in the poorest countries [5]. The persistence of PRDs leads to a reduced quality of life and wellbeing for people and hinders economic growth in developing countries [6].

In Cameroon, diseases listed as PRDs are very common. For instance, malaria accounts for most hospitalisations and absences from work. HIV accounts for about 114 new infections daily, with the highest prevalence rate recorded in the southwest region of Cameroon. The presence of HIV has led to an increase in the number of tuberculosis cases in the country, making it the third listed major PRD [7,8]. People may avail of healthcare services to respond to PRDs, but they usually have to pay out of their own pocket, with a consequent heavy toll on family budgets $[9,10]$.

In order to get a better understanding of the inter-linkages between poverty and diseases, we designed a study of people's responses to health challenges in two distinct groups of people in Cameroon. These groups were students at two state universities [11] and plantation workers (and dependants of workers) of the Cameroon Development Corporation (CDC). In this paper, we focus on the survey carried out in CDC camps. Camps are settlements in which plantation workers live. Living in plantation camps has been associated with overcrowding, poor sanitation and rapid spread of diseases [12]. Despite having a paid job, people in plantation camps face financial challenges because their salaries are very low. Such conditions have significant consequences for the kinds of decisions or actions in which they engage with respect to their health [13-15]. The aim of this study was to acquire a deeper understanding of the inter-linkages between poverty and disease by investigating how CDC 
camp dwellers respond to diseases that adversely affect their health and wellbeing. In order to achieve this aim, we drew on stipulations of the health belief model $[16,17]$.

The health belief model (HBM) (see operationalisation in Fig 3.1) indicates that a health behaviour is determined by two main beliefs. The first is a belief in the presence of a health threat, characterised by perceived susceptibility towards disease as well as perceived severity of the disease. This implies, in our case, a perception that camp dwellers have of the risk of being infected by PRDs and the distress this can cause. The second is a belief in the perceived benefits of, and perceived barriers to, engaging in a health behaviour. These perceptions constitute a belief about the effectiveness of the actions taken to remedy the situation $[17,18,19]$. The HBM offers a tool with which we can obtain a deeper understanding of how and why people living in CDC camps in Cameroon respond to diseases in the ways they do. Proper understanding of disease responses by CDC camp dwellers is essential for the development of successful efforts to promote health in plantation camps.

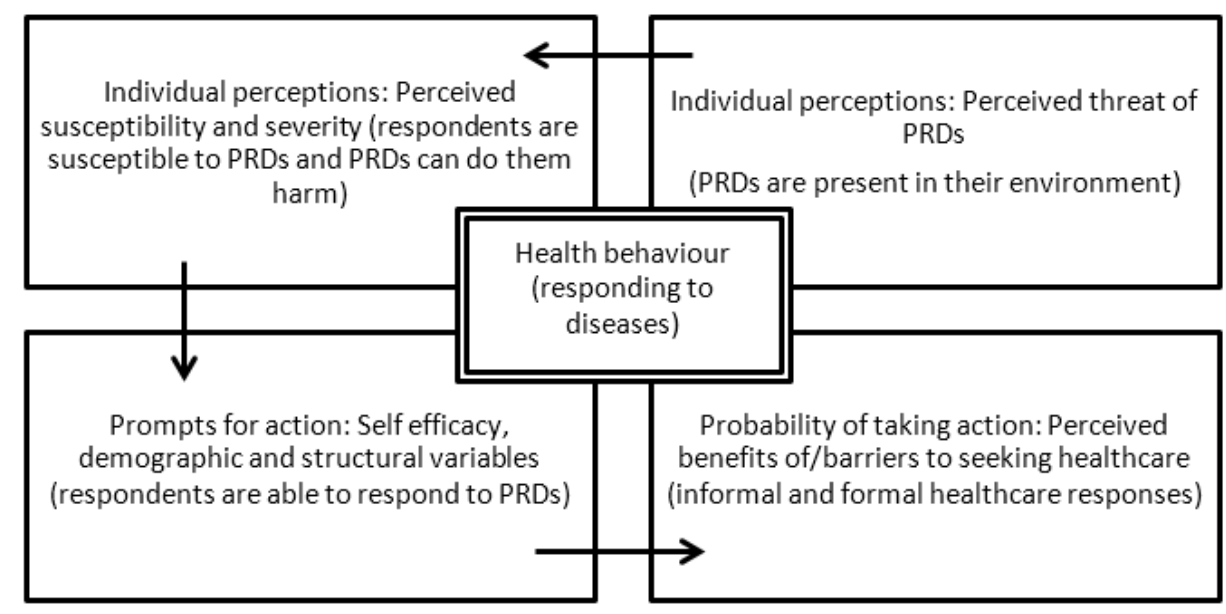

Figure 3.1: Operationalisation of the health belief model

\section{Methods}

\section{Ethical statement}

Ethical approval for this study was provided by the Wageningen University review board and the health and human resource departments of CDC. The aim of the study was carefully explained to all respondents. Respondents signed an informed consent form before participating in the study. 


\section{Survey design and respondents}

Our study was part of a larger project seeking to unravel complexities between poverty and health/diseases, focusing on disease responses and coping strategies among respondents from two distinct settlements: CDC camps and university campuses in Cameroon. Fieldwork for this study took place in 2013 and 2014. The results obtained from the study involving the students have been published elsewhere [11].

CDC is an agro-industrial organisation, located in the southwest region of Cameroon, formed in 1947 with the aim of developing tropical crop plantations for export and the national market. It runs banana, rubber and oil palm plantations. As a corporation, CDC offers its workers free healthcare services and free housing in settlements, called camps, usually found close to the plantations it runs. Most CDC labourers have a low education level. Camp respondents who participated in this study had jobs as tappers, harvesters, camp and compound workers, weeders, security guards, toilet cleaners, clearers and dependants.

The camps included in our study were the Limbe camp (located in Limbe), $4.0225^{\circ} \mathrm{N}$, $9.1954^{\circ} \mathrm{E}$, Sonne camp and Camp 7 found in the Tiko vicinity $4.0786^{\circ} \mathrm{N}, 9.3590^{\circ} \mathrm{E}$. These three camps vary in size. Sonne and Camp 7 each house about 50 households, whereas Limbe camp had more than 200 hundred households. People living in the different CDC camps face similar problems with respect to living conditions, even though some camps are in a worse state than others in terms of having basic necessities like a reliable supply of water and electricity.

In order to be eligible for this study, respondents had to be living in a CDC camp as a worker or a worker's dependant. In Limbe camp, sampling of respondents followed what has been previously described by Moyou [20] whereby, for a population of less than 1,000 inhabitants, one out of every two houses is selected for the research. In Sonne camp and Camp 7 however, all houses were visited and a member was requested to participate because these were smaller camps with fewer inhabitants. We envisaged getting one member to fill out the questionnaire per household visited. The camps were visited during hours when workers had returned from the field/farm, and this was usually after midday.

\section{Survey instrument}

The survey instrument used for this study was as previously described in our study of university students in Cameroon [11]. This questionnaire was drawn up in line with the health belief model (HBM) [16]. For a detailed description see Makoge et al [11].

\section{Respondents' individual perceptions}

Perceived threat in our study was twofold [16,21], primarily, a perceived susceptibility to- 
wards diseases. In this case, questions centred on previously reported aspects with a direct impact on health, namely, food availability, balanced diet, good and permanent water, and sanitation challenges [22,23]. The perceived severity of the disease came second. This was not investigated because this aspect has already been reported in other studies [24-27].

Other options for PRD choices, namely, cholera, diarrhoea, typhoid fever and meningitis were included in our study in addition to those listed by health governing bodies such as the WHO.

\section{Respondents' prompts to action}

Prompts to action can be understood as the camp dwellers' perception that they can take actions to respond to diseases that they face. A question about response to malaria was included because malaria is commonplace in the country $[27,28]$.

\section{Probability of respondents taking action}

Perceived benefits of, and barriers to, the effectiveness of a contemplated action would turn prompts to action into actual action [16]. Several possibilities for actions in the formal and informal medical sectors were included in the questionnaire.

Finally, also included were questions relating to socio-demographic variables like age, sex and so forth because of their role in people's responses to disease [29].

\section{Procedure}

Prior to the actual survey reported here, draft questionnaires were pre-tested amongst labourers at the $\mathrm{CDC}$ head office to ensure that the questions were comprehensible. Following from this pre-test, a few questions were reformulated for greater clarity.

The questionnaires were either self-administered or administered interview-style. The first household selected for the distribution of questionnaires was the one closest to the entrance to the camp. In the case of Limbe camp, we then moved on to other houses in the camps, selecting one out of every two houses and requesting participation. The questionnaires were left with those who could self-administer it and picked up later in the day. In Camp 7 and Sonne camp, questions were asked interview-style and the first author or a trained assistant noted down responses given. A total of 237 camp dwellers completed the questionnaire out of a possible 247 , giving a response rate of $95.9 \%$.

\section{Data analysis}

The data were analysed using SPSS Statistics version 22 (SPSS Inc. IBM). Before analysis, data from pre-coded questionnaires were entered into SPSS and checked for errors by the 
first author and an assistant. Chi-square tests were used to analyse differences between the camps as well as other factors included in the survey, such as general disease response strategies and malaria response strategies. We performed logistic regression analysis to explain patterns observed in the way people responded to malaria. Socio-demographic factors (age, sex, educational status, marital status and income) were included in the model. The odds ratio of factors shown to have an influence on people's health, such as food, water, and sanitation challenges, and seeking formal healthcare for malaria, was calculated. $\mathrm{p}$ values $<0.05$ were considered to be significant.

\section{Results}

\section{Respondents' characteristics}

The demographic distribution of the respondents is shown in Table 1. Of the 237 camp dwellers that participated in this study, $56.4 \%$ were male and $43.6 \%$ were female. Half of the respondents were married. The income of most camp dwellers was between 20,000 FCFA and 50,000 FCFA (between 33 and 82 US\$) per month. Respondents from Sonne camp and Camp 7 had basic primary school education or no formal education. About $40 \%$ of respondents from Limbe camp had received education at secondary school level. Differences were seen among the different camps in relation to age, education and income. In terms of numbers, 160 respondents were from Limbe camp. This is one of the biggest camps owned by CDC. Limbe camp had more respondents who were younger, more educated and unmarried than Sonne camp and Camp 7 (Table 3.1). 
Table 3.1: Background characteristics of CDC camp respondents

\begin{tabular}{llll} 
Camp settings & & & \\
\hline Limbe camp & Camp 7 & Sonne camp & ${ }^{*} p$ \\
$(\mathrm{n}=160)$ & $(\mathrm{n}=43)$ & $(\mathrm{n}=34)$ & value \\
\hline Column \% & Column \% & Column \% &
\end{tabular}

\begin{tabular}{llllll}
\hline Sex & male & 53.5 & 55.8 & 70.6 & \multirow{2}{*}{0.188} \\
\cline { 2 - 5 } & female & 46.5 & 44.2 & 29.4 & \\
\hline Education & $\begin{array}{l}\text { no formal education/ } \\
\text { FSLC }\end{array}$ & 59.7 & 97.6 & 97.1 & \multirow{2}{*}{0.000} \\
\cline { 2 - 5 } & secondary education & 40.3 & 2.4 & 2.9 &
\end{tabular}

\begin{tabular}{|c|c|c|c|c|c|}
\hline \multirow{5}{*}{$\begin{array}{l}\text { Participants' } \\
\text { age in ranges }\end{array}$} & $<25$ & 17.7 & 9.3 & 0.0 & 0.001 \\
\hline & $25-34$ & 34.2 & 32.6 & 11.8 & \\
\hline & $35-44$ & 29.1 & 39.5 & 38.2 & \\
\hline & $45-54$ & 13.9 & 14.0 & 38.2 & \\
\hline & 55 and over & 5.1 & 4.7 & 11.8 & \\
\hline \multirow[t]{2}{*}{ Marital status } & married & 39.0 & 69.8 & 79.4 & 0.000 \\
\hline & single & 61.0 & 30.2 & 20.6 & \\
\hline \multirow{4}{*}{$\begin{array}{l}\text { Participants' } \\
\text { income level }\end{array}$} & $<20$ thousandFCFA & 25.2 & 26.2 & 0.0 & 0.011 \\
\hline & 20-50thousandFCFA & 52.2 & 64.3 & 79.4 & \\
\hline & 50-100thousandFCFA & 15.7 & 4.8 & 17.6 & \\
\hline & $>$ 100thousandFCFA & 6.9 & 4.8 & 2.9 & \\
\hline
\end{tabular}

${ }^{*} p$-values are from chi square analysis

Further analysis did not reveal a significant effect of any of the background variables on the way respondents responded to diseases. Therefore, we considered the three camps as a single group of CDC camp respondents.

\section{Respondents' belief in diseases as a threat and perceived vulnera- bility towards PRDs}

The top three diseases identified by respondents as most common were malaria: $93.2 \%$, typhoid: $27.7 \%$ and diarrhoea: $15.7 \%$. However, answers given to the question on what res- 
pondents perceived as major PRDs showed malaria, cholera and diarrhoea as the top three. Major PRDs listed by WHO, namely, HIV/AIDS and TB, were not highly rated by our respondents (Table 3.2).

Table 3.2: Respondents' Classification of Common Diseases and PRDs (Camps)

\begin{tabular}{lll}
\hline Diseases & \multicolumn{2}{l}{ Respondents' classification (\%)* } \\
\cline { 2 - 3 } & Common diseases & PRDs \\
\hline Malaria & $\mathbf{9 3 . 2}$ & $\mathbf{4 0 . 3}$ \\
Typhoid fever & $\mathbf{2 7 . 7}$ & 8.8 \\
Diarrhoea & $\mathbf{1 5 . 7}$ & $\mathbf{1 7 . 7}$ \\
Cholera & 10.2 & $\mathbf{2 0 . 8}$ \\
HIV/AIDS & 7.2 & 14.2 \\
TB & 2.6 & 4.4 \\
STIs & 1.7 & 3.5 \\
Meningitis & 0.9 & $\mathrm{na}$ \\
\hline
\end{tabular}

${ }^{\star}$ More than one response was possible; na $=$ not asked

The main cause attributed to disease presence was (lack of) hygiene (72.3\%). Poor hygiene conditions increase in situations where many families share the same toilet facilities, and this increases respondents' vulnerability to diseases. In this study, up to $54 \%$ of respondents reported that they shared toilet facilities with more than 10 other households. Such living conditions would lead to an increase in infection risk. Other causes attributed to disease presence were lack of knowledge (23.4\%), poverty (17.9\%), poor education (14\%) and climate (14\%).

\section{Prompts for action: respondents' response to diseases}

The different ways in which camp dwellers respond to diseases based on their socio-demographic characteristics are indicated in Table 3.3. Using formal healthcare services was reported as the way in which most respondents would generally respond to diseases. This was independent of socio-demographic characteristics. 
Table 3.3: Variation in Health-seeking Practices by Socio-demographic Differences

\begin{tabular}{|c|c|c|c|c|}
\hline & & Formal & Informal & Both \\
\hline & & $\%$ & $\%$ & $\%$ \\
\hline \multirow[t]{2}{*}{ Sex } & male & 83.7 & 14.0 & 2.3 \\
\hline & female & 84.4 & 14.6 & 1.0 \\
\hline \multirow[t]{2}{*}{ Education } & $\begin{array}{l}\text { no formal } \\
\text { education/FSLC }\end{array}$ & 80.8 & 17.8 & 1.4 \\
\hline & O Level/A Level & 90.4 & 7.7 & 1.9 \\
\hline \multirow{5}{*}{$\begin{array}{l}\text { Participants' age } \\
\text { in ranges }\end{array}$} & $<25$ & 78.6 & 21.4 & 0.0 \\
\hline & $25-34$ & 89.9 & 8.7 & 1.4 \\
\hline & $35-44$ & 85.1 & 12.2 & 2.7 \\
\hline & $45-54$ & 74.4 & 23.1 & 2.6 \\
\hline & 55 and over & 85.7 & 14.3 & 0.0 \\
\hline \multirow[t]{2}{*}{ Marital status } & married & 81.4 & 17.7 & .9 \\
\hline & single & 86.0 & 11.2 & 2.8 \\
\hline \multirow{5}{*}{$\begin{array}{l}\text { Employment sta- } \\
\text { tus }\end{array}$} & employed for wages & 85.6 & 12.5 & 1.9 \\
\hline & housewife & 88.9 & 11.1 & 0.0 \\
\hline & student & 75.9 & 24.1 & 0.0 \\
\hline & self-employed & 76.5 & 17.6 & 5.9 \\
\hline & retired & 100 & 0.0 & 0.0 \\
\hline \multirow{4}{*}{$\begin{array}{l}\text { Participants' in- } \\
\text { come level in ran- } \\
\text { ges }\end{array}$} & $<20$ thousandFCFA & 82.6 & 15.2 & 2.2 \\
\hline & 20-50thousandFCFA & 83.3 & 15.2 & 1.5 \\
\hline & 50-100thousandFCFA & 96.9 & 3.1 & 0.0 \\
\hline & $>$ 100thousandFCFA & 71.4 & 21.4 & 7.1 \\
\hline
\end{tabular}

Note: Figures may not add up to exactly $100 \%$ because of rounded values.

\section{Respondents' response to malaria}

The reported use of formal healthcare services to respond to diseases in general $(84.1 \%)$ changes remarkably when it comes to malaria. These inconsistencies are illustrated in Table 3.4. Regarding malaria, the use of informal treatment and medication was indicated as the preferred response $(88.5 \%)$, with only about $5 \%$ of respondents reporting the use of formal healthcare services. 
Table 3.4: Inconsistencies in Disease Responses towards Malaria and Other Diseases

\begin{tabular}{llll}
\hline & Formal & Informal & Both \\
\hline Health-seeking practices in general & $84.1 \%$ & $14.2 \%$ & $1.8 \%$ \\
Health-seeking practices in the case of malaria & $4.7 \%$ & $88.5 \%$ & $6.8 \%$ \\
\hline
\end{tabular}

In order to explain observed inconsistencies, we sought to find out which socio-demographic factors would predict seeking formal healthcare in the case of malaria. Results from logistic regression analysis, presented in Table 3.5, showed that socio-demographic factors were not predictors of the healthcare choices in the case of malaria.

Table 3.5: Logistic Regression Model with Seeking Formal Healthcare in the Event of Malaria as Dependent Variable

\begin{tabular}{llccl}
\hline Variables & B & S.E. & Sig. & Exp(B) \\
\hline Age & .025 & .035 & .482 & 1.025 \\
Sex & -.024 & .641 & .971 & .977 \\
Educational sta- & -.662 & .901 & .462 & .516 \\
tus & & & & \\
Marital status & 1.173 & .737 & .111 & 3.233 \\
Income & .205 & .448 & .646 &. \\
Nagelkerke R2 & & &
\end{tabular}

Information regarding the presence or absence of water, sanitation and food challenges faced by respondents and the choice of either a formal or an informal, or both types of response to malaria can be seen in Table 3.6.

Table 3.6: Variation in Sanitation, Food and Water Challenges with Respect to Malaria Responses

\begin{tabular}{|c|c|c|c|c|}
\hline \multirow{2}{*}{ Sanitation, food, and water challenges } & & \multicolumn{3}{|c|}{ Response to malaria } \\
\hline & & Formal \% & Informal \% & Both \% \\
\hline \multirow{2}{*}{$\begin{array}{l}\text { Does participant share toilet with other } \\
\text { houses? }\end{array}$} & yes & 4.7 & 84.7 & 6.0 \\
\hline & no & - & 3.8 & 0.9 \\
\hline \multirow{2}{*}{$\begin{array}{l}\text { Are there water cuts in the neighbour- } \\
\text { hood? }\end{array}$} & yes & 3.8 & 43.6 & 2.6 \\
\hline & no & 0.9 & 44.9 & 4.3 \\
\hline \multirow{2}{*}{$\begin{array}{l}\text { Is food readily availability for the parti- } \\
\text { cipant? }\end{array}$} & yes & - & 27.9 & 5.6 \\
\hline & no/sometimes & 4.3 & 60.9 & 1.3 \\
\hline
\end{tabular}




\begin{tabular}{lllll} 
Does participant cook his/her meals & yes/sometimes & 3.8 & 65.5 & 5.5 \\
& no & 0.9 & 23.0 & 1.3 \\
$\begin{array}{l}\text { Does participant consider his/her diet to } \\
\text { be balanced }\end{array}$ & yes/sometimes & 3.0 & 55.3 & 6.0 \\
& no & 1.7 & 33.2 & 0.9 \\
$\begin{array}{l}\text { Are there days when participant misses } \\
\text { one or more meals? }\end{array}$ & yes & 3.8 & 71.9 & 2.1 \\
& No & 0.9 & 16.6 & 4.7 \\
\hline
\end{tabular}

Note: Values on table may not add up to exactly $100 \%$ because of rounded values

Odds ratio analysis of people who were facing these challenges and using formal healthcare services as a response to malaria showed that only respondents faced with the challenge of unreliable water facilities showed higher odds of seeking formal healthcare services as a response to malaria (see Table 3.7). The other challenges listed in Table 6 do not show significant results.

Table 3.7: Odds Ratios and 95\% Confidence Interval for Seeking Formal Healthcare in the Presence of Threats

\begin{tabular}{lll}
\hline Predictor variables (threats) & \multicolumn{1}{c}{ OR $(\mathbf{9 5} \% \mathbf{C I})$} & P value \\
\hline Toilet sharing & $.497(.062-4.004)$ & 0.503 \\
Water cuts & $.261(.117-.583)$ & 0.001 \\
Food availability & $1.727(.772-3.861)$ & 0.179 \\
Food cooking & $.894(.396-2.017)$ & 0.787 \\
Balanced meal & $.690(.323-1.475)$ & 0.337 \\
Food miss day & $.909(.389-2.125)$ & 0.826 \\
\hline
\end{tabular}

\section{Prominent informal healthcare responses to malaria}

Almost $80 \%$ of respondents reported using small pharmacies as their primary means of malaria treatment. A small pharmacy refers to any small shop selling medication. Another way of dealing with malaria was by carrying out self-medication practices, reported by $13.5 \%$ of respondents. In self-medication, a combination of different medicinal plants are brewed as tea and consumed to prevent and treat malaria. Common medicinal plants reportedly used were mango leaves, pawpaw leaves, guava leaves, aloe vera and fever grass.

\section{Probability of taking action: determinants for seeking formal and informal healthcare}

On the question of how soon respondents would seek formal healthcare when ill, $51.9 \%$ of 
respondents reportedly sought formal healthcare at the onset of disease symptoms. Formal healthcare was sought by $20.4 \%$ when illness was severe and by $20 \%$ only after self-medication had failed. Seeking formal healthcare was based on certain determinants.

In Table 3.8, factors that determined the use (or not) of formal healthcare services are indicated. Having money (reported by 50.6\%) was the most important factor enabling people to make use of official medical facilities other than those of CDC. Other factors triggering the use of formal healthcare services were unavailability of drugs at home and duration of illness.

Table 3.8: Determinants for Use of Formal Healthcare Facilities

\begin{tabular}{lr}
\hline Determinants & \% (N) \\
\hline Money & $50.6(117)$ \\
Unavailability of drugs at home & $22.1(51)$ \\
Duration of illness & $12.6(29)$ \\
Severity of illness & $12.6(29)$ \\
Attitude of hospital staff & $10.4(24)$ \\
Distance to healthcare service & $7.8(18)$ \\
Time & $0.4(1)$ \\
Fear & $0.4(1)$ \\
\hline
\end{tabular}

\section{Discussion}

The aim of this study was to acquire a deeper understanding of the inter-linkages between poverty and disease by investigating how CDC camp dwellers in Cameroon respond to diseases that adversely affect their health and wellbeing. Such investigations provide insights needed to properly design interventions to improve people's health conditions.

Our study showed that camp dwellers differentiated between what they perceived as common diseases and what they perceived as PRDs. Malaria, for example, is considered as both a common disease and a PRD. Typhoid fever is considered a common disease but not named among major PRDs, whereas cholera is perceived as a major PRD but not as a very common disease (see Table 2). These perceptions of PRDs differ from the official list (malaria, HIV and TB) put forward by international and national governing bodies such as the WHO or the Cameroon ministry of public health (MINSANTE) and highlight complexities that exist in respondents' disease classification $[3,25]$. Respondents' perceptions vis-à-vis diseases 
must be considered in any intervention because perceptions have been shown to influence the way people respond to diseases [26,30]. Our study revealed that diseases associated with poor hygiene conditions are those that are perceived by respondents as being poverty-related. The exact reason for the difference in classification of PRDs by respondents and by official reports is unclear, but if the main reported attributed cause for disease presence, i.e. poor hygiene conditions, is considered, then the perceived strong link between common diseases, PRDs and poor hygiene indicates a reason for camp dwellers' classification. By implication, poverty for our respondents is more about living in poor hygiene conditions than lack of money. Health challenges are not about not having access to healthcare services, as workers and their dependants have free access to CDC clinics, but rather about coping with the consequences caused by the immediate living environment. Even though most people would like to live in a good hygiene environment, it becomes more difficult to have that in camp conditions with limited space and commonplace congestion [12]. In camps therefore, the immediate living environment acts as an element that exacerbates poor hygiene conditions and the spread of diseases [31].

Efforts to curb the devastating effects of PRDs, then, should focus strongly on hygiene practices and how they can be improved. The report of families sharing toilet facilities with more than 10 other households in the camps underlines this point. Such conditions increase the risk of infections and the spread of diseases and are potentially fertile ground for the spread of epidemics. Respondents mentioned poverty and climatic conditions as reasons for common disease presence. Such attributions did not rate as highly as poor hygiene conditions. This once again highlights where the focus should lie in designing health interventions.

The way people perceive diseases, the attributions they indicate for disease presence and the perceived effectiveness of health actions against diseases influence how people respond to these diseases [17]. The health belief model enables a deeper understanding of how these different factors interact and lead to the final decision on which course of action to take [16]. Our study revealed that responses to diseases varied. Generally, the dominant response is to seek formal healthcare (84.1\%). This is understandable, as camp dwellers have the option of free healthcare services offered by CDC, which seeks to promote the health and wellbeing of its workers [32]. However, it is interesting to see that, in the case of malaria, the most common PRD, almost $90 \%$ of respondents reported that they would use informal healthcare practices. Similar results were found in our study among students [11].

One of the reasons for this inconsistency could be that, although malaria is very common $[27,33]$, headache and fever, the early symptoms of malaria, are also very common even though not particular to malaria. Crump et al [34] in their study on malaria diagnosis pointed out that the error rate for malaria can be quite high. This may imply that in many in- 
stances taking informal medication on the basis of early symptoms is effective in making the symptoms go away, probably because they are not caused by malaria. This sustains the belief that informal medication is effective against malaria. Camp dwellers' experience in dealing with malaria in other ways than hospital-based care thus likely reveals the complexity of malaria and an overall inefficiency of official healthcare facilities due to the lack of an integrated approach to fighting malaria. The HBM helps to explain this, as responding to a disease with the intention of being cured is determined by a belief in a health threat and a belief in the effectiveness of the response chosen, e.g. formal or informal practices sought for treatment and cure. The use of small pharmacies and self-medication practices are therefore perceived to be equally beneficial if not better for getting cured. Moreover, the results from our qualitative study in the same setting [35] revealed that people disliked drugs prescribed at the CDC healthcare services for malaria because of their severe side effects. Respondents reported that this was a factor keeping them away from the clinics [35]. Our results reveal that an offer of free medical care is not sufficient to cause people to use the facilities. This is contrary to reports in another study, which indicated that people do not use formal healthcare services because of lack of financial means [36]. In the camps, other factors, for example treatment quality, also matter when services are free as explained above. Such factors are perhaps more important than financial concerns, as confirmed in other studies. In Ghana for example, even though the government abolished fees for hospital-based care for expectant mothers, these women did not avail of this because of a lack of trust in the system [37]. CDC would probably see an increase in the use of the services it offers if it revisited its current treatment policy against diseases such as malaria. Providing more effective drugs in a consistent manner and improving workers' living conditions would go a long way towards establishing an integrated approach to fighting malaria.

It has been reported previously that poor socio-demographic status plays a role in people's utilisation of the formal healthcare system [38]. This was not the case in our study, as none of the socio-demographic factors (age, sex and so on) predicted using formal healthcare in the case of malaria. That notwithstanding, when threats to people's health and wellbeing such as lack of basic necessities (permanent water supply, toilet facilities, affordable and available food) are considered, our study showed that only people who experienced water cuts had higher odds of seeking formal healthcare in the case of malaria. The reason for this is not very clear. Unreliable and poor water supply is linked to an increase in unsanitary conditions [39] and increased risk of infectious diseases such as malaria. An increased frequency of infections, therefore, could be a reason why these people seek the free formal healthcare services offered by CDC. Further research is needed to clarify this.

Respondents reported factors that would facilitate their use of formal healthcare facilities to respond to diseases. Having money was the most important reason enabling formal res- 
ponse to disease. This confirms what has been reported in other studies [40,41]. In the CDC case, as workers and their dependants can receive free treatment at the hospital, having money would probably be an incentive to seek other 'better' formal healthcare facilities that do not belong to CDC. Seeking such treatment would therefore require out-of-pocket payment. Other triggers were unavailability of drugs at home, duration of illness and perceived severity of diseases. Our results add to studies on determinants of utilisation of formal healthcare services in countries and confirms perceived severity of disease as an incentive for hospital-based care $[1,2,41,42]$.

Our study has revealed the way people in CDC camps respond to diseases that adversely affect their health and wellbeing. It provides insights that help to explain why a disease like malaria is such a problem in Cameroon. In a parallel study on university students in Cameroon [11], we showed that students, with a much better educational background than the CDC workers, respond to malaria in very similar ways. Because students have to pay for official healthcare, reliance on self-medication practices and informal medication was even more prominent, especially for malaria. It is interesting to note that such different groups of people have the same responses towards malaria. As malaria is still a major public health problem [33], our results could mean that informal responses to malaria probably contribute to its persistence as a public health problem. Informal responses cannot be eliminated. By using the HBM, we have been able to highlight the repertoire of options people have available to respond to malaria (self-medication and small pharmacies). We therefore recommend that government policy and also CDC policy should include seeking to improve informal practices such as self-medication for malaria and also aim to train informal healthcare providers such as vendors in small pharmacies so that they will be able to administer the right medication in the right dosages.

\section{Study limitations}

Our respondents were from CDC camp settings, which is a particular group of respondents. By focusing primarily on this group, our study may be limited in its external validity across other non-camp settings. Also, we used the health belief model in this study. A limitation with this model is that there may be reasons (e.g. social) why people engage in health behaviour other than trying to avoid a negative outcome, and these would be ignored by the model. That notwithstanding, use of the HBM elucidated inter-linkages between poverty and health in a poor setting, and this is essential for the design of health promotion interventions in poor countries. 


\section{Conclusion}

Our study showed that camp dwellers perceived differences between common diseases and PRDs and attributed these to poor hygiene conditions characteristic of their dwelling place. Our study also revealed a list of major PRDs (malaria, cholera and diarrhoea) different from those listed by international and national health bodies, indicating a need to revisit the current classification of major PRDs. This is important and indicates a need to increase the range of focus from malaria, HIV and TB to include cholera and diarrhoea, which respondents perceive as major PRDs. Our respondents' association of poverty and related diseases with the conditions of the immediate environment highlights the fact that poverty has to be understood as being more than lack of money or not having access to healthcare services. Camp dwellers showed that they played an active role in matters concerning their health and wellbeing. This is highlighted by the fact that, despite free healthcare services offered by CDC, almost $90 \%$ of respondents did not immediately use these services for malaria treatment. They instead engaged in informal treatment practices including the use of small pharmacies and self-medication practices. By so doing, they showed that resolving health challenges is not limited to using free health services but extends to employing a repertoire of options that are available to them.

It is the duty of the Cameroon government and other organisations in Cameroon such as the CDC to seek to reduce the burden posed by PRDs. Prompt and effective diagnosis, management and treatment of PRDs is essential but not sufficient to control PRDs. An understanding of the inter-linkages between poverty and health or poverty and disease in addition, as we have shown in this paper, increases the likelihood of successful interventions against PRDs. 


\section{References}

1. Burtscher D, Burza S. Health-seeking behaviour and community perceptions of childhood undernutrition and a community management of acute malnutrition (CMAM) programme in rural Bihar, India: a qualitative study. Public Health Nutr 2015;18(17): 3234-3243. https://doi.org/10.1017/S1368980015000440

2. Ahmed SM, Adams AM, Chowdhury M, Bhuiya A. Changing health-seeking behaviour in Matlab, Bangladesh: do development interventions matter? Health Policy Plan 2003;18: 306-315.

3. WHO. Global report for research on infectious diseases of poverty. Geneva: World Health Organisation; 2012.

4. Singh AR, Singh SA, Diseases of poverty and lifestyle, well-being and human development. Mens Sana Monographs 2008;6: 187-225.

5. Stevens P. Diseases of poverty and the 10/90 Gap. IPN Working Papers on Intellectual Property, Innovation and Health. London: World Health Organisation; 2004.

6. WHO. Poverty and health. Geneva: World Health Organisation; 2016.

7. MINSANTE. Profil des estimations et projections en matiére de VIH et SIDA au Cameroun 2010-2020. Yaoundé: Ministère de la Santé Publique; 2009.

8. Pefura-Yone EW, Kengne AP, Kuaban C. Non-conversion of sputum culture among patients with smear positive pulmonary tuberculosis in Cameroon: a prospective cohort study. BMC Infect Dis 2014;14: 1-6.

9. Jaja PT. Health-seeking behaviour of Port Harcourt city residents: a comparison between the upper and lower socio-economic classes. J Public Health Africa 2013;4(1): 9. Available from: http://dx.doi.org/10.4081/jphia.2013.e9

10. Kankeu HT, Ventelou B. Socioeconomic inequalities in informal payments for health care: an assessment of the 'Robin Hood' hypothesis in 33 African countries. Soc Sci Med 2016;151: 173-186.

11. Makoge V, Maat H, Vaandrager L, Koelen M. Poverty-related diseases (PRDs): unravelling complexities in disease responses in Cameroon. Trop Med Health 2017;45: 2. doi: 
$10.1186 / \mathrm{s} 41182-016-0042-5$

12. de la Cova C. Race, health, and disease in 19th-century-born males. Am J Phys Anthropol 2011;144: 526-537.

13. Crabbe F, Carsauw H, Buve A, Laga M, Tchupo J, et al. Why do men with urethritis in Cameroon prefer to seek care in the informal health sector? Genitourin Med 1996;72: 220-222.

14. Kamgnia B. Use of health care services in Cameroon. Int J Appl Economet Quant Stud 2006;3(2): 53-64.

15. Hughes R, Chandler C, Mangham-Jefferies L, Mbacham W. Medicine sellers' perspectives on their role in providing health care in North-West Cameroon: a qualitative study. Health Policy Plan 2012;28(6): 636-646. Available from: https://doi.org/10.1093/hea$\mathrm{pol} / \mathrm{czs} 103$

16. Janz NK, Becker MH. The health belief model: a decade later. Health Educ Behav 1984;11: 1-47.

17. Koelen MA, van den Ban AW. Health education and health promotion. Wageningen, NL: Wageningen Academic Publishers; 2004.

18. Mackian S, Bedri N, Lovel H. Up the garden path and over the edge: where might health-seeking behaviour take us? Health Policy Plan 2004;19: 137-146.

19. Grundy J, Annear P. Health-seeking behaviour studies: a literature review of study design and methods with a focus on Cambodia. Melbourne, Australia: The Nossal Insitute for Global Health; 2010.

20. Moyou-Somo R, Essomba P, Songue E, Tchoubou NN, Ntambo A, et al. A public private partnership to fight against malaria along the Chad-Cameroon pipeline corridor: I. Baseline data on socio-anthropological aspects, knowledge, attitudes and practices of the population concerning malaria. BMC Public Health 2013;13: 1-10.

21. Hochbaum G, Rosenstock I, Kegels S. Health belief model. Rockville, MD: United States Public Health Service; 1952.

22. WHO. Guidelines for drinking-water quality: recommendations. Geneva: World Health 
Organisation; 2004.

23. Mensah P, Yeboah-Manu D, Owusu-Darko K, Ablordey A. Street foods in Accra, Ghana: how safe are they? Bull World Health Org 2002;80: 546-554.

24. CCAM. About_malaria: for a malaria free Cameroon. Yaoundé: CCAM; 2009.

25. MINSANTE. Plan Strategique Nationale de la lutte contre le paludisme au Cameroon 2007-2010. Yaoundé: Ministère de la Santé Publique; 2007.

26. Makoge V, Maat H, Edward N, Emery J. Knowledge, attitudes and practices towards malaria in Mbonge and Kumba sub-divisions in Cameroon. Int J Trop Dis Health 2016;15: 1-13.

27. Kimbi HK, Nkesa SB, Ndamukong-Nyanga JL, Sumbele IU, Atashili J, et al. Knowledge and perceptions towards malaria prevention among vulnerable groups in the Buea Health District, Cameroon. BMC Public Health 2014;14: 1. doi: 10.1186/1471-245814-883

28. Ndo C, Menze-Djantio B, Antonio-Nkondjio C. Awareness, attitudes and prevention of malaria in the cities of Douala and Yaounde (Cameroon). Parasit Vectors 2011;4: 181. doi: 10.1186/1756-3305-4-181

29. Glanz K, Rimer BK, Viswanath K. Health behavior and health education: theory, research, and practice. Hoboken, NJ: Wiley; 2008.

30. Maslove DM, Mnyusiwalla A, Mills EJ, McGowan J, Attaran A, et al. Barriers to the effective treatment and prevention of malaria in Africa: a systematic review of qualitative studies. BMC Int Health Hum Rights 2009;9. doi: 10.1186/1472-698X-9-26

31. Boelaert M, Meheus F, Sanchez A, Singh SP, Vanlerberghe V, et al. The poorest of the poor: a poverty appraisal of households affected by visceral leishmaniasis in Bihar, India. Trop Med Int Health 2009;14: 639-644.

32. Cameroon Development Corporation. Cameroon Development Corporation. Available from: http://cdc-cameroon.net/new2014/

33. Abate A, Degarege A, Erko B. Community knowledge, attitude and practice about malaria in a low endemic setting of Shewa Robit Town, northeastern Ethiopia. BMC Public 
Health 2013;13: 312. doi: 10.1186/1471-2458-13-312.

34. Crump JA, Morrissey AB, Nicholson WL, Massung RF, Stoddard RA, et al. Etiology of severe non-malaria febrile Illness in Northern Tanzania: a prospective cohort study. PLOS Negl Trop Dis 2013; 7: e2324.

35. Makoge V, Maat H, Vaandrager L, Koelen M. Health-seeking behaviour towards poverty-related disease (PRDs): a qualitative study of people living in camps and on campuses in Cameroon. PLOS Negl Trop Dis 2017;11: e0005218.

36. Peters DH, Garg A, Bloom G, Walker DG, Brieger WR, et al. Poverty and access to health care in developing countries. Ann N Y Acad Sci 2008;1136: 161-171.

37. Ganle JK, Parker M, Fitzpatrick R, Otupiri E. A qualitative study of health system barriers to accessibility and utilization of maternal and newborn healthcare services in Ghana after user-fee abolition. BMC Pregnancy Childbirth 2014;14: 425. doi: 10.1186/ s12884-014-0425-8

38. Shaikh BT, Hatcher J. Health seeking behaviour and health service utilization in Pakistan: challenging the policy makers. J Public Health 2005;27: 49-54.

39. Zolnikov TR. The maladies of water and war: addressing poor water quality in Iraq. Am J Public Health 2013;103: 980-987.

40. Taffa N, Chepngeno G. Determinants of health care seeking for childhood illnesses in Nairobi slums. Trop Med Int Health 2005;10: 240-245.

41. Abdulraheem IS, Parakoyi DB. Factors affecting mothers' healthcare-seeking behaviour for childhood illnesses in a rural Nigerian setting. Early Child Dev Care 2009;179: 671683.

42. Adedokun BO, Morhason-Bello IO, Ojengbede OA, Okonkwo NS, Kolade C. Helpseeking behavior among women currently leaking urine in Nigeria: is it any different from the rest of the world? Patient Prefer Adherence 2012;6: 815-819. 


\section{Chapter 4}

Health-Seeking Behaviour towards Poverty-Related Disease (PRDs): A Qualitative Study of People Living in Camps and on Campuses in Cameroon

Valerie Makoge, Harro Maat, Lenneke Vaandrager, Maria Koelen

This chapter is published as Health-Seeking Behaviour towards Poverty-Related Disease (PRDs): A Qualitative Study of People Living in Camps and on Campuses in Cameroon PLOS

Neglected Tropical Diseases (2017) 11(1): e0005218. doi: 10.1371/journal.pntd.0005218 


\section{Abstract}

Poverty-Related Diseases (PRDs) emphasize poverty as a 'breeding-ground' for a range of diseases. The study presented here starts from the premise that poverty is a general condition that can limit people's capacity to prevent, mitigate or treat diseases. Using an interpretation of health seeking behavior (HSB), inspired by the salutogenic approach, we investigated how people deal with PRDs, their ability and strategies put in place to cope. We collected HSB data from two groups of respondents in Cameroon: labourers of the Cameroon Development Corporation (CDC) living in settlements called camps and students of the state universities of Buea and Yaoundé living in settlements we refer to as campuses. By selecting these groups, the study offers a unique view of how different people cope with similar health challenges. We carried out semi-structured interviews with 21 camp dwellers and 21 students in a cross-sectional study. Our findings revealed 1) respondents use multiple resources to cope with PRDs. 2) Respondents' perceptions of diseases and connection with poverty closely ties to general hygienic conditions of their living environment. 3) Utilization of health facilities is not strongly dependent on financial resources. 4) Volatile health facilities are a major challenge and reason for people to revert to other health resources. The study brings out the need for organisations (governmental and non-governmental) to strengthen people's capacities to cope with health situations through better health and housing policies geared at incorporating practices currently used by the people and supporting pro-hygienic initiatives. 


\section{Introduction}

Even though a large number of diseases in low-income countries like Cameroon are preventable and treatable, they still form a big threat to people's health and well-being. The critical connection between diseases and poverty has caught the attention of national and international health agencies who aim to use this known connection in strategies to reduce the deleterious effects of diseases. The term poverty-related diseases (PRDs) is generally used to indicate poverty as a breeding ground for a range of diseases that can be more easily prevented or treated when living conditions and public services rise to higher developmental levels [1]. The World Health Organisation identifies malaria, HIV and tuberculosis as major PRDs [2]. Cameroon, located in Central Africa, is a nation in which PRDs are a major public health concern. Malaria accounts for most hospital consultations [3]. All people living in Cameroon are at risk of malaria, but the burden is felt more on the poor. The prevalence of HIV in Cameroon is highest in the sub-region of West and Central Africa standing at 5.1\% [4]. Also, Cameroon is considered to be medium endemic for tuberculosis [5].

Healthcare insurance policies are almost non-existent in Cameroon. Most healthcare expenditures are paid by family members. Treatment costs therefore imply a major financial burden, especially when health challenges are severe. Some healthcare options in Cameroon include government hospitals and healthcare centres, church-affiliated hospitals and clinics, private doctors, (un)official pharmacies, community health workers and street vendors .

Studies in relation to poverty and health typically argue that people in low-income countries lack financial, material or mental means to prevent disease and do not have access to quality healthcare, and that this results in reduced health and increased disease incidence among the poor $[2,6,7]$.

The study presented here starts from the premise that poverty is a general condition that can limit people's capacity to prevent, mitigate or treat diseases. That notwithstanding, we add a second premise, that people living in conditions of poverty can find ways to deal with health threats. Most research on PRDs works from the first premise only, focusing on limiting factors $[8,9]$, and little attention is paid to people's coping mechanisms. In our study, emphasis is put on the latter without ignoring the importance of the first. With our study, we hope to shed more light on what people do to manage their health despite the difficulties they face.

Using the notion of health-seeking behaviour (HSB), we investigated people's HSB towards PRDs, their ability and strategies put in place to cope. Main approaches within the field of HSB focus either on the process of illness response or on the utilisation of the formal healthcare system [10-12]. In our study, we looked at how our respondents engage in a variety of 
health-seeking practices to respond to PRDs in their settings i.e. HSB dynamics which we define as the interplay of different factors which influence decisions people take to manage health challenges at subsequent stages in the process of improving their health. We consider HSB more broadly, as actions taken by people to ensure good health in conditions of poverty and how people deal with partly (mal)functioning and partly inaccessible health facilities. To the best of our knowledge, HSB with regard to PRDs have not been reported before, and studies carried out in Cameroon on HSB towards any disease are rare. Insights about HSB, we argue, can reveal unique elements necessary to inform health policies about more integrated forms of health support for people living in poor conditions through building on the agency of local people and supporting community health in more ways than merely offering medical facilities.

Our interpretation of HSB was inspired by the salutogenic approach to health. The principle of salutogenesis, as formulated by Antonovsky [13], is that people's state of being can be projected on a health continuum, between a state of ease (total health) and dis-ease (total absence of health). He observed that people are constantly confronted with stressors in their daily lives, ranging from psychosocial stressors (e.g. unexpected job loss) to physical and biochemical stressors (e.g. polluted water), and these cause a tension that shifts people's position on that continuum. Coping successfully with stressors leads to a movement towards the ease (health) end of the continuum, what Antonovsky calls the salutogenic pathway. If stressors are not coped with successfully, stress experienced by people leads to breakdown, either physical or mental - a movement towards the dis-ease end of the continuum or pathogenic pathway [14, 15]. People in Cameroon are confronted with stressors (poverty, disease and so forth) in their daily lives. Being able to deal effectively with these stressors will enable them to move forward and live healthy and fulfilling lives. The salutogenic model helps to refine the HSB model by differentiating between stressors and resources as factors determining people's strategies and responses to health challenges.

The objective of this study was to investigate HSB towards PRDs in two different groups of people in Cameroon. We collected HSB data from labourers of the Cameroon Development Corporation (CDC) living in settlements called camps and students of the state universities of Buea and Yaoundé living in settlements called campuses. These two dissimilar groups offer a unique view of how different people cope with the same issue. In order to attain our objective, we asked the following research questions:

- What are the health challenges faced by people in camps and on campuses?

- How are health challenges managed by people in camps and on campuses?

- What are the dynamics of HSB in the camps and on the campuses? 


\section{Methods}

\section{Characteristics of the study settings and population}

Cameroon is located in Central Africa. The country is divided into ten regions with about 22 million inhabitants. This study was conducted in the camps and on the campuses providing housing to wage labourers of CDC and to students of the state universities of Buea and Yaoundé, respectively. The settings were selected because 1) they are both host to people originally from different parts of Cameroon settled in the settings for work or studies, respectively, and 2) differences in the participants' socio-demographic characteristics offered an opportunity to see different people's responses to PRDs.

The first setting (camps) was made up of three camps (Limbe camp, camp 7 and Sonne camp) all belonging to CDC, a parastatal agro-industrial company with plantations in the southwest region of Cameroon. CDC employs about sixteen thousand people, the majority of them being low-paid, low-educational-level wage labourers who live in camps provided by CDC [16]. Camps vary in size, housing from scores (e.g. camp 7 and Sonne camps) to hundreds (Limbe camp) of families and are similar in terms of housing, activities and living conditions. CDC offers its labourers and their family members free healthcare services in CDC clinics (or the only CDC hospital, in Tiko, Southwest Cameroon). These free services include consultations, laboratory examination and medication when available.

The second setting (campuses) was made up of two universities: University of Buea (UB) and University of Yaoundé (UNIYAO) found in the Southwest and Centre regions, respectively. UB has a population of over twelve thousand students [17], and UNIYAO has over thirty-three thousand students (2007 estimate) [18]. Most students live in neighbourhoods in the vicinity of the campuses. Students can rent rooms either on-campus or off-campus, but most rent off-campus because, on-campus, available rooms are few for the high demand. Student neighbourhoods are similar around both universities in terms of housing, activities and living conditions. For healthcare, unlike in the camps where it is provided free by CDC, students have to pay for the services themselves off-campus.

\section{Study design and respondents' characteristics}

This study was part of a larger research project, focusing on a wider set of health-related factors and responses from people to health challenges in the two research sites. The overall objective of the study is to understand how conditions of poverty impacted the health of people and how they managed these challenges. The study reported here was cross-sectional in design and took place in 2013. Semi-structured interviews were conducted using an interview guide with 21 camp dwellers and 21 students. In the camps, the respondents were fourteen males and seven females. Fourteen of these had basic primary education, three had 
no formal education, three had secondary education, and one had high school education. Twelve respondents from the camps were married, six were single and three either separated or widowed. On the campuses, there were 16 females and five males. All campus respondents were single.

In order to be eligible for the study, a person had to be living in the camps as a worker, or a dependant of a worker (camp respondents), or a student of UB or UNIYAO (campus respondents). Respondents from CDC camps were employed as tappers, camp and compound cleaners, security guards, weeders or dependent household members. Students interviewed were part of programmes such as educational psychology, journalism, diplomacy, English, life sciences and so forth.

\section{Procedure}

To reach different job categories and study programmes, respondents from the camps were selected after consultations with camp supervisors, and students were selected after consultations with student leaders. Selection of respondents purposefully weighed towards camp dwellers who were CDC workers and university students living in the Molyko and Ngoa-Ekelle neighbourhoods because respondents in these areas had experience with the way CDC or health services around the universities worked respectively. Camp supervisors and student leaders were entry points into the settings. These were members of the student community, in case of campuses, and CDC employees in case of the camps, known to and knowing the people.

Recruitment sites were the houses of camp dwellers and student buildings. Respondents were introduced to researcher and the research and consent was sought for participation. Respondents anonymity was assured during this process. All respondents approached agreed to be interviewed. Data collection stopped when no new information was obtained with newly recruited respondents [19].

\section{Interview guide}

An interview guide was designed after preliminary visits to the camps and the campuses, conversations with health overseers of the camps and student leaders, and observations of activities in the settings. Observations were made of meetings that usually take place each morning before workers go to the field, meetings of CDC workers, meetings with health overseers and camp supervisors, general daily activities in the camps and on the campuses. The interview guide was designed on the basis of the observations, HSB literature, the health continuum of the salutogenic model $[12,20-23]$ and sought to identify PRDs and other health challenges and how people coped with them. The first part of the guide had background or entry questions ascertaining the demographic characteristics of the respon- 
dents. What followed were questions to identify health challenges, enabling respondents to reflect on how they managed these challenges. Most of the interviews were conducted in English. Pidgin-English was used in interviews when preferred in the camps. Interviews were conducted in the camps by the first author, assisted by a CDC head office junior worker. Interviews on the campuses were conducted by the first author assisted by a trained student assistant.

\section{Data analysis}

The interviews were audio-taped, and detailed field notes were also taken. Interviews in English were transcribed verbatim style. Pidgin-English interviews were translated into English as they were being transcribed. Data were analysed using the ATLAS.ti 7.5 software (Scientific Software Development). Thematic analysis was carried out following Braun and Clarke's [24] protocol. The analysis process started with reading the transcripts several times and then generating codes. The transcripts were printed, read over several times for familiarisation with the data and then coded twice; first on raw transcripts and then in ATLAS.ti. Coding was guided by the salutogenic health model [13] and HSB literature [12, 22, 23]. The interest for the paper presented here was health seeking behaviour. Braun and Clarke's protocol [24] permit the possibility of flexibility in identifying themes in several ways. We identified themes based on our research questions. This implies we did a top-down coding. For the interest of our study, it was important to first of all identify the health challenges faced by respondents from the data. This made up one theme and the codes were common diseases and PRDs. We then identified general themes relating to health seeking behaviour reported in literature from the data. These themes still followed from our research questions i.e. how are health challenges were managed by people on camps and campuses. To answer these, we coded following practices such as self-medication, traditional medicine, using small pharmacies etc. From the data, we could see emerging patterns in health seeking behaviour and these were abstracted as dynamics of HSB in the camps and campuses.

Thematic analysis revealed that health challenges faced by respondents related to the presence of diseases such as PRDs, living conditions and healthcare services (functionality, accessibility and affordability). Management strategies revealed are categorised as informal and formal healthcare strategies, as shown on Table 4.1, alongside key elements associated with that theme. Further analysis of health challenges and management strategies revealed detailed patterns of HSB, highlighted and illustrated with quotations to explain why people do what they do health-seeking-wise, i.e. HSB dynamics. These related to local perceptions (effectiveness of medication to treat disease), perceived severity of disease (low or high) and financial considerations (flexibility of payment options). 
Table 4.1: Health management strategies and identified elements emerging from the interviews

\begin{tabular}{ll}
\hline Health challenge management strategies & Identified elements \\
\hline Informal healthcare strategies & \\
& a) Self-medication \\
& b) Traditional medicine (herbs or traditional \\
& doctor) \\
& c) Buying from small pharmacies/road vendors \\
& d) Consultations at quart-doctors ${ }^{*}$ or small \\
pharmacies & a) Going to CDC clinics \\
Formal healthcare strategies & b) Going to hospitals
\end{tabular}

* Students still at medical school or medical graduates not yet legally established

\section{Ethical clearance}

The study was approved by the Wageningen University review board and the Human Resources and Health departments of CDC. The aim and the procedure of the study were explained to all respondents who met the inclusion criteria. Respondents were informed of their right to leave at any stage without explanation. Respondents were assured of anonymity, and each respondent signed an informed consent form before participating in the study.

\section{Results}

The results section is divided into three parts, presented first for camps and then for campuses where applicable. Firstly, we address health challenges. Secondly, we address HSB in the settings and, thirdly, we address dynamics relating to HSB in the camps and on the campuses.

\section{Health challenges}

Respondents were asked to identify common diseases in their living environments, say which were PRDs and attribute causes for these diseases. The major perceived common diseases were also major perceived PRDs. Malaria was identified as the most commonly perceived disease in both settings. Its presence was attributed to poverty, poor hygiene, poor living conditions, being in the tropics, the high presence of mosquitoes and lack of mosquito nets.

Malaria is common because it is an illness that is present in Africa... There are those who would always like to get the place dirty. I can say malaria is still present because in some homes the people don't have nets ... (Male camp respondent) 
Typhoid fever followed malaria in high perceived prevalence and also as a PRD.

Malaria and typhoid. People [students] eat outside in poor places because they cannot even manage to eat in good restaurants... Then malaria too, because they can't buy mosquito nets, and some of them live in very low-class cités [student housing] because of lack of money. (Male campus respondent)

Poverty, poor hygiene and bad water were reported as attributed causes for typhoid. Only respondents from campuses named sexually transmitted infections (STIs) as common PRDs.

Other reported health challenges related to financial constraints, quality of treatment received (camps), shortage of drugs at CDC pharmacies and attitude of CDC clinic staff (camps). The nature of poverty in both settings is therefore linked to poor living conditions and finances. Health challenges therefore relate not only to exposure to diseases but also to the reliability, affordability and functionality of medical services.

\section{Management strategies towards diseases}

After identifying the health challenges, respondents reported on how they maintained their health and on how they managed health challenges. These are classified below as health maintenance strategies, informal and formal healthcare strategies.

Health maintenance strategies: Hygiene practices came out clearly as efforts employed by respondents to maintain health. In the camps, strategies employed were at both the individual and the community level. Hygiene practices at individual level included re-heating leftover food before consumption to avoid stomach upsets, cleaning clothes, beddings, houses and toilets, and using clean water as much as possible. At community level, hygiene practices reported were clean-up campaigns organised once every month for the general cleaning of camp surroundings.

We ensure that the compound is neat, we clean up fallen leaves from trees because when there are leaves, mosquitoes hide inside... (Female camp respondent)

We organise special days as clean-up campaigns ... the clean-up campaign is held every first Saturday of the month. During this campaign we make sure we keep places clean, especially the taps, because we believe that it is from the taps that we can have cholera-contaminated water. (Male camp respondent)

University students live mostly in single rooms. Their reported hygiene practices were mostly at individual level and included keeping themselves, their rooms and their surroundings 
clean. It also involved using bleach in water carried from wells in cases where there was no pipe-borne water. It was also reported that students in a student building could come together to clean up their surroundings, but this was not as systematic as in the camps. Other strategies reported to maintain health on the campuses were a sporadic medical check-up, using condoms during sexual intercourse, abstinence from sex, taking herbs or prophylactics.

Informal healthcare strategies: Informal healthcare strategies were basically deployed outside official healthcare channels and included self-medication, traditional medicine and other informal strategies.

Self-medication emerged as a dominant element under informal healthcare strategies. Self-medication was reported as the first response to any disease threat in the camps, even with available free healthcare services. Self-medication refers to using substances to selftreat self-diagnosed conditions. It usually occurred when illness severity was perceived as low. In the quote below, tablets were used to self-treat a self-diagnosed condition.

If you have paracetamol you take about three and drink and sit in the house and see what happens... The first thing to do is to try to treat it yourself. (Female camp respondent)

Camp respondents reported that, at the first sign of illness, first-aid was administered. This was usually medication found at home (as indicated in the quote above) or bought from informal sources such as street vendors or small pharmacies, or traditional medicine or herbs.

Self-medication was reported more on the campuses than in the camps. At the first sign of illness, campus respondents reported using medication they had at home. The quotes below indicate respondents' practice of self-medication.

Here, as students, there's a lot of auto medication [self-medication]. (Male campus respondent)

For us what happens is that, when someone in the house falls sick, we don't know what is wrong and so we start first with what we have at home as tablets. (Female campus respondent)

Respondents in both settings were able to give the names of drugs they used for self-medication purposes, especially in cases of commonly perceived PRDs like malaria. Coartem (an anti-malarial) was the drug most often named as the treatment taken for malaria. Aspirin, paracetamol and ibuprofen where reported as medicines taken for fevers. 
Self-medication was reportedly practiced in both settings using a very similar set of sources: medication that is available at home, buying cheap medication from street vendors and in small quantities (daily doses), buying medication from small pharmacies without a hospital prescription, and consuming bark, roots or leaves of plants (consuming herbs).

Traditional medicine (Table 4.2) emerged as the second most important element under informal healthcare strategies against PRDs. It was reported in the camps that traditional medicine could come either before hospital care,

Most times we would do the traditional concoction using mango sticks, pawpaw leaves and when this doesn't work that's when we take it to the hospital. (Female camp respondent)

or after hospital visit, in which case respondents reported going to the hospital to get a diagnosis before deciding the kind of HSB in which to engage depending on what they were told.

As for me, when I discovered that I had typhoid, after the hospital, I came home and started on herb treatment because I know of leaves which can treat the typhoid. (Female camp respondent)

Table 4.2: Reported remedies for treating diseases

\begin{tabular}{llll}
\hline Diseases & Strategy reported & Origin of response \\
\hline Malaria & - & $\begin{array}{l}\text { Boil together mango sticks, pawpaw } \\
\text { leaves and other herbs and drink }\end{array}$ & Camps/campuses \\
& $\begin{array}{l}\text { Boil okongobong and add a tin of evapo- } \\
\text { rated milk and drink }\end{array}$ & Camps \\
\hline Cholera & - & Salt in a litre of water & Camps \\
\hline Typhoid fever & - & $\begin{array}{l}\text { Pound 2000 CFA francs (3.5 US\$) worth } \\
\text { of okongobong and add a little water and } \\
\text { milk }\end{array}$ & \\
& - & $\begin{array}{l}\text { Mix limes, okongobong and water and } \\
\text { drink }\end{array}$ & Camps \\
\hline Pains and aches & - & Consume mashed guava leaves & Campus \\
\hline Gastritis & - & Consume bitter kola \\
& & honey seed mixed with & Campus \\
\hline
\end{tabular}

${ }^{*}$ Okongobong is a leafy vegetable common in Cameroonian and Nigerian cuisine

${ }^{*}$ Bitter kola, or Garcinia kola, is a tropical plant with medicinal properties

There were other reported uses for traditional medicine in the camps. Toilet cleaners reportedly use traditional medicine to ward off the toilet smell from their bodies. 
When I feel the nausea, I go to an old man who will treat me with traditional medicines... He gives me grass to eat and also some to bathe with because, after I clean the toilet, the smell follows me around. (Male camp respondent)

Traditional medicine practice was also reported on the campuses. Herbs were mentioned as a first response to disease treatment because of lack of money necessary for hospital consultations.

... I think for me most of the guys take herbs as the first step. You see, we are all students and sickness can attack one at every time, and we don't have money, so the basic step is to spin around and see if you can find the herbs around your house. It works. Something like malaria even, the scientists have done their work but I think the best way to get rid of it is to use herbs. (Male campus respondent)

Two other informal healthcare strategies were reported by respondents. One was consultations with quart-doctors for students. Students use the term quart-doctors to refer to doctors in the neighbourhoods (quarter-doctor). Quart-doctors could be a variety of semi-professionals, mostly students still in medical school or young doctors who have graduated from medical school but do not have a place to practice medicine legally.

In the student areas, there are clandestine doctors and student doctors and these are more affordable than the hospitals ... (Male campus respondent)

Quart-doctors were reported to run their practice from their rooms or from paid-for extra rooms transformed into offices in student buildings.

The second strategy was consultation at small pharmacies for respondents both in the camps and on the campuses. A small pharmacy is any small shop with some medication in it. It was reported that the person selling medication is called "doctor", and this vendor could also give prescriptions even though he/she is not a trained medical professional, therefore playing a consulting role similar to the quart-doctors, with the difference that quart-doctors at least have some medical training.

Formal healthcare strategies: In the camps, formal healthcare strategies referred mostly to visiting the free $\mathrm{CDC}$ clinics (or the CDC hospital in Tiko), which offered free consultations, laboratory examination and treatment. However, factors - for example poor quality of treatment received - hindered full exploitation of this option. Students reported that the last-resort option for seeking health was to go to the hospital. Hospitals around the universities were both public and private and required payment for services to be made fully and 


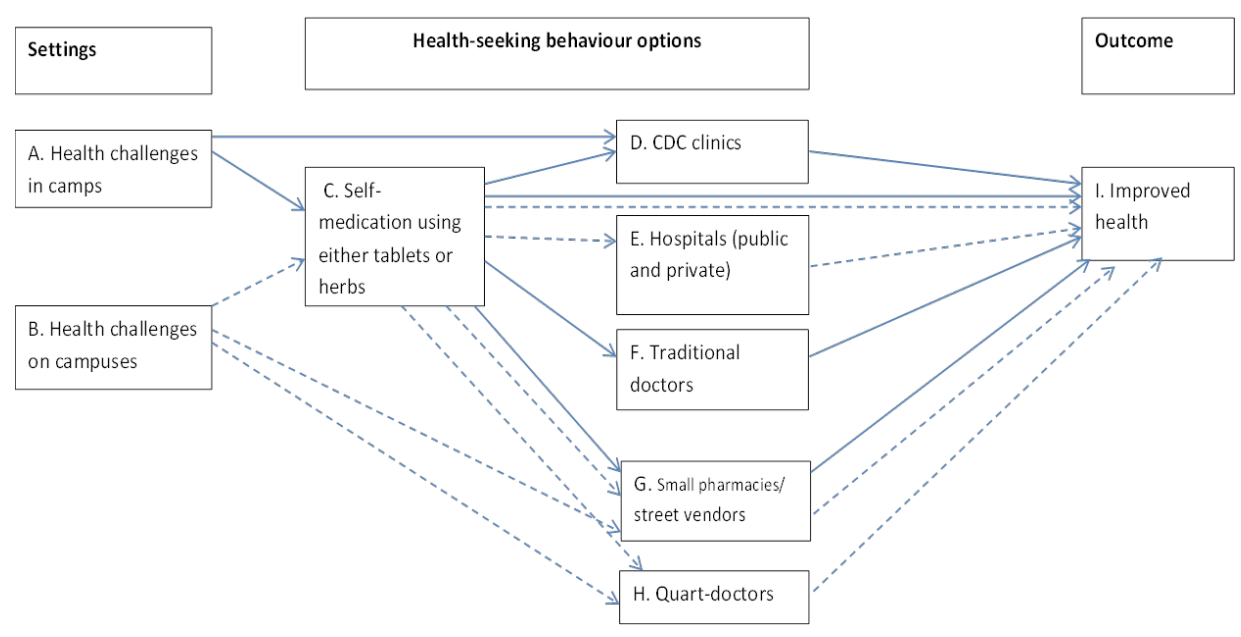

Figure 4.1: Schematic model of dynamics of HSB in camps and on campuses

in advance, thereby reducing their appeal for students who were already under financial constraints.

\section{Dynamics of health-seeking behaviour}

A major finding in our study was that HSB appeared very dynamic (see Fig 1). Factors behind the dynamics were local perceptions, perceived disease severity and financial constraints.

Local perceptions: Local perceptions of diseases influenced HSB. There were some diseases that respondents believed could not be treated with tablets but could be treated with herbs. Examples of such diseases were malaria and typhoid fever, both of which were commonly perceived PRDs in their living environments. The following quotes illustrate this perception.

I know that there's no tablet which treats malaria. All the tablets do is reduce discomfort. It is only traditional medicines that treat malaria. They can give you tablets to reduce discomfort for a month or so, but after that any other attack is more severe. So for me, I think that, if one has a malaria attack, it is best to go directly to the traditional way. You will be treated when you go traditional, and malaria will not be a problem for you anymore. (Male camp respondent)

We take herbs especially when it is a typhoid case. People say that the hospital can't treat that, they can only calm it down and so, in such cases, herbs are the way to go. (Female campus respondent) 
Perceived severity of disease: The perceived severity of the disease, whether high or low, reportedly influenced whether HSB was formal or informal.

Except when it is very serious that I can rush to the hospital [CDC clinic]. (Female camp respondent)

I go to the hospital depending on the severity of the illness or procedure. (Male campus respondent)

The preferred alternative in both settings when illness was not perceived as severe enough to go to the clinic or the hospital was home treatment (self-medication) or buying drugs from street vendors and small pharmacies. This happened even in the camps despite freely available healthcare, and even when these were out-of-pocket payment alternatives.

...There are other good antimalarial drugs and not expensive... I bought Artequin for 500 CFA francs and it was effective. When somebody is sick, I always go immediately to the CDC clinic. I go there so that they can detect what is wrong. If malaria is detected, I will go and buy drugs from somewhere else. (Male camp respondent)

Financial considerations: Financial constraints also influenced the type of HSB that people adopted. Formal HSB was reported more in the camps than on the campuses. Camp respondents reported that, as healthcare services were free for them, they were more likely to consider going to the CDC clinics when ill.

...when you go to other hospitals, whatever they have to do, they ask for money: consultation, lab etc., but since the CDC clinic is where we work and as it is free for us, we quickly go there. (Female camp respondent)

However, camp respondents engaged in a careful self-diagnosis and weighing of options before turning to the clinic. Awareness about the poor quality of the treatment received at the clinics was set against local perceptions or the perceived severity of the disease before the decision to go to the clinic was taken.

The medicine that is given [at CDC clinics] for malaria breaks one down, it makes one restless, and blocks ones ears. (Female camp respondent)

Students reported that they would rarely use formal healthcare (hospitals) because of financial constraints, but also when disease severity was perceived as low. For these reasons, they engaged in self-medication and other health-seeking strategies such as recourse to 
quart-doctors who were their informal healthcare providers and an alternative to both formal hospital care and street-vendor healthcare. Students reported using quart-doctors because of proximity, affordability and also payment flexibility (accepting collateral such as national identity cards instead of immediate cash payment).

...students have no money; they can't borrow medicine from there [hospitals]. In that case, the students are forced to go to quart-doctors. (Male campus respondent)

Although cheaper than going to the hospital, participants reported a need for caution when consulting with quart-doctors.

Quart-doctors are those people who open clandestine medicine shops who have not been authorised to practice. Quart-doctors are common in Molyko [place where University of Buea is located]. Quart-doctors do carry out abortions even. You know the rate of unwanted pregnancies in Molyko is very high. Quart-doctors are very cheap because they are out to make money... (Male campus respondent)

Consulting at small pharmacies was another option followed because students could not afford to go to the hospital. This usually came after the failure of self-medication using tablets at home or herbs. Small pharmacies were reportedly appealing because they were cheaper and flexible in selling daily doses when requested.

When I was sick with malaria, I went to the pharmacy to buy drugs since we are in school and cannot afford to go to the hospital and do consultation so we go to the pharmacy and just consult there and they prescribe to us what they can. (Female campus respondent)

Finally, even though students said that they did not rush to the hospital, they reported situations that would make them do so, for example when the illness severity was perceived as high; this usually occurred when they had not succeeded in treating themselves in the ways described above. Strategies reported for paying for healthcare included loans from friends and support from parents and relatives.

If you feel too bad, you go the hospital, maybe you start from pharmacies before eventually going to the hospital when it is serious. People will first of all start with self-treatment and, if it doesn't work, then they will go to the hospital. (Male campus respondent) 


\section{Discussion}

The aim of our study was to investigate HSB towards PRDs in two different groups of people in Cameroon. In both groups, there was a clear interaction between challenges in general living conditions, finances and health. Our findings show that malaria and typhoid fever are perceived as major PRDs, with a clearly expressed link to poor hygiene as the root cause. In both settings, people's response to health threats, and practices to prevent and to quickly overcome disease, typically demonstrate an eclectic use of available options and services. Official healthcare, in the form either of free CDC clinics as in the camps or of paid-for public hospitals for students, is only one of the available options. There is also a variety of self-medication practices and services and medication from unofficial sources, resulting in a hybrid platform for HSB. The case of the CDC clinics shows that free healthcare services do not stop self-medication practices and the use of alternative healthcare. Below, we discuss key findings of our study.

\section{PRDs}

As in other developing countries, malaria was perceived as a common disease in both settings [25-27]. Its presence was attributed to poverty, poor hygiene and tropical climatic conditions conducive to mosquitoes. Typhoid fever was also perceived as a major PRD in both settings. This is not in line with the WHO [2] classification of major PRDs, which does not include typhoid fever. Our results suggest that more attention should be paid to diseases linked to hygiene in research into PRDs and policies formulated to fight PRDs. Situation-specific hygiene conditions are a potential source of diseases, but our findings show that people understand the importance of good hygiene and can mobilise to improve their immediate living environment. However, the perceived persistence of diseases suggests that the efforts made by people may not be sufficient to significantly reduce the PRD burden. Health policies must be geared towards actions in support of people's initiatives to improve their living conditions.

Malaria and other PRDs pose burdens for the health and well-being of people in the studied settings, and conditions of poverty only serve to aggravate such burdens. Our study has created a better understanding of how two dissimilar groups of people, in terms of education and occupation, manage very similar conditions in which lack of financial resources and general poverty affect health. Our findings show that people find versatile and creative ways to combine available resources to improve their health and well-being, i.e. a move towards the ease end of the salutogenic ease-dis(ease) continuum. The purpose of a HSB study is usually to find out how people interact with health systems - the hindrances to, and facilitators of, engaging with formal health systems [12]. In our study, we have gone further and additionally looked at how people manage means at their disposal. We have looked at both 
formal and informal HSBs as well as the dynamics at play as people seek health.

Our study showed that HSB could be influenced by many variants, such as the attitude of staff (camps), quality of treatment, perceived severity of disease, respondents' (lack of) money and also respondents' local perceptions about diseases. In the following sections, we discuss respondents' management of diseases as well as the dynamics underlying HSB.

\section{Management strategies}

The people in the camps and on the campuses demonstrated unique ways of dealing with PRDs and other health issues, and it was interesting to find similarities among two such different groups.

In both settings, self-medication was indicated as a first response to illness, and this was not a function of education (since both educated and uneducated respondents were involved in the practice) but rather of poverty, perceived disease severity and the volatility of health services. Volatile health facilities refer to facilities which are not consistently functional, accessible or affordable. This refers especially to camp situations in which people are 'entitled' to free treatment and medication but these are often unavailable and patients are asked to come back several times requiring them to pay transport for that for which they do not have the money and so they stop going.

Self-medication is a reported practice in other countries as well $[6,7,28,29]$. What our study shows is that people are knowledgeable about the treatment needed for their illnesses. The capacity for self-diagnosis and subsequent action to find the required treatment was not limited to official clinics or pharmacies but rather reflected a much wider array of treatment options. When asked about this, people were able to report various recipes as treatment for malaria, typhoid and so forth, and (brand) names of pills for these diseases. Further research could investigate the effectiveness of the different recipes reported as treatments. Even though self-medication was practiced in both settings, it was more common in the student milieu. This is probably because students face more financial constraints and weigh their options for spending money on medication against various other expenses. The situation in the CDC camps, however, makes clear that free healthcare services do not eliminate self-medication (first-aid) and the use of alternative sources by camp respondents. Factors such as poor quality of drugs received at the clinics were reported as main reasons for self-medication. The side-effects associated with these drugs did not permit respondents to complete the treatment and also resulted in a preference for drugs from other sources or the use of herbs. Respondents also reported frequent drug shortages at the CDC pharmacy, requiring either several trips to the clinic or, the preferred option, a shift to self-medication. Shortage of drugs at health centres has also been reported in other countries like Tanzania as 
a reason for self-medication $[30,31]$. Another reason for choosing self-medication over free clinics was the reported poor attitude of the medical staff. The way people are received in healthcare services and treatment quality are therefore important issues to be considered by CDC and other health providers in order for the services they provide to be effectively used [32]. From the above, we can see that self-medication was considered for several reasons, mainly to save time and money, to have a choice about the kind of medication to take and to have control over a health situation. However, using self-medication as a first response to disease could lead also to delay in seeking appropriate treatment if it fails [12].

Traditional medicine was another way in which respondents primarily managed diseases. This was reported as seeking a traditional healer or as that part of self-medication in which the respondents used plants (herbs). This type of HSB was common in both settings, as respondents unanimously reported their use of herbs to prevent and treat diseases. Herbs were reportedly considered an enticing alternative because they were accessible, cheaper, natural and devoid of chemicals found in tablets that cause severe side-effects (as reported in the camps). Herbs were used to treat malaria, typhoid and aches. This finding adds to previously reported studies on the use of herbs for treatment of conditions such as gynaecological complaints [33] and liver diseases [34].

\section{HSB dynamics}

The dynamics of HSB were found to be based mainly on three crucial aspects. These were: local perceptions of disease, perceived severity of disease and financial considerations.

Local perceptions of disease: It was important to understand in our study perceptions people had towards diseases and treatment options, as it was clear from their reports that these perceptions influenced their HSB. Other studies have shown that local beliefs can influence whether respondents accept medical treatments for a disease or not [35-37]. In fact, local beliefs have been reported to influence even the perceived causes and recognition of symptoms for diseases [36]. In our study, malaria and typhoid were diseases that respondents believed could not be treated using tablets. The response to malaria and typhoid was therefore guided by these perceptions. HSB then leaned towards what was expected to bring cure, and in our study this was herbal remedies. It was only when this route did not work and the disease was perceived to be more severe than thought that other options were considered.

Perceived severity of disease: It was also important to understand at which point disease was considered as severe in our study, because perceived severity was a factor influencing HSB [38]. The decision to seek healthcare took into consideration whether disease severity was perceived as low or high [39]. Once the severity of the disease was established, the decision on a formal or an informal next step was made. The respondents indicated that illness 
was considered severe when the first measure - self-medication - to treat it failed to bring relief. As in other countries, self-medication was common when illness was not perceived as severe [39-40]. This was done using drugs available at home, home concoctions with herbs or drugs bought at small pharmacies. This practice was seen both in the camps and on the campuses. When severity was perceived as high, multiple factors influenced the path of action pursued, including questions of where to go next, how much that option would cost and whether there was cost/payment flexibility.

Financial considerations: Respondents tended to avoid hospitals, which they described as being expensive and strict in payment options offered. Collateral was not accepted and instead upfront payment was required. Hospitals were therefore not visited until conditions worsened and became unbearable. Finance for healthcare was crucial to determine whether or not to seek treatment and which kind of treatment should be sought. The high cost associated with visiting hospitals was indicated as justification for not going, except in cases of high perceived severity [41]. The healthcare provider's flexibility in relation to payment was an important factor in HSB, especially on the campuses. Health providers who were not strict about cost of treatment and payment options were more appealing options than those who demanded prompt and full payment [39]. Payment flexibility and accessibility made quart-doctors very appealing for students. Flexibility in selling small doses at cheaper rates made small pharmacies and street vendors enticing for people in camps and on campuses.

\section{Methodological reflection}

In this study we did not focus on gender-based management strategies but rather settings-based (camps and campuses) management strategies to health challenges. We therefore have not reported information (if any) of existing differences in the way males and females respond to diseases. An analysis of gender-based responses to health issues within the settings would be interesting for further research. That notwithstanding, we have provided information on diversity in respondents in terms of age, education and occupation and how this relates to their response to health challenges in the settings.

By purposefully selecting respondents with different jobs and students of different study programs, we acknowledge an element of researcher bias. However, this is common with qualitative studies which seek respondents who have information or experience with the phenomenon under study. Also, since we were not getting any new information with newly recruited respondents, we believe that we have covered the experiences of most people living in the camps or on campuses. 
We recognise that one of the limitations of a qualitative study is the reduced possibility to generalise the findings across the wider population. That notwithstanding, qualitative studies such as ours offer an opportunity to go in-depth in the case studied and bring out rich dynamics which will hardly be captured by quantitative studies. Our selection of two research sites, camps and campuses, was not meant as a comparative study but as a way to gain deeper insight into the variety of ways poverty is a co-determinant for health and disease. By doing so our study provides rich information on the types of health challenges the people in camps and on campuses have and also how they manage these challenges. We also acknowledge that this information cannot be generalised across other groups in Cameroon which may have their own health seeking strategies.

\section{Conclusion}

The aim of this study was to investigate HSB towards PRDs in two different groups of people. Our findings have revealed remarkable insights into the reasons behind HSB and strategies used. We started from two premises: 1) poverty is a general condition limiting a person's ability to prevent, mitigate or treat diseases; 2) people living in conditions of poverty can find ways to manage health threats and improve their conditions. Our study showed that people's own perceptions of diseases and the connection with poverty were closely tied to the general hygiene in their living environment. For example, the presence of malaria and typhoid were attributed to poor hygiene. Moreover, access to health facilities was not a clear-cut situation dependent on financial resources. Our findings showed that volatile health facilities are a major challenge and a reason for people to have recourse to other resources. Regarding people in the camps, despite free healthcare services offered by CDC, respondents reported using self-medication as a response to disease, showing that the interaction between poverty and HSB is much broader than financial means. With regard to the students' situation, a specific grey zone of healthcare was visible in the form of quart-doctors, in most cases people with some medical training at academic level but without official positions as medical doctors. The results from both settings show a substantial level of perceived knowledgeability and control over personal health conditions. The versatile response, using a variety of resources in a complementary way, is the main mechanism associated with HSB in the camps and on the campuses. The results of this study are intended to promote the need for organisations (governmental and non-governmental) to strengthen people's capacities to cope with their health situations. This can be done on the one hand through better health policies geared at incorporating and improving self-medication and traditional practices currently used. On the other hand, through improved housing policies geared at supporting initiatives people have in place such as the clean-up campaigns reported in this study. A focus on capacity building at a societal level by CDC and the Cameroon government is essential to fill the gaps left by systemic weaknesses of the extant healthcare system revealed in this study. 


\section{References}

1. Stevens P. Diseases of poverty and the 10/90 Gap. IPN Working Papers on Intellectual Property, Innovation and Health. 2004; London, UK. Retrieved 26 May 2016 from http:// www.who.int/entity/intellectualproperty/submissions/en/InternationalPolicyNetwork. pdf

2. World Health Organisation [interent]. Global report for research on infectious diseases of poverty. 2012; Retrieved 17 September 2015 from http://apps.who.int/iris/bitstre am/10665/44850/1/9789241564489_eng.pdf

3. CCAM. About malaria: For a malaria free Cameroon. A bilingual publication of Cameroon Coalition Against Malaria. 2009;2(1):1-28.

4. MINSANTE. Profil des Estimations et Projections en Matière de VIH et SIDA au Cameroun 2010-2020. Yaoundé: Ministère de la Santé Publique; 2009. p. 17.

5. Pefura-Yone EW, Kengne AP, Kuaban C. Non-conversion of sputum culture among patients with smear positive pulmonary tuberculosis in Cameroon: a prospective cohort study. BMC Infect Dis. 2014;14(1):1-6. doi: 10.1186/1471-2334-14-138

6. Ahmed SM, Adams AM, Chowdhury M, \& Bhuiya A. Changing health-seeking behaviour in Matlab, Bangladesh: Do development interventions matter? Health Policy Plan. 2003; 18(3): 306-315. doi: 10.1093/heapol/czg037

7. Burtscher D \& Burza S. Health-seeking behaviour and community perceptions of childhood undernutrition and a community management of acute malnutrition (CMAM) programme in rural Bihar, India: A qualitative study. Public Health Nutr 2015; doi: 10.1017/ s1368980015000440

8. Halperin D \& Allen, A. Is poverty the root cause of African AIDS? AIDS Anal Afr 2001; 11(4): 1-3.

9. Lozano R, Naghavi M, Foreman K, Lim S, Shibuya K, Aboyans V, . . Murray CJL. Global and regional mortality from 235 causes of death for 20 age groups in 1990 and 2010: A systematic analysis for the Global Burden of Disease Study 2010. The Lancet, 2012; 380(9859): 2095-2128. doi: http://dx.doi.org/10.1016/S0140-6736(12)61728-0

10. Chen M T, Li C. Y, Lin HC, Shen WW, Hsieh PC, \& Chen CC. Health-seeking behavior, 
alternative medicine, and quality of life in Taiwanese panic disorder patients. Int J Psychiatry Med 2013 17(3): 206-215. doi: 10.3109/13651501.2012; 713111

11. Chenge MF, Van Der Vennet J, Luboya N O, Vanlerberghe V, Mapatano MA, \& Criel B. Health-seeking behaviour in the city of Lubumbashi, Democratic Republic of the Congo: Results from a cross-sectional household survey. BMC Health Serv. Res. 2014; 14(1). doi: $10.1186 / 1472-6963-14-173$

12. Mackian S, Bedri $\mathrm{N} \&$ Lovel $\mathrm{H}$. Up the garden path and over the edge: Where might health-seeking behaviour take us? Health Policy Plan. 2004; 19(3): 137-146. doi: 10.1093/ heapol/czh017

13. Antonovsky A. The salutogenic model as a theory to guide health promotion. Health Promot Int, 1996; 11(1): 11-18.

14. Eriksson M. Unravelling the mystery of salutogenesis: The evidence base of the salutogenic research as measured by Antonovskys Sense of Coherence Scale. Doctoral thesis in social policy at $\AA A$ U, 2007. Vasa: Faculty of Social and Caring Science.

15. Lindström B, \& Eriksson M. Contextualizing salutogenesis and Antonovsky in public health development. Health Promot Int. 2006; 21(3): 238-244. doi: 10.1093/heapro/dal016

16. Cameroon Development Corporation [Internet]. CDC. 2009; Retrieved July 2014 from http://www.cdc-cameroon.com/Subpages/

17. University of Buea. [Internet]. About UB. 2014; Retrieved 15 August 2015 from http:// www.ubuea.cm/about/

18. Institut National de la Statistique [Internet]. Annuaire Statistique du Cameroun. 2010 ; Retrieved from http://www.statistics-cameroon.org/downloads/annuaire2010/chap6.pdf.

19. Strauss A, Corbin J. Basics of qualitative research: Techniques and procedures for developing grounded theory. Sage Publications, Inc; 1998.

20. Antonovsky A. Health, stress, and coping. 1979; San Francisco, CA: Jossey-Bass.

21. Antonovsky A. Unraveling the mystery of health: How people manage stress and stay well: 1987San Francisco, CA: Jossey-Bass. 
22. Grundy J, \& Annear P. Health-seeking behaviour studies: A literature review of study design and methods with a focus on Cambodia. Health Policy and Health Finance Knowledge Hub Working Paper Series No. 7. Melbourne, Australia: The Nossal Institute for Global Health. 2010

23. MacKian S. A review of health seeking behaviour: Problems and prospects. 2003; Manchester, UK: The University of Manchester, Health Systems Development Programme.

24. Braun V \& Clarke V. Using thematic analysis in psychology. Qual Res Psychol . 2006; 3(2): 77-101.

25. Audu O, Bako Ara I, Abdullahi Umar A, Nanben Omole V \& Avidime S. Sociodemographic correlates of choice of health care services in six rural communities in North Central Nigeria. Adv Public Health 2014; 7. doi: 10.1155/2014/651086

26. Imbahale SS, Fillinger U, Githeko A, Mukabana WR, \& Takken W. An exploratory survey of malaria prevalence and people's knowledge, attitudes and practices of mosquito larval source management for malaria control in western Kenya. Acta Tropica 2010. 115(3): 248-256. doi: 10.1016/j.actatropica.2010; 04.005

27. Musoke D, Karani G, Ssempebwa JC \& Musoke MB (2013). Integrated approach to malaria prevention at household level in rural communities in Uganda: Experiences from a pilot project. Malar J. 2013; 12(1). doi: 10.1186/1475-2875-12-327

28. Abosede OA. Self-medication: An important aspect of primary health care. Soc. Sci. Med. 1984. 19(7), 699-703. doi: http://dx.doi.org/10.1016/0277-9536(84)90242-9

29. Friend-du Preez N, Cameron N \& Griffiths P. "So they believe that if the baby is sick you must give drugs." The importance of medicines in health-seeking behaviour for childhood illnesses in urban South Africa Soc. Sci. Med. 2013; 92: 43-52. doi: 10.1016/j. socscimed.2013.05.014

30. Chipwaza B, Mugasa JP, Mayumana I, Amuri M, Makungu C \& Gwakisa PS. Self-medication with anti-malarials is a common practice in rural communities of Kilosa district in Tanzania despite the reported decline of malaria. Malar J. 2014; 13(1): 1-11. doi: $10.1186 / 1475-2875-13-252$

31. Kahabuka C, Moland KM, Kivale G \& Hinderaker SG. Unfulfilled expectations to services offered at primary health care facilities: Experiences of caretakers of underfive chil- 
dren in rural Tanzania. BMC Health Serv. Res. 2012; 12. doi: 10.1186/1472-6963-12-158

32. Shaikh BT \& Hatcher J. Health seeking behaviour and health service utilization in Pakistan: Challenging the policy makers. J. Public Health. 2005; 27(1): 49-54. doi: 10.1093/ pubmed/fdh207

33. Steenkamp V. Traditional herbal remedies used by South African women for gynaecological complaints. J Ethnopharmacol. 2003; 86(1): 97-108. doi: http://dx.doi.org/10.1016/ S0378-8741(03)00053-9

34. Stickel F \& Schuppan D. Herbal medicine in the treatment of liver diseases. Dig Liver Dis. 2007; 39(4): 293-304. doi: http://dx.doi.org/10.1016/j.dld.2006.11.004

35. Helman CG. Culture, Health and Illness. 2007 (5th ed.). London: Hodder Arnold.

36. Makoge V, Maat H, Edward N, \& Emery J. Knowledge, attitudes and practices towards malaria in Mbonge and Kumba sub-divisions in Cameroon. Int J Trop Dis Health. 2016; 15(2): 1-13.

37. Sabuni LP. Dilemma with the local perception of causes of illnesses in Central Africa: Muted concept but prevalent in everyday life. 冈Qual. Health Res. 2007; 17(9): 1280-1291. doi: $10.1177 / 1049732307307864$

38. Asampong E, Dwuma-Badu K, Stephens J, Srigboh R, Neitzel R, Basu N \& Fobil JN. Health seeking behaviours among electronic waste workers in Ghana. BMC Public Health, 2015; 15(1): 1065.

39. Biswas P, Kabir ZN, Nilsson J \& Zaman S. Dynamics of health care seeking behaviour of elderly people in rural Bangladesh. International Journal of Ageing and Later Life.2006; 1( 1): 69-89.

40. Stevenson FA, Britten N, Barry CA, Bradley CP \& Barber N. Self-treatment and its discussion in medical consultations: How is medical pluralism managed in practice? Soc. Sci. Med. 2003; 57(3): 513-527.

41. Abdulraheem I S \& Parakoyi DB. Factors affecting mothers' healthcare-seeking behaviour for childhood illnesses in a rural Nigerian setting. Early Child Dev Care 2009; 179(5): 671-683. doi: 10.1080/03004430701500885 


\section{Chapter 5}

Health dynamics in camps and campuses: stressors and coping strategies for well-being among labourers and students in Cameroon

Valerie Makoge, Harro Maat, Lenneke Vaandrager, Maria Koelen

This chapter has been submitted and is under review as:

Health dynamics in camps and on campuses: stressors and coping strategies for well-being among labourers and students in Cameroon. 


\section{Abstract}

For many people living in low-income countries, poverty implies an increased exposure to conditions that threaten health and wellbeing. Besides poor sanitary conditions, poor food quality or other biophysical factors, social-psychological factors also increase disease risks, for example poor work conditions, debts or status differences. Despite the challenging conditions caused by poverty, people may consider themselves healthy because they have learned to cope with their situation. This may be as a result of life experiences which expose people to both challenges and potential solutions. In this paper we present results from studying health and wellbeing challenges and mechanisms to cope with challenges among people who are living under conditions of poverty in two different settings: workers of the Cameroon Development Corporation (CDC) and students of the university of Buea and the university of Yaoundé. We used the salutogenic model of health, emphasising people's 'sense of coherence' that enables them to employ resources to overcome stressors. We performed a cross-sectional study interviewing 21 CDC workers and 21 students. Our results show that all respondents experienced stressors, some specific to the settings and others general to all. Specific stressors were bad labour conditions for workers and study stress for students. General stressors were poor living conditions, poor healthcare and financial uncertainty. As a response to the stressors, respondents devised several coping mechanisms, such as looking for alternative ways to make additional money, preventive action and improvisation to manage health and work challenges. Social networks and shared activities, for example religious and other social meetings, were revealed as avenues which enhance coping with stressors. We conclude that supporting and promoting such avenues is essential for enhanced and continuous coping with stressors.. 


\section{Introduction}

For many people living in low-income countries, poverty implies an increased exposure to conditions that threaten health and wellbeing [1]. More specifically, poverty exposes people to more risk factors for diseases and poor nutrition, and reduces their capacity to maintain their health [2]. International agencies addressing diseases of poverty or poverty-related diseases (PRDs) focus mostly on the main infectious diseases [1]. The World Health Organisation (WHO) classifies malaria, HIV and tuberculosis as major PRDs [3].

The connection between poverty and disease, obvious as it may seem, is not always straightforward. When, for example should a person be considered ill or healthy? According to the WHO, health is 'a state of complete physical, mental and social well-being and not merely the absence of disease or infirmity' [4]. This definition was unprecedented at the time of its conception over 60 years ago and has not been modified since, even though trends in diseases have changed, as well as the ways in which people manage health and illness. Although seemingly inclusive, the WHO definition has been criticised for its projection of an ideal situation that few people can attain [5] and for ignoring the efforts that people make with respect to their challenges. For example, people have been shown to consider themselves very healthy in situations that others would characterise as great adversity [6]. Similarly, people with chronic diseases have shown tendencies to manage these diseases and live fulfilled lives [7].

These points of critique formed the basis of our study on the relationship between poverty and health. In challenging situations caused by poverty, people may consider themselves healthy because they have learned to cope with their situation. This is a result of life experiences that expose people to both challenges and potential solutions [6]. In Cameroon, $40 \%$ of the population are considered as living below the poverty line [8,9]. In this paper, we present results of studies on health and wellbeing challenges, and mechanisms to cope with these challenges, among two different groups of people who are living under conditions of poverty: employees (and their dependants) of the Cameroon Development Corporation (CDC) and students at the University of Buea and the University of Yaoundé. Both groups have income levels around the official poverty indicator of $\$ 1.90$ a day. Using the salutogenic model of health (SMH), we investigated stressors and coping mechanisms of the two selected groups. Such an approach provides insights that are useful to target health promotion efforts geared towards people's own capacities in places where official health services are defective and out of reach for the poor.

The SMH does not consider health and disease as a state or (permanent) condition but rather as a dynamic process. Antonovsky [10] portrayed health as moving along a continuum, 
indicating, at one extreme, complete lack of health (dis-ease) and, at the other extreme, full health (ease). The salutogenic model therefore assumes that a wide variety of factors have an impact on the health-disease continuum. In our study, we focused on the different areas that have been reported to play a role in the health and wellbeing of people, such as living conditions, job, healthcare services, relationships and so on [11].

The SMH offers a platform for the identification and understanding of what people experience as stressors and resources. A key ability for a person is his/her capacity to comprehend and have an overview of a situation and foresee a way out. This follows from the person's life experiences, i.e. a balance in life with respect to stressors and resources as well as having a life that is predictable and finally actively taking part in the shaping of his/her life [6]. Such experiences are essential for putting in place what Antonovsky called Sense of Coherence (SOC). There are three key components of SOC [12]. Firstly, a person has a sense of what to expect in a given situation (comprehensibility). Secondly, a person has an immediate sense that, in his or her situation, there are resources that can be employed (manageability). Thirdly, a person realises that it makes sense to act upon a situation (meaningfulness). The means available to people, termed General Resistance Resources (GRRs) and Specialised Resistance Resources (SRRs), can be material, biological, personal or social in nature. Having a strong SOC is linked to being more able to identify and use GRRs and SRRs [13]. The combination of SOC, GRRs and SRRs allows an individual or group to be effective in avoiding or combatting stressors [12]. The SMH thus considers a person's own capacities in relation to health as a key resource and a crucial element in making other resources relevant in dealing with stressors, which affect everyone at one time or another. The presence of a stressor creates a tension that will cause people to shift in their position on the continuum either towards the health pole, when they overcome the challenges, or towards the dis-ease pole, when they fail to do so.

In sum, the aim of our study was to investigate the different types of stressors experienced by camp dwellers and university students and to explore their ability to draw on identified resources to circumvent life's challenges. This information is essential for a better understanding of what health means and how people attain health in conditions of poverty [6]. We sought to answer three questions: 1) What types of stressors are experienced by camp dwellers and university students? 2) What coping mechanisms do respondents use to deal with stressors affecting their health and wellbeing? 3) What recommendations can be given to increase resources for coping and reduce stressors experienced in the lives of our respondents?

To the best of our knowledge, the SMH has hardly been used in studies in developing countries. By using this model among two different groups of people in Cameroon, we provide a promising lens through which PRDs can be understood and managed. 


\section{Methods}

\section{Characteristics of the study settings and population}

Cameroon, located in Central Africa, is a country with great diversity in culture, geography and climate. The study presented here was conducted in the housing offered to workers of $\mathrm{CDC}$, an agro-industrial company with plantations in the southwest region of Cameroon, and among students at the state universities of Buea and Yaoundé. These settings, referred to as camps and campuses respectively, were selected firstly because they are both home to people who originally came from different parts of Cameroon and moved to the settings for work or studies, respectively, and secondly because respondents in both settings have a low income. The groups also differ on other socio-economic characteristics, e.g. age, education, marital status, and on coping mechanisms. By including these two groups, we offer a comprehensive view of the diverse nature of stressors that people encounter.

CDC employs about sixteen thousand people, the majority of them being low-paid, low-educational-level wage labourers who live in camps with their families [14]. Three CDC camps were included in our study: Limbe camp, Camp 7 and Sonne camp. Small CDC camps, such as Camp 7 and Sonne camp, have about 50 households each, whereas large camps, like Limbe camp, tend to have several hundred households. The general living conditions in the different CDC camps are poor. CDC workers in the different camps perform similar tasks for the organisation. As a worker, a person together with his or her family is entitled to free healthcare services offered at CDC clinics or hospital, including consultation, laboratory analysis and free medication, if available.

In the campus setting, our study includes students from two universities, University of Buea (UB) and University of Yaoundé (UNIYAO), located in the Southwest and Centre regions respectively. UB has a population of over twelve thousand students [15], and UNIYAO has over thirty-three thousand students (2007 estimate) [16]. Most students live in neighbourhoods in the vicinity of the campuses because, on-campus, available rooms are too few for the high demand. The student neighbourhoods in Buea and Yaoundé are similar in terms of available housing, the types of activities carried out in the neighbourhoods and students' general living conditions. Students have to pay for healthcare themselves, off-campus and in cash.

\section{Study design and respondents' characteristics}

This study was cross-sectional in design and part of a larger study, with data collected over 2013 and 2014. The overall objective was to reveal the complex connections between conditions of poverty and health/disease and how people manage, despite these complexities. 
We carried out semi-structured interviews with 21 camp dwellers and 21 students. Fourteen of the camp dwellers interviewed were male and seven were female. Fourteen of these had basic primary education, three had no formal education, three had secondary education and one had high school education. Twelve camp dwellers were married, six were single and three either separated or widowed. In the campus setting, 16 of the students were female and five were male, and all of them were single.

In order to be eligible for the study, a person had to be living in the camps as a worker, or a dependant of a worker (camp respondents), or a student at UB or UNIYAO (campus respondents). Camp dwellers who took part in this study were employed by CDC as rubber tappers, camp and compound cleaners, security guards or weeders. One camp dweller was a dependant of a CDC worker. Students interviewed were taking university courses such as educational psychology, journalism, diplomacy, English, life sciences and so forth.

\section{Procedure}

In order to reach different job categories and study programmes, respondents from the camps were selected after consultations with camp supervisors, and students were selected after consultations with student leaders. Selection of respondents purposefully included camp dwellers who were CDC workers (or dependants) because these camp dwellers would have classic camp-dweller experience and resources to deal with stressors. University students living in the Molyko (UB) and Ngoa-Ekelle (UNIYAO) neighbourhoods were purposefully selected for this study because these students would have commonplace student experiences of stressors and coping resources.

Camp dwellers were recruited in their houses in the camps, and students were recruited in their rooms in the student buildings. Respondents were introduced to the researcher and the research, and consent was sought for participation. Respondents' anonymity was assured during this process. All respondents approached agreed to be interviewed. After 21 interviews in each setting, it appeared that no new information was forthcoming, therefore data collection stopped [17].

\section{Ethical considerations}

This study was approved by the Wageningen University review board and CDC's human resources and health departments. The aim and the procedure of this study were explained to all respondents who met the inclusion criteria. Respondents were informed of their right to leave at any stage without explanation. Respondents were assured of anonymity, and each respondent signed an informed consent form before participating in the study. 


\section{Interview guide}

An interview guide was designed after preliminary visits to the camps and the campuses, conversations with health overseers in the camps and student leaders, and observations of activities in the settings. Observations were made of meetings that usually take place each morning before workers go to the field, meetings of CDC workers, meetings with health overseers and camp supervisors, and general daily activities of camp dwellers and students. The interview guide was designed on the basis of the observations and the SMH $[10,18]$ and sought to identify stressors and coping mechanisms that made use of identified resources of camp dwellers and students. The first part of the guide contained background or entry questions ascertaining the respondents' demographic characteristics. Then respondents were asked to rate their health as poor, fair, good or very good. What followed were questions to identify factors that challenge their daily lives (stressors), such as jobs for the workers and studies for the students and health for both groups. Probing enabled respondents to reflect on the resources on which they drew to manage these challenges. Most of the interviews were conducted in English. Pidgin-English was used in interviews when preferred in the camps. Interviews in the camps were conducted by the first author, assisted by a CDC head office junior worker. Interviews on the campuses were conducted by the first author helped by a trained student assistant.

\section{Data analysis}

The interviews were audio-taped, and detailed field notes were also taken. Interviews in English were transcribed verbatim style by the first author. Pidgin-English interviews were translated into English as they were being transcribed. Data were analysed using the ATLAS. ti 7.5 software (Scientific Software Development). Thematic analysis was carried out following Braun and Clarke's [19] protocol. This protocol offers flexibility in identifying themes in various ways. The analysis process started with reading the transcripts several times for familiarisation with the data and then generating codes. The transcripts were imported into ATLAS.ti and coded. The data were coded top-down, guided by the SMH[20]. We identified themes encompassing stressors and coping mechanisms using identified resources (see Table 5.1). Codes relating to workers' jobs were for example: Job_risks and Job_workcon, and codes relating to academics were for example: Acad_lecturerstress and Acad_photocopyingstress.

We also identified mechanisms through which respondents drew on resources to manage stressors, i.e. resistance resources (RR). An example is the theme 'alternative ways to make additional money'. Examples of codes that fell under this category were: RR_farm, RR_business. 


\section{Table 5.1: Summary of themes and associated factors}

\begin{tabular}{ll}
\hline $\begin{array}{l}\text { Categories following from the salu- } \\
\text { togenic model of health }\end{array}$ & Operationalisation of categories \\
\hline 1. Stressors experienced & a) Lack of space and poor living conditions \\
& b) Poor working conditions, low payment and \\
& intimidation \\
& c) Overload of social responsibilities and living up \\
& to family expectation \\
& d) Poor healthcare, healthcare inequality and lack \\
& ef medication \\
& e) Uncertain remittances and financial problems \\
\hline 2. Drawing on resources for coping & a) Perceived health \\
& boping mechanisms) \\
& b) Alternative ways to make additional money \\
& c) Maintaining social relationships \\
& d) Taking part in religious activities and faith \\
& e) Preventive action and improvisation \\
\hline
\end{tabular}

\section{Results}

In this section, we start with a brief description of the context, followed by a description of the range of stressors experienced by the two different groups of respondents. Finally, we elaborate on mechanisms for coping with stressors. The stressors experienced by respondents were classified under five main themes that emerged from the data analysis: lack of space and poor living conditions; poor working (study) conditions, low income and intimidation; overload of social responsibilities and living up to family expectations; poor healthcare, healthcare inequality and lack of medication; and uncertain remittances and financial problems. Table 5.2 provides an overview of these factors and how they are experienced. First, the results for camp respondents are presented and then those for campus respondents, where applicable.

\section{Life in camps and on campuses}

People in camps live a life that is ordered by the work regime of the plantation. They start their working day at $5 \mathrm{am}$ with meetings where they hear general announcements and tasks are allocated for the day. They are then transported by truck to the plantations where they carry out their expected tasks. Those who do not work in the plantations but in the camp compounds are also allocated tasks, which they perform in their camp or any other camp to which they have been assigned. After work, usually after midday, the workers are brought back by truck. Some go to their farms at this time, while others rest or engage in any other 
activity. In the event of ill-health, there is an office in each camp called the AID post, where mild illnesses are handled. A nurse who lives in the camp is in charge of this post. She has medications like pain killers and disinfectants for cuts that she can give to camp dwellers who need them. People who have illnesses that are beyond the competencies of the AID post are transferred to the clinic or hospital by a car (also called ambulance) that comes to pick up patients from the camps on certain days in the week.

Students live a life that is quite different from the people in the camps. They are younger and more educated, and all who took part in this study were single. Young and single camp dwellers have to take care of themselves, their children and their siblings. Among the student respondents, two mentioned being parents of at least one child. Most students still depend financially for their upkeep on their parents who are in different parts of the country. Students live in single rooms around the university premises. The students' lives centre on their studies.

\section{Stressors}

A stressor was operationalised as challenges faced by respondents for which they did not have an immediate response.

\section{Lack of space and poor living conditions}

Life in the camps was characterised by congestion. Camp respondents indicated that factors that challenged their health and wellbeing were linked to accommodation space and poor living conditions. Respondents reported that many families lived a cramped lifestyle, often having to share bedroom space with their children. They also reported that the conditions in which they lived were deplorable. For example, heavy rainfall during the rainy season worsened living conditions.

If you had walked up to my house you would feel sorry for me because water just comes into my home. When rain falls, no one can come into my house because it is usually flooded. The water gets up to waist level. You have to move in this water before going to the kitchen. (Male camp respondent)

The students also reported that they lived in deplorable conditions. Landlords and neighbours were blamed for the state of students' houses and poor hygiene conditions, respectively. They reported that their living environment was conducive to the proliferation of mosquitoes, with consequent frequent malaria attacks as well as the spread of other diseases.

The rooms are cheap and dirty and the toilets are dirty and you can be sharing a toilet with 20 people. In the morning they form a line to use the bathroom and go in one after 
the other...poverty makes people live in such conditions. When it rains, the water from the rain carries excrement because the people are opening their toilets to let excrement out. So when the water is passing in front of your house it is smelly and it can even enter your house. (Male campus respondent)

Electricity and water cuts were common in both camp dwellers' and students' lives. In the camps, Limbe camp had a regular electricity supply. In Sonne camp, electricity was rationed. It came on between $6 \mathrm{pm}$ and $10 \mathrm{pm}$, if it was available. Camp 7 had no electricity supply.

We go sometimes for even three months without any light. (Male camp respondent)

\section{Poor work and study conditions, low income and intimidation}

For camp dwellers, jobs played a central role in their daily lives. Even though having a job guarantees a salary at the end of the month, CDC workers were very discontent with their jobs and especially with the salary they received at the end of each month. The poor working conditions that hampered their wellbeing were related to job risks, to lack of equipment for work and to treatment received from their bosses.

The stress is with my boss. The way he acts with me makes me feel stressed out because the way I deal with people, I take everybody like a friend, like family, so when you are playing games with me, when I discover it, I feel bad. (Male camp respondent)

There are many risks. We can be contaminated with any disease. Also, there are many broken bottles around leading to the risk of cuts while cleaning. (Female camp respondent)

As with camp dwellers' jobs, the students' studies had a central role to play in their daily lives. Students expressed strong feelings about what they thought was not going right at the university. The following quote sums up the general feeling of students:

The major one is academic stress. For instance, if they give you an assignment for which you have to spend a lot for transportation, it stresses you out financially and the traffic you encounter also stresses. Thinking also about what is next after your degree [future] whether to look for a job or... it becomes more stressful. (Female campus respondent)

Student life came with challenges both on- and off-campus and even extended to fears about the future. These challenges were likely to affect their wellbeing and productivity, as they observed. The major challenges reported were campus-related, examination-related, assignment-related and also lecturer-related. Most students had complaints about their lecturers. 
Lecturers were considered to be mostly unavailable, capable of sexual harassment, not motivating, inconsiderate and making things unnecessarily difficult.

Life is a jungle on campus. People want to graduate but there are those who are trying to make sure they don't [lecturers]. (Male campus respondent)

Also, frustrations with lecturers were exacerbated by the large number of assignments the students had to do and which often required money. According to the students, lecturers frequently ordered them to repeat a task, and this made the financial burden heavier.

There are some days that, when you go to school, each lecturer has an assignment for you to be submitted the next day in the morning and so you have to do like four assignments that same night ... and so this gives me a lot of stress. (Female campus respondent)

...sometimes you spend the money and you are given a fail mark and asked to redo it and you have to spend some more money on redoing the assignment. When you call home for the money, or an uncle, and you have to call again for money for the same purpose, it looks like you were joking [not serious]... (Male campus respondent)

Students also complained about the small lecture halls on campus and about the fact that the halls were not adapted for physically challenged students.

\section{Overload of social responsibilities and living up to family expectati- ons}

An overload of social responsibilities derives from ways in which family, friends, neighbours and so forth can have a challenging impact on respondents' lives.

Families can be strong sources of support, but dealing with them can also be challenging when there is an overload of social responsibilities. Camp dwellers experienced challenges taking care of their children because they had limited means and consequently not enough food for the family. Also, extended family obligations, marital conflicts and dealing with teenagers were reported to be challenging for parents.

They [children] cause me stress because they are stubborn. You send them on errands and they don't go and you have to repeat whatever over and over again... (Female camp respondent)

Family problems. Too many people needing me to intervene in their problems. (Male 
camp respondent)

Unlike camp dwellers, students depended financially on their parents. Parents had expectations about their children completing their studies quickly and becoming independent. Because parents were far away, they were not always able to tend to the needs of their children regularly or as promptly as the students might need. Also, because students were facing a reality of which their parents were not aware, parents' expectations could add to the pressure that students were under. Other social challenges adding to the emotional burden of students stemmed from intimate relationships. These challenges were likely to create an imbalance in the students' lives that they had to manage.

I have been told [by parents] that if I have a degree then I have to decide what to do. They say they will wash their hands of me and so this is like a blow to me because I have the desire to forge ahead with [further my] studies. As for now, I don't know what I am going to do. (Male campus respondent)

He [boyfriend] is really a source of stress. At times when I need him, he is not just there. (Female campus respondent)

\section{Poor healthcare, healthcare inequality and lack of medication}

Even though consultations and treatment are free, camp dwellers had very strong negative feelings about the services they were receiving. For example, it is routine for a car-'ambulance' to be sent to the different camps to pick up patients for the hospital on Mondays, Wednesdays and Fridays. However, this car could be late in coming, with potentially fatal consequences for severely ill workers.

...We have lost people like that. We were waiting for the ambulance and it wastes a lot of time coming and the man dies. This has happened to about three people. (Male camp respondent)

Also, workers reported experiencing health inequality in the services offered by CDC. In such cases, there was a perception that management staff received better quality treatment than the labourers.

If a field assistant goes to the hospital, they would look for a carton [box] containing the real drugs and give them to them, which are necessary, but as workers, you go you will never receive this kind of treatment. (Male camp respondent)

CDC has pharmacies with drugs for the patients who attend the clinics. However, it was 
reported that, when drugs run out of stock, they are not immediately replenished. In such cases, management staff would buy the medication themselves and be reimbursed, but the labourers would not be reimbursed if they bought medication. Furthermore, the drugs, when available, were reported to be of questionable quality for the field workers and not for the management staff. Medication for camp dwellers was reported to be administered sometimes without a laboratory diagnosis and with a poor attitude on the part of the medical staff.

As for CDC, I don't even want to think about them because, if you follow them, you will die. They don't care for the workers. They say they give free medication but when you go [to the CDC pharmacy], the medication is unavailable. They write prescriptions that are continuously unavailable. (Male camp respondent)

The drugs that are given to you are not good first of all. They don't give good drugs. (Male camp respondent)

The consequences of taking drugs with severe side-effects would certainly affect the productivity of camp respondents. In addition, they reported that the one day sick leave to which they were entitled further hampered their productivity.

One thing too, is that you are not given many days off as sick leave. You are given only one day and, the rest of days for which you have to drink the medicine, you are unproductive because of the side-effects. (Male camp respondent)

Students reported that the main stressor in relation to healthcare was the money required to pay for hospital visits. As they did not have free medical services at their disposal, students were required to pay in advance and in cash for any medical services they needed. Because of this, there was a tendency to delay seeking medical help until they had tried self-medication or small pharmacy consultations and the illness still persisted and was therefore perceived as severe.

...the real pharmacy [medicine] is expensive and, when I ask for a cheaper option, there usually isn't and so I will now go back to the street vendors who will tell me they have something for a very cheap price and so that's what I'd get. (Female campus respondent)

\section{Uncertain remittances and financial problems}

The effect of limited finances was felt across many levels in the lives of camp dwellers and students. Camp respondents complained about having a small salary, which often was not 
enough for taking care of their immediate and extended families. In addition, they expressed uncertainty about the amount.

Life is hard, things are very expensive and the salary is low. (Male camp respondent)

Workers were paid per hour, and they were not always sure how many hours had been registered as work hours for them by their immediate supervisors/bosses. Such uncertainty created a feeling of despair among the workers, as can be seen in their comments with regard to their lives as CDC workers.

Students faced financial uncertainty as well, especially uncertainty about when parents would send money, and how much. Their financial needs spanned rents, accommodation facilities, upkeep, health and also academic demands (photocopying, printing and research).

Financial problems again. Some people don't have computers. All our assignments need to be typed, so it's a problem of money to type here and come and give [hand in] at 7 oclock. This is all boring and stressful. (Male campus respondent)

Financial constraints were reported to reduce students' quality of life. They were also perceived as a reason for increased sexual promiscuity, with the consequence of an increased risk of sexually transmitted infections.

Students go out with a teacher because they want money and/or marks. They want somebody to take care of them by giving them money. Students go out with other rich students because they want money. (Female campus respondent) 


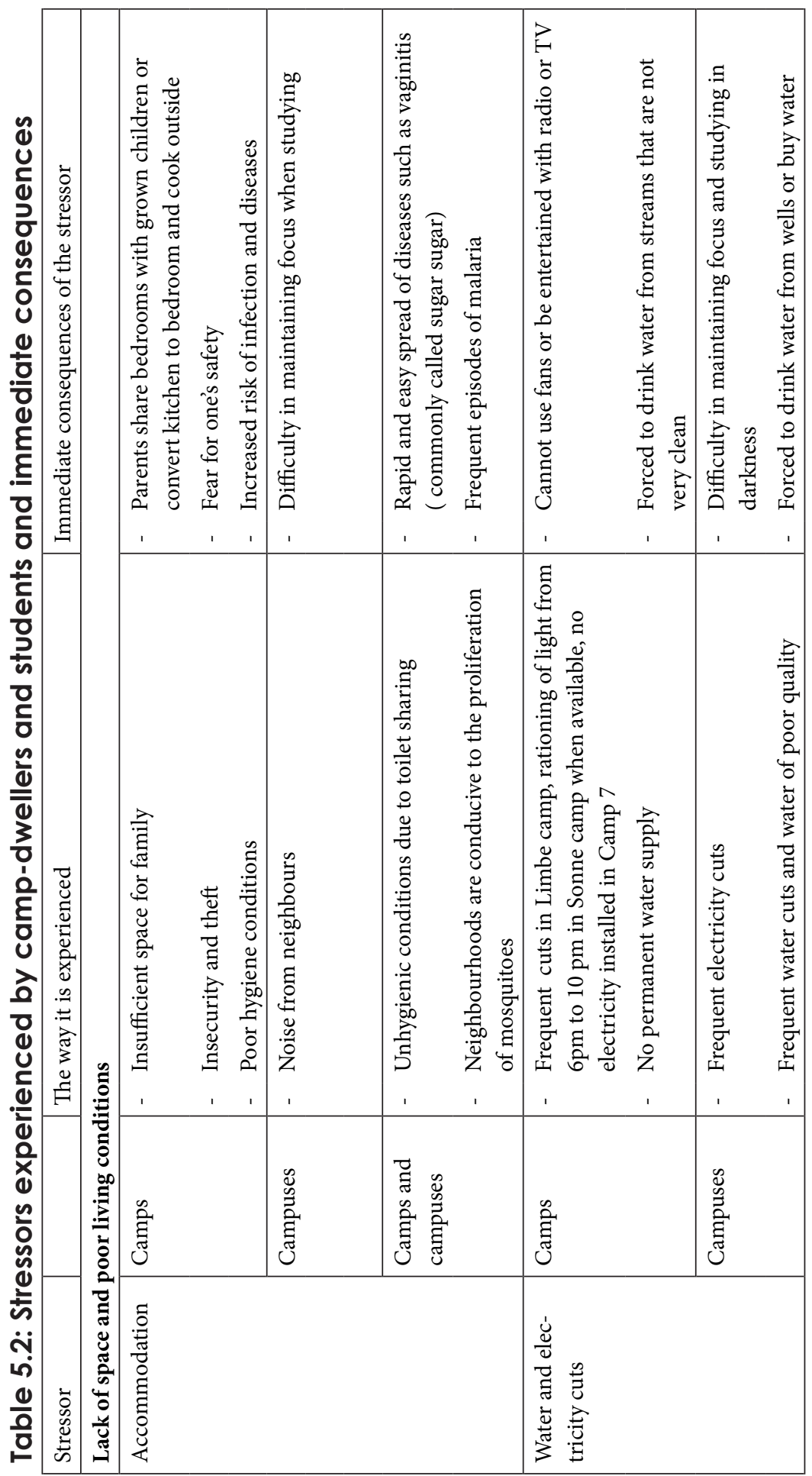




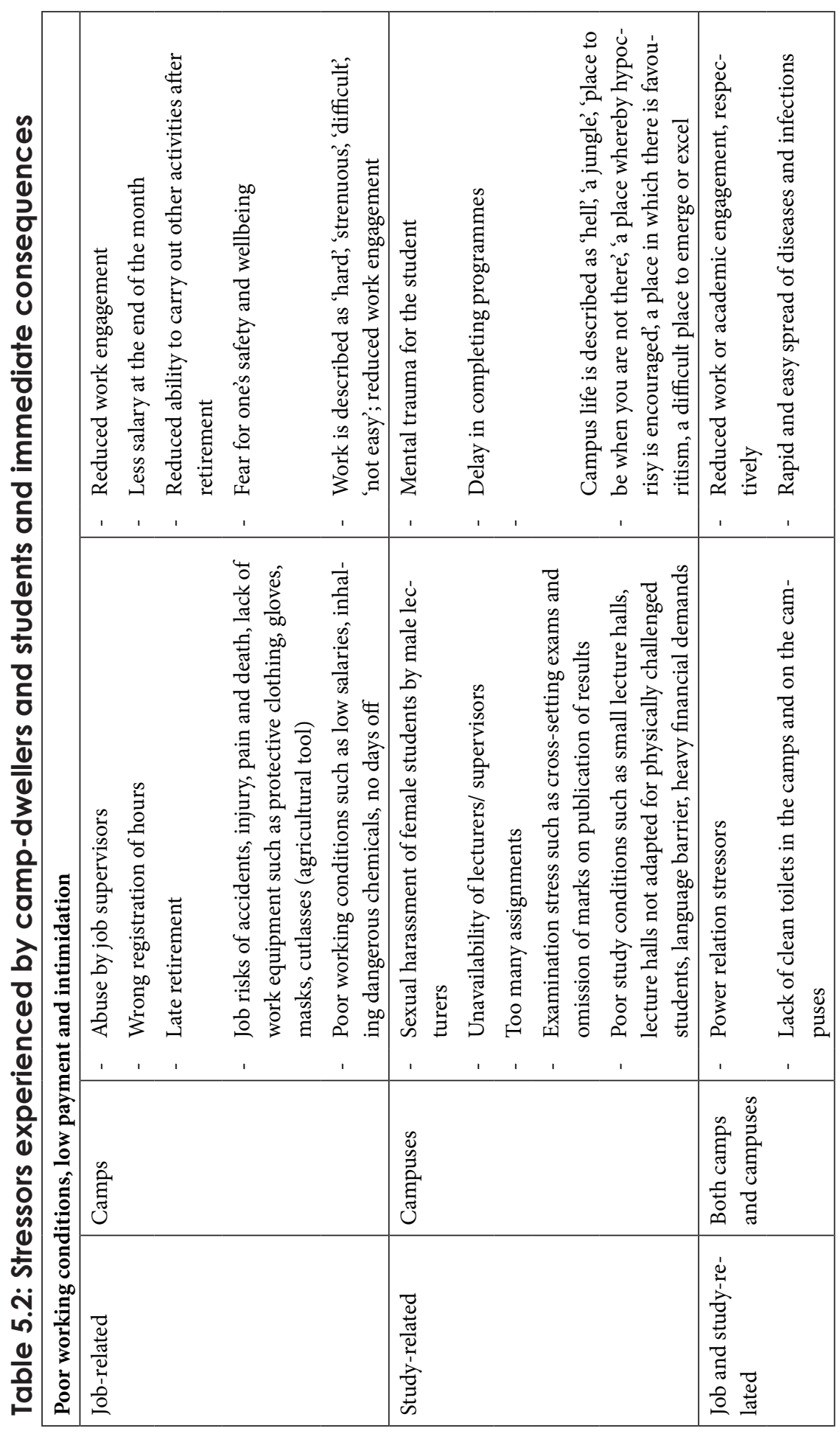




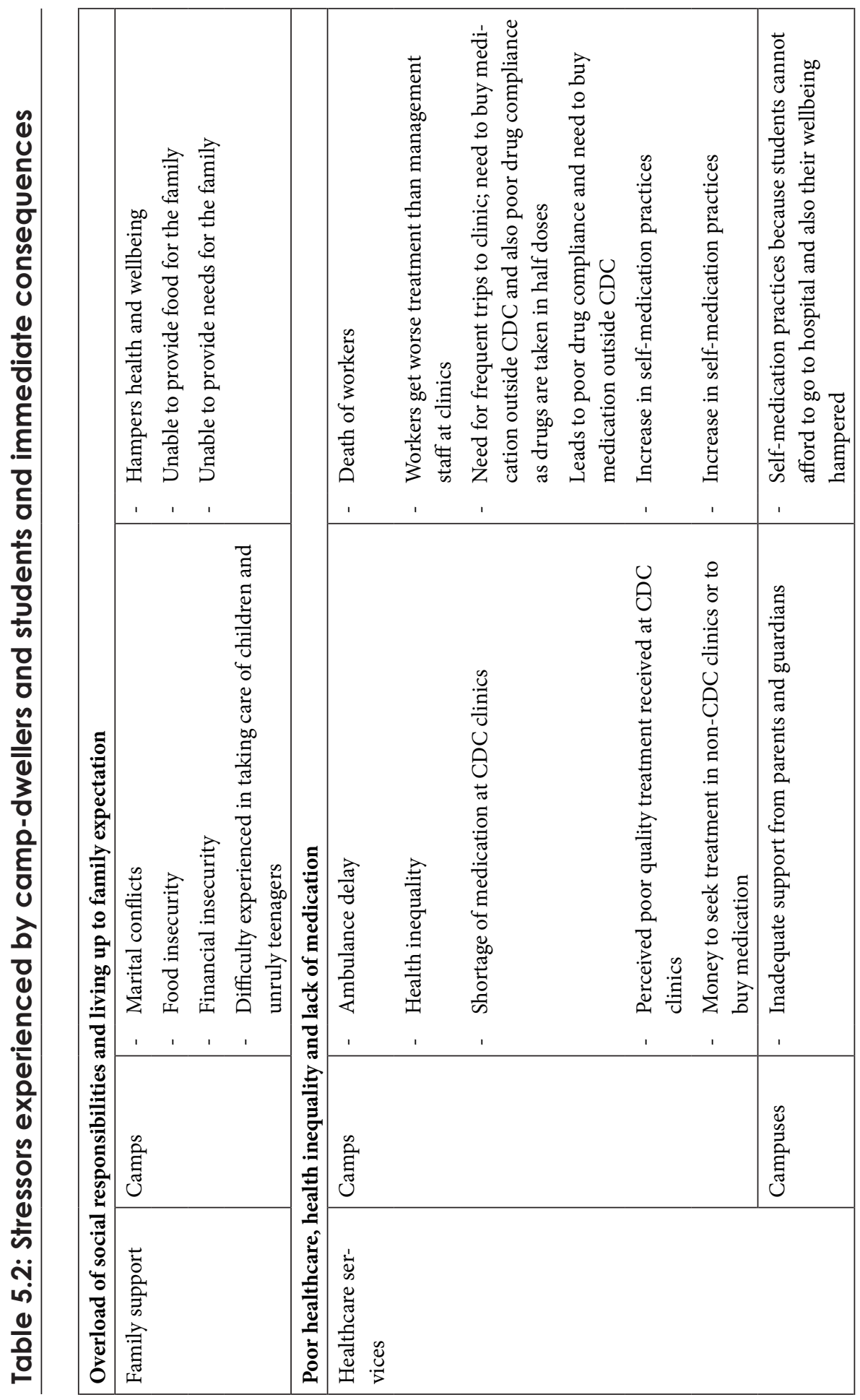




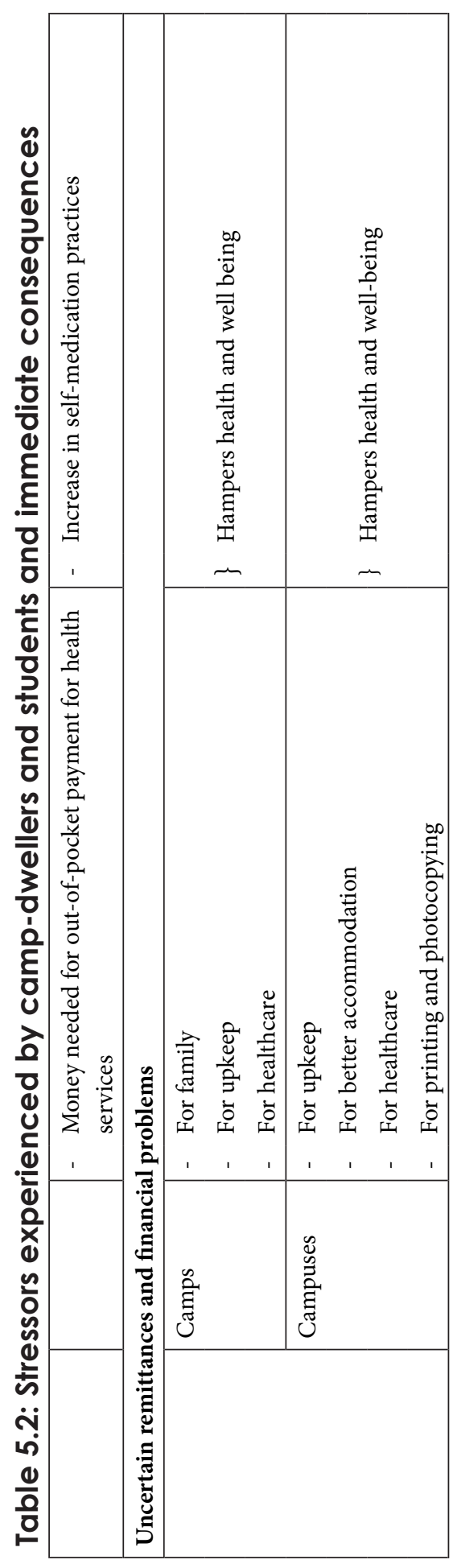




\section{Perceived health in the settings}

One thing our study has made clear is that many stressors exist in the lives of camp dwellers and students. That notwithstanding, people reported being mostly in good health. People's health was seen as a resource that enables them carry out their activities. Their responses indicated that good health was not only about how one feels physically, but also included mental or emotional considerations. Pains and headaches were considered to be a normal part of life. This implies that it was possible for respondents to say they were in good health even when they were physically in distress.

Good health is feeling fine, being able to do anything, having the ability to do something. (Male campus respondent)

The question which then follows from the above is what coping mechanisms would therefore ensure perceived good health and wellbeing in the face of the stressors that we have just reported? In the section below, we expatiate on respondents' coping mechanisms.

\section{Drawing on resources for coping with stressors: coping mechanisms}

Our study revealed several mechanisms through which respondents managed the challenges they faced. Some mechanisms encompassed a resource drawn upon to manage several stressors, whereas other mechanisms encompassed resources used to manage a specific stressor. Table 5.3 gives a detailed account of the resources available and how they are drawn upon by respondents. Below, we report on these mechanisms.

\section{Alternative ways to make additional money}

Camp dwellers found several ways to augment their income. They looked for business opportunities that could bring in additional money, such as selling crops from their farms or basic everyday needs for camp dwellers. Also, they were involved in saving schemes commonly known as njangi and credit union schemes. Having side-jobs, such as making skewers, or borrowing money to pay back with interest (also known as '10 for 13') were mechanisms in place to augment income. Farming, for example, was a means not only to ensure food security, but also to make more money for other essential purchases.

We are organized in that, when we face financial difficulties, the [my] wife will harvest some crops and sell in order to have money to buy fish, crayfish and other small things necessary for the house. So what is not sold we bring home and manage on it. (Male camp respondent) 
The students also reported looking for business opportunities. Baking and selling clothes and shoes to other students were ways to make additional money. Side-jobs such as parttime teaching were also reported, the income from which helped take care of students' financial needs.

I am also a teacher. I have students, I teach, I do private teaching. I have students whom I take... Teaching is a way to augment my income to take care of myself at the university. (Female campus respondent)

\section{Maintaining social relationships}

Social relationships offered respondents practical, financial and/or emotional support. The responses showed clearly that both the camp dwellers and the students had a rich social network which was supportive in many ways. The social network ranged from immediate family members (parents and siblings) to extended family members (aunts, uncles and so forth) to neighbours, then neighbourhood groups and then church groups and traditional or village groups. It could be seen that these networks were important for the wellbeing of the respondents, who therefore had to maintain and care for these relationships so that they could continuously procure the expected benefits from them. A well-maintained relationship, for example between neighbours, ensured support in times of need.

I have a good relationship with neighbours. I have been here for eight years and I have never quarrelled with my neighbours. This is because of the love that we have for one another, because when there are problems in their houses, I will intervene and when I have problems too, they will intervene. (Male camp respondent)

Being part of groups such as church or neighbourhood groups also gave meaningful life experiences to camp dwellers, with multifaceted benefits.

I joined because it [neighbourhood group] permits me to join with my neighbours once in a while and share some common ideas. We are organised in a way that, every week, we bring a bar of soap each and this helps us, because many people bring the bar of soap and one person takes it home and it goes around in turns like that. Also, if you are sick and in the hospital, contributions are made and given to you and, although they will not assist you totally, they are there for support and partial assistance. So there is a small financial benefit in it. (Female camp respondent)

Students counted on support from their parents, older siblings and other family members like aunts and uncles, and they reported that these relationships had to be cared for so that they could continuously be supportive. For example, students were expected to perform well 
in their studies so that parents would continue paying for them.

My parents are very supportive especially when it comes to education. (Female campus respondent)

Relationships with friends, classmates, neighbours, youth groups, church groups, alma mater groups, village groups also required care and maintenance because of the practical (and sometimes disciplinary), emotional and financial benefits attached to them.

I am part of YAS [Young Amity Sisters] because I like their aim, their goal. One of their aims is to help the less privileged. We visit the less privileged, we visit the sick in hospitals, we also protect our interests, we do njangi, daily savings. Our savings are very compulsory... You have to make sure that, during every meeting day, you save so as to avoid paying a fine. (Female campus respondent)

\section{Taking part in religious activities and faith}

A belief in God was highlighted as a major coping resource for respondents. Most camp dwellers and students who took part in this study were engaged in one religious-related activity or another. Their belief in God created an expectation of seeing positive changes in their circumstances or situations, and this was a motivating factor to engage in, and to keep, that relationship. Believing that God was in control gave respondents the feeling that the stressors they faced were manageable and worthy of engagement.

Camp dwellers were active members of church groups. Some were in the choir, others in women's or men's groups in the church, and they all confirmed having meaningful experiences (spiritual, moral, financial, learning or supportive) because they were part of such groups. Faith and hope were spiritual attributes that equipped respondents to engage their challenges.

...when you hear the sermon, you will forget about your problems for a while and have hope in life that better things will come to you. Also, going to church, we learn through our friends. I belong to the CWF [Christian Women's Fellowship] and there are things we have learned, such as overcoming shyness, and also being a peacemaker and resolving quarrels and conflicts. At first, I liked to get into quarrels, but now I am the trouble shooter. (Female camp respondent)

For the students also, being active in a church group was seen as very helpful in solving a myriad of challenges including loneliness and financial, spiritual and moral issues. 
If you belong to a church and you have problems, they could pray for you in the church. If you are sick, or have financial problems, they would contribute and give you money. They could pray for you or could contribute. For example, somebody's house burned down and they contributed to help him buy new furniture. (Female campus respondent)

\section{Improvisational capacity and preventive action}

In this section, we report on specific mechanisms employed by respondents to address specific stressors. Such specific stressors were related to their work conditions (work equipment, repairs), study conditions (assignments, language barrier, lecture halls), living environment (lack of space, water, poor sanitation) and health (medication with side-effects in CDC, financial constraints for hospital-based care for the students) (see Table 3 for details).

CDC workers who understood the modus operandi of the company showed improvisational capacity and pro-activeness as a sign of being in control of their circumstances. For example, for tasks that required work equipment, $\mathrm{CDC}$ often failed to provide protective materials such as gloves, cutlasses (a type of agricultural cutting tool) or protective masks. Respondents reported buying these themselves or improvising in order to improve their working conditions.

If it is not in stock, we buy to help ourselves. (Female camp respondent)

...I used my child's towel to cover my nose, and put on my flip-flops to work and I had to work like that because, if I don't work, I will not be paid even for two hours of work. (Male camp respondent)

Improvisational capacity was also seen when camp dwellers went to the clinics and medication was unavailable. They reported active responses in which they used other possible options such as small pharmacies and herbal treatment.

...when I see the street vendors passing by, I buy medication and take it. (Male camp respondent)

For students, an important goal was to succeed academically despite any challenges. For example, Anglophone students who faced language barriers took preventive action to avoid failing by negotiating with invigilators for translations of the examination questions, which were set in French. They also improvised on ways to improve their mastery of the French language without taking formal classes. 
...reading books and watching French movies and documentaries, and also interacting since I hang out a lot with friends and I get to meet Francophones... and so I am forced to speak French. So with time, I improve my French. (Female campus respondent)

Not all students were actively trying to cope with stressors. Actually, some students reported passive responses or coping styles towards study-related stressors. These could be described as emotional or avoidance responses to challenges. Abandoning the task, crying, eating chocolates and sleeping or eating were ways reported by several respondents for coping with the too many assignments they had to do.

Students' improvisation for lack of access to professional doctors was seen in the employment of the services of quart-doctors (medical school students or recently graduated medical school students who are not yet legally practicing medicine). Also, as a substitute for expensive medication, students resorted to buying generic drugs from small pharmacies.

...students have no money, they can't borrow medicine from here [hospitals]. In that case, the students are forced to go to quart-doctors. (Male campus respondent) 


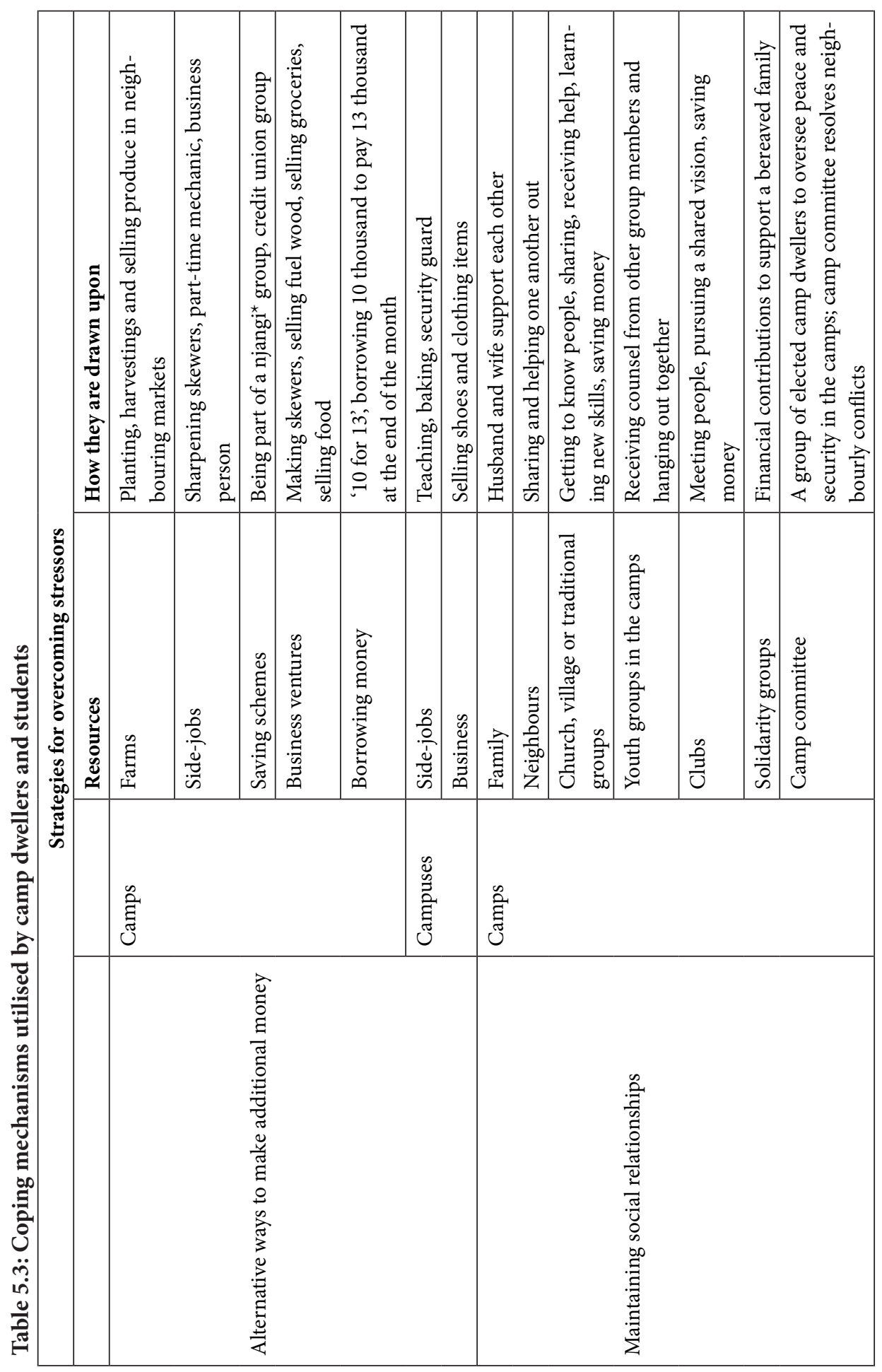




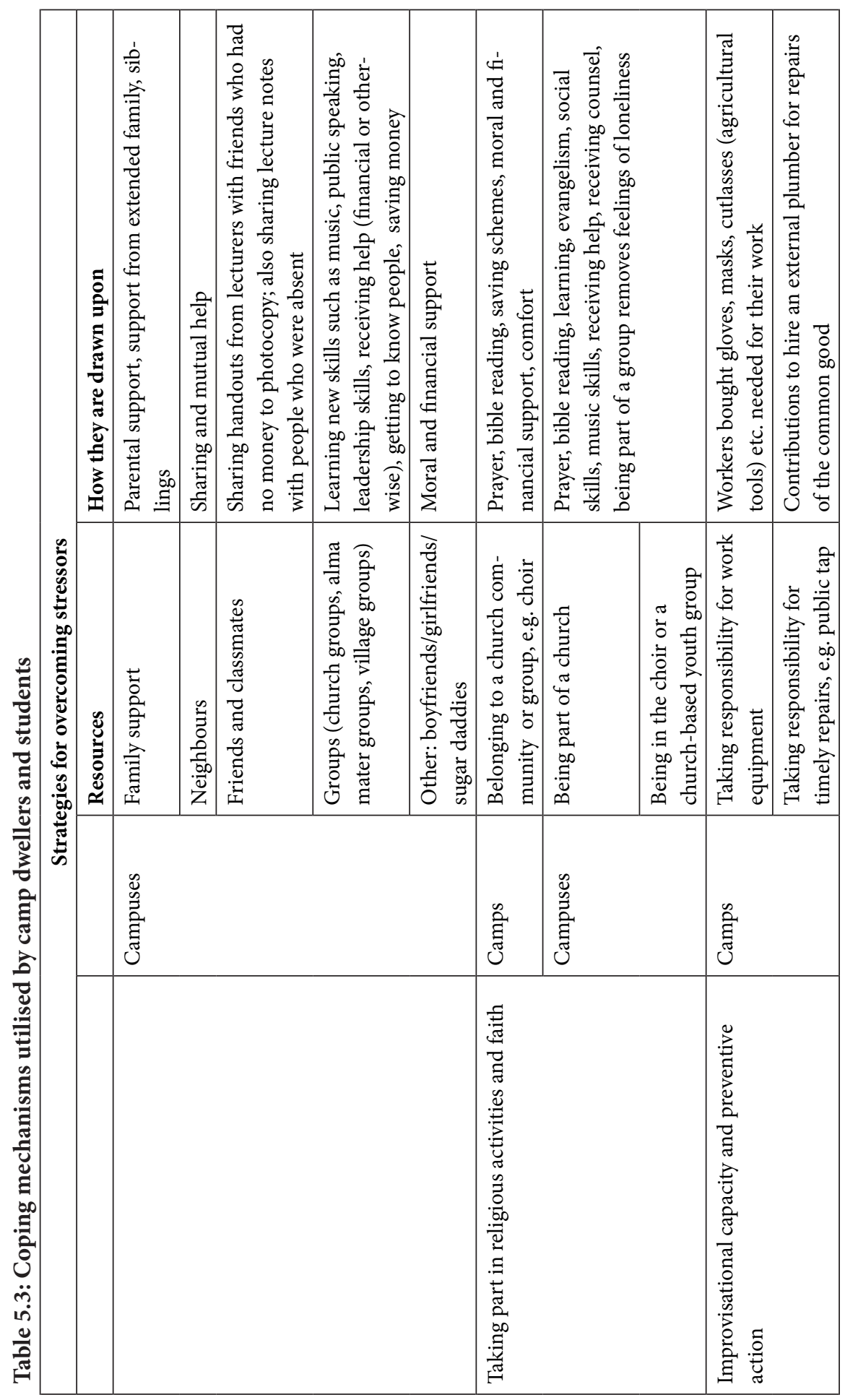




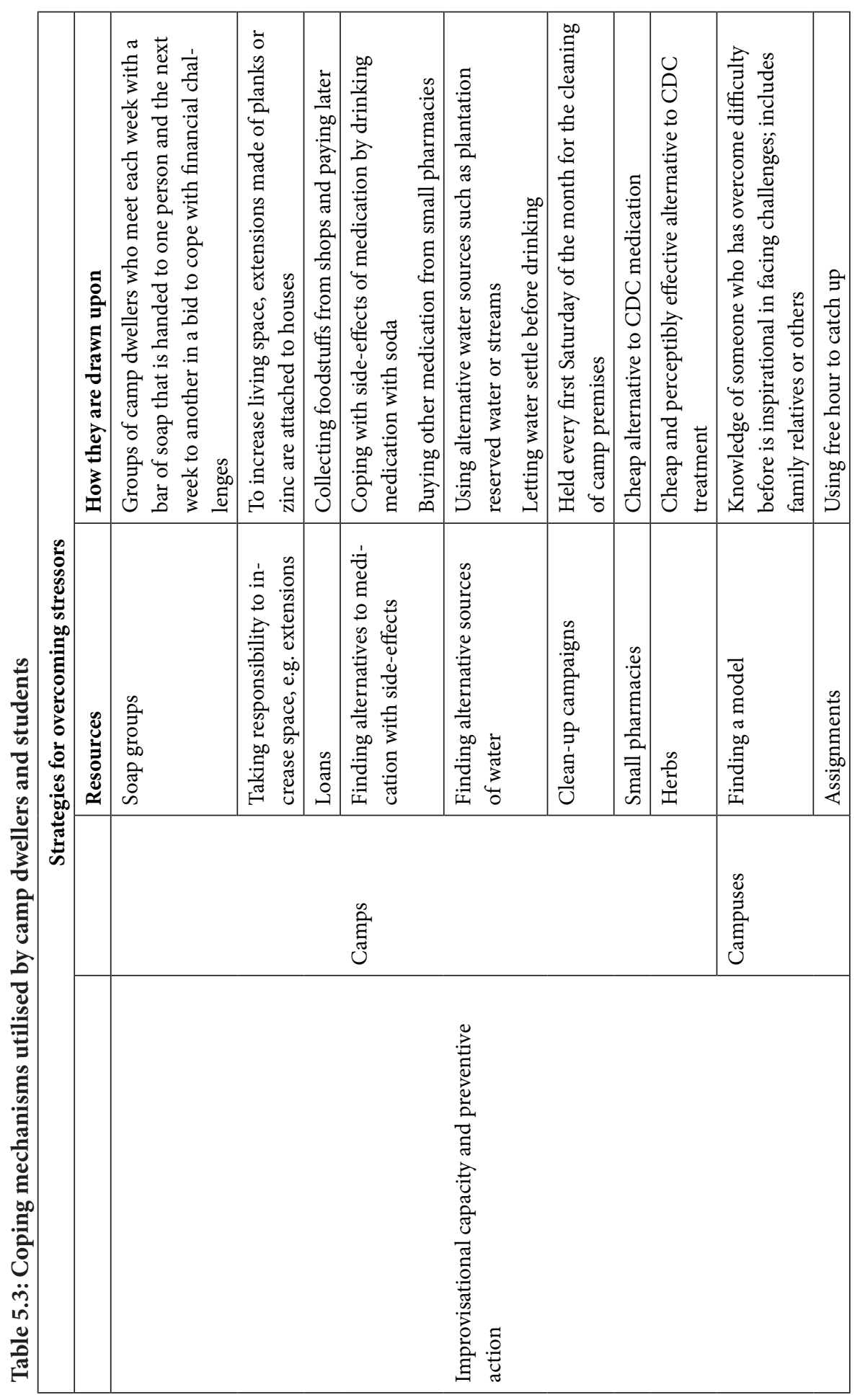




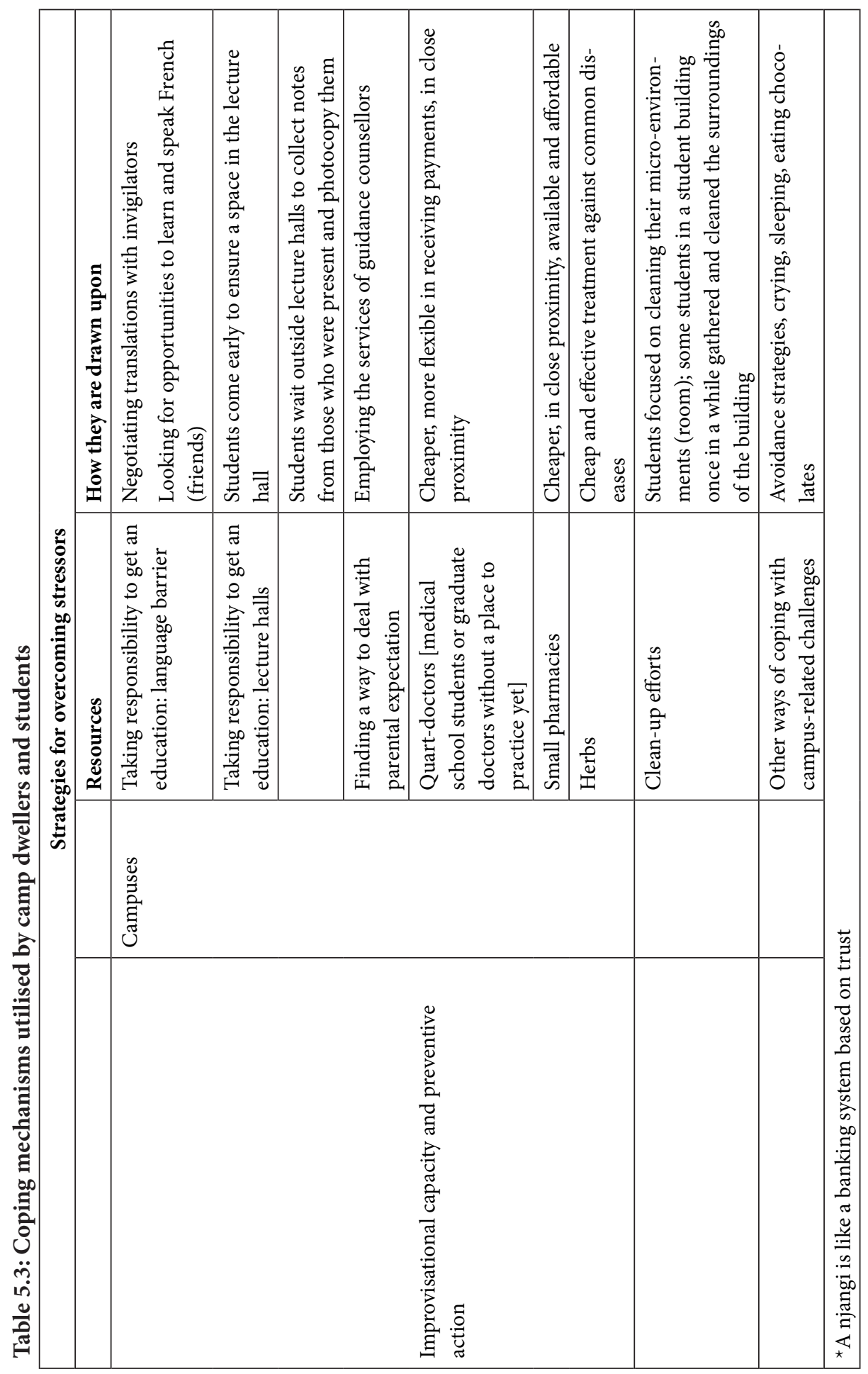




\section{Discussion and Conclusion}

The aim of our study was to investigate the different types of stressors experienced by camp dwellers and university students and to explore their ability to draw on identified resources to circumvent life's challenges and live fulfilled lives. Salutogenesis offered a platform on which we could highlight people's efforts to cope with factors that challenge their health and wellbeing and to have meaningful life experiences. This aspect has been strongly ignored in the current fight against PRDs. Our study attempted to fill this gap by expatiating on how people manage the challenges in their lives. The purpose for outlining how people manage is not to show that respondents are well off. They still face many challenges that affect their health and wellbeing negatively and are aware of the poor living conditions, and their consequences, with which they have to deal. By including in our study the mechanisms through which people deal with stressors, we offer scope for rethinking health policies and providing health services to people living in poverty, as well as for rethinking social policies and areas to strengthen people's capacities.

Four major insights emerge from our study. Firstly, stressors are experienced by all respondents, some specific to each group and others common to both groups. Secondly, there is a thin line between stressors experienced by people and the resources on which they draw to overcome stressors, as sometimes what people draw on as resources could become what they experience as stressors and vice versa, e.g. work for the camp dwellers and studies for the students. Thirdly, even in the presence of a variety of stressors, respondents report good health and meaningful life experiences. Fourthly, respondents adopt mechanisms to cope with stressors to ensure that they live the lives they want, e.g. finding alternative ways to make additional money to address financial challenges.

\section{Stressors experienced}

It has long been noticed that health and wellbeing are determined by factors not limited to the healthcare system [21]. These factors, which include people's living environments, their daily activities and their relationships just to name a few, have all been shown to affect people's health and wellbeing positively or negatively. Stressors are a given and are in themselves neither negative nor positive[10] but express their impact upon interaction with a person. In other words, peoples' capacity to manage determines the effect of the stressor.

Our study showed that many stressors experienced by respondents were linked to their immediate living environment. They complained of the poor hygiene conditions in which they lived, which were conducive to an increased disease risk. This indicates that interventions to fight against poverty and related diseases should have a special focus on hygiene conditions and ways to improve them. Apart from living conditions, having limited finances was 
experienced as a stressor in the lives of respondents in both settings. For example, the salary received by workers was reportedly insufficient to enable workers meet their family obligations. Students also complained of the heavy financial demands of their studies (e.g. printing and photocopying). People who cope with financial challenges are those who actively look for ways to deal with the consequences of these challenges. According to the SMH, a strong SOC enables people to manage their challenges by bringing together the resources that they need [10]. Our study revealed mechanisms through which people coped with challenges. In the case in point here, respondents were able to find alternative ways to augment their income as a coping mechanism, e.g. side-jobs and farming practices. This shows that respondents were actively participating in matters that concerned them [13].

\section{Interchangeability between stressors and resources for coping}

Another finding in this study is that there was a thin line between stressors experienced and resources on which people drew to cope. It was interesting to see that a factor could be a resource for coping at one time and at another time a stressor. This was visible particularly with respect to work and studies, to social relationships and to healthcare.

Work and studies were important aspects that gave meaning to the lives of camp dwellers and students, respectively [22]. However, the terms used to describe work or studies indicated that these were also a major source of stress (see Table 2). Work was associated with low salary, inflicted pain and injury, and so forth, leading to a vicious relationship of poor job conditions, poverty and poor health [23]. Poor job conditions led to pain and injury and consequently fewer hours worked and therefore less money for the CDC workers. Such tendencies have been confirmed by other studies [22-24]. It is therefore in the interest of employers, such as CDC, to improve the working conditions of their employees and thus have a more productive labour force [24]. That notwithstanding, camp workers showed improvisational skills to make their working conditions better (e.g. using towels as protective masks), indicating an active understanding and management of a challenge.

The students associated studies with too many assignments, financial burdens and so on. Study-related stressors were commonplace and the most highlighted stressors for the students. This has been confirmed in another study [25]. However, our finding that study-related stressors were the most highlighted differs from findings in Hurst et al.s [26] review in which relationship stressors were the most highlighted in the 40 studies included [26]. In our study, the perceived high level of intimidation of students by lecturers may explain why university stressors were more prominent. To respond to study-related stressors, respondents displayed coping mechanisms, e.g. improvisational skills to learn French. 
The two examples given above (work and studies) show that respondents participated actively in issues that concerned them. It also shows limitations in the services offered by organisations such as the CDC or universities. The pertinence of daily activities, work on plantations for the CDC workers and study for the students, as main sources of stressors indicates that employers, schools and universities are not fully playing the important roles they have in health and wellbeing provisions. A healthy work or study climate clearly encompasses more than basic facilities or (free) healthcare services; it includes rethinking work (study) packages and task division. It is important for organisations to seek ways to restructure work or study in a way that benefits people's health and wellbeing.

To delve further into the interchangeability between stressors and resources for coping, we underline social relationships such as family and neighbours, which are important sources of support. These relationships can also engender negative feelings of frustrations when the relationships are not properly maintained, e.g. in the case of an overload of social responsibilities for camp dwellers or failure to meet parents' expectations for the students. In our study, students reported experiencing stress because their parents expected them to complete their studies on time and become independent. This is different from the finding in the review by Hurst et al. [26]. In their review, the stress was more from expectations of the students themselves striving for perfection. What is perceptible here is that it is unrealistic to think that people can study without any stress factors (whether from parents or from the students themselves). The important thing is therefore to find the capacity to manage [13], and our study has shown the influence of a rich social network in this regard and efforts made to maintain the network, so that the benefits can be continuously reaped.

Lastly, in the camps, even though healthcare services were free for the CDC workers and their families, the hassles attached to them, such as poor medication with severe side-effects, poor attitude on the part of medical staff, constant unavailability of medication and so forth, gave people negative experiences when they used them but also elicited specific mechanisms to bypass the challenges imposed. Specific practices of self-medication and drug purchasing outside CDC were employed by camp dwellers to cope with the challenges.

The above examples emanating from our study show that stressors are everywhere and need to be managed. People's capacity to manage stressors is seen in the ability to create balance in chaos. By creating alternative ways to make additional money, or by actively making an effort to maintain relationships, people are creating balance in their lives, i.e. they are making timely adjustments in their lives to reduce the unwanted aspects of a stressor by identifying and using available resources in order to live more fulfilling lives [6]. 


\section{Good health and wellbeing in the midst of stressors}

Even in the presence of stressors, most respondents reported good health and meaningful life experiences. This was in part because of the social groups to which they belonged, which are instrumental in aiding respondents to cope with stressors. Studies have shown that stable social support is linked to a stable community and also to promoting a strong SOC $[27,28]$. This richness of our respondents' social networks (family, youth groups, church groups and so forth) was visible in this study and effective in enhancing coping. Religion has been reported to be a resource used to overcome great adversity [29], and this was confirmed in our study. Even though a belief in God has been previous reported to be a way of avoidance coping in stressful situations [30,31], in our study respondents' belief in God added meaning to their lives and equipped them to take active steps towards coping.

The capacity to deal with stressors is also facilitated when resistance resources such as GRRs are present. We were able to identify that resistance resources employed by respondents were either generalised resistance resources (GRRs), which are resources that address a multitude of stressors, or specialised resistance resources (SRRs), which are summoned to address a particular stressor. GRRs and SRRs enable people to perceive their lives as structured and organised [32]. GRRs have been reported to ascertain the extent to which SRRs are available to people [33]. This is confirmed in our study when we see the way a coping mechanism such as finding alternative ways to make additional money can play out. Here, GRRs such as farming practices or having side-jobs lead to an increase in income and ensure or facilitate the use of SRRs, for example using small pharmacies, street vendors or quart-doctors (for the students) as a way to respond to diseases. SOC, GRRs and SRRs in combination therefore play a vital role in our respondents coping effectively [34] and explain the perception of good health in our study, even in the midst of stressors. 


\section{Recommendations}

From the insights obtained in our study, we make the following recommendations:

- Improvements in the healthcare system and living conditions should pay more attention to adequate and reliable functioning of facilities. Improving the use and employment of limited means can be equally effective as bringing in new or additional equipment.

- $\quad$ Promotion and facilitation of social encounters should receive more attention in health policies, as our study has indicated enormous benefits from such encounters/activities.

- Facilitation by CDC for camp dwellers to have extra plots for farming should be considered so as to promote the planting of fruits and vegetables for consumption and sale. 


\section{References}

1. Singh AR, Singh SA. Diseases of poverty and lifestyle, well-being and human development. Mens Sana Monogr. 2008;6: 187-225.

2. Ningaye P, Alexi TY, Virginie TF. Multi-poverty in Cameroon: A structural equation modeling approach. Soc Indic Res. 2013;113: 159-181.

3. WHO. Global report for research on infectious diseases of poverty. Geneva: World Health Organisation; 2012.

4. WHO. Preamble to the constitution of the World Health Organisation as adopted by the International Health Conference, New York, 19-22 June, 1946; signed on 22 July 1946 by the representatives of 61 states; 1948 .

5. Huber M, Knottnerus JA, Green L, Horst Hvd, Jadad AR, et al. How should we define health? BMJ. 2011;343. doi: 10.1136/bmj.d4163

6. Bull T, Mittelmark MB, Kanyeka NE. Assets for well-being for women living in deep poverty: Through a salutogenic looking-glass. Crit Public Health 2013;23: 160-173.

7. Cole RE, Reiss D. How do families cope with chronic illness? Hillsdale, NJ: Lawrence Erlbaum; 1993.

8. World Bank. The World Bank annual report. Washington, DC: World Bank; 2011.

9. PNUD. Rapport sur la pauvreté rurale au Cameroun. New York: United Nations Development Program; 2006.

10. Antonovsky A. Health, stress, and coping. San Francisco, CA: Jossey-Bass; 1979.

11. Alnazly E. Coping strategies and socio-demographic characteristics among Jordanian caregivers of patients receiving hemodialysis. Saudi J Kidney Dis Transpl. 2016;27: 101-106.

12. Lindström B, Eriksson M. A salutogenic approach to tackling health inequalities. In: Morgan A, Ziglio E, Davies M, editors. Health assets in a global context: Theory, methods, action. New York: Springer; 2010, pp. 17-39. 
13. Eriksson M, Lindström B. Life is more than survival: Exploring links between Antonovsky's salutogenic theory and the concept of resilience. Scand J Public Health. 2011;39: 85-92.

14. Cameroon Development Corporation. Cameroon Development Corporation; 2009. Available from: http://www.cdc-cameroon.com/Subpages/

15. Buea Uo. About UB. Cameroon: University of Buea; 2014.

16. INS. Annuaire statistique du Cameroun. Cameroon: L'Institut National de la Statistique du Cameroun; 2010.

17. Strauss A, Corbin J. Basics of qualitative research: Techniques and procedures for developing grounded theory. Thousand Oaks, CA: Sage; 1998.

18. Antonovsky A. Unraveling the mystery of health: How people manage stress and stay well. San Francisco, CA: Jossey-Bass; 1987.

19. Braun V, Clarke V. Using thematic analysis in psychology. Qual Res Psychol. 2006;3: 77-101.

20. Antonovsky A. The salutogenic model as a theory to guide health promotion. Health Promot Int. 1996;11: 11-18.

21. Kumar S, Preetha GS. Health promotion: An effective tool for global health. Indian J Community Med. 2012;37: 5-12.

22. Awang A, Amir AR, Osman W. Job behavioral factors and turnover intention: A case study at Sime Darby Property Limited. Int J Adv Manag Econ. 2013;2: 103-115.

23. Stankevitz K, Schoenfisch A, de Silva V, Tharindra H, Stroo M, et al. Prevalence and risk factors of musculoskeletal disorders among Sri Lankan rubber tappers. Int J Occup Environ Health. 2016;22(2): 1-8. http://dx.doi.org/10.1080/10773525.2016.1168073

24. Munisamy S. Identifying factors that influence job performance amongst employees in oil palm plantation. Project paper. Open University Malaysia; 2013. Available from: http://library.oum.edu.my/repository/979/1/library-document-979.pdf

25. Verger P, Combes J-B, Kovess-Masfety V, Choquet M, Guagliardo V, et al. Psychological 
distress in first year university students: Socioeconomic and academic stressors, mastery and social support in young men and women. Soc Psychiatry Psychiatr Epidemiol. 2009;44: 643-650.

26. Hurst CS, Baranik LE, Daniel F. College student stressors: A review of the qualitative research. Stress Health 2013;29: 275-285.

27. Sagy S, Antonovsky H. Adolescents' reactions to the evacuation of the Sinai settlements: A longitudinal study. J Psychol 1986;120: 543-556.

28. Sagy S, Braun-Lewensohn O. Adolescents under rocket fire: When are coping resources significant in reducing emotional distress? Glob Health Promot. 2009;16: 5-15.

29. Manuti A, Scardigno R, Mininni G. Me, myself, and God: Religion as a psychocultural resource of meaning in later life. Cult Psychol. 2016;22: 3-34.

30. Lazarus RS, Folkman S. Coping and adaptation. In Gentry WD (Ed.), The handbook of behavioral medicine. New York: Guilford; 1984, pp. 282-325.

31. Laurin K, Kay AC, Moscovitch DA. On the belief in God: Towards an understanding of the emotional substrates of compensatory control. J Exp Soc Psychol. 2008;44: $1559-1562$.

32. Skärsäter I, Dencker K, Bergbom I, Häggström L, Fridlund B. Women's conceptions of coping with major depression in daily life: A qualitative, salutogenic approach. Issues Ment Health Nurs. 2003;24: 419-439.

33. Mittelmark MB, Sagy S, Eriksson M, Bauer GF, Pelikan JM, et al. The handbook of salutogenesis. Heidelberg: Springer Open; 2017. doi 10: 978-973.

34. Volanen S-M, Lahelma E, Silventoinen K, Suominen S. Factors contributing to sense of coherence among men and women. Eur J Public Health. 2004;14: 322-330. 


\section{Chapter 6}

Poverty-related diseases: factors that predict coping in two Cameroonian settings

Valerie Makoge, Lette Hogeling, Harro Maat, Lenneke Vaandrager, Maria Koelen

This chapter is under review as Poverty-related diseases: factors that predict coping in two Cameroonian settings. Health Promotion International. 


\section{Abstract}

In this paper, we explore the connection between poverty and health (poverty-related diseases: PRDs) by investigating the factors that play a role in how two groups of people in Cameroon cope with health challenges: workers in a large agro-industrial organisation (living in 'camps') and students in two major universities (living on 'campuses'). We investigated factors reported in the literature as being associated with coping, summarised under the 'salutogenic umbrella', as well as demographic, social and environmental factors. A total of 509 respondents from camps and campuses participated in this study. We used a combination of standardised and un-standardised survey instruments to measure coping. We used Chi-square and ANOVA tests to investigate bivariate differences and multiple logistic regression analysis to determine which significant survey factors predicted coping. Our results showed expected and unexpected differences between the settings. Individual dispositional factors such as sense of coherence (SOC), self-efficacy, subjective wellbeing and self-rated health differed significantly between the settings. Expected coping resources like income and self-efficacy did not differ between non-copers and copers. Two factors emerged as predictors of coping: living environment (setting) and SOC. Our results highlight the need for a multidimensional perspective on poverty and also the need to apply the salutogenic approach in PRD research. In particular, the emphasis this approach puts on stressors and the capacity to employ a variety of resources to overcome stressors is a fruitful way to better understand PRDs and the importance of location-specific circumstances where poverty, health and diseases are connected. 


\section{Introduction}

Health services in developing countries have limited capacity to address people's healthcare needs. Poor people in particular have less access to health services and more difficulty in mitigating health challenges [1]. The critical connection between diseases and poverty has caught the attention of national and international health agencies, leading to the term poverty-related diseases (PRDs) [2,3]. In this paper, we explore further the connection between poverty and health by investigating the factors that play a role in coping with health challenges in two different groups of people in Cameroon: Cameroon Development Corporation (CDC) workers, living in what are called 'camps', and students at the universities of Buea and Yaoundé living in neighbourhoods, referred to as 'campuses'.

In developing countries like Cameroon, a variety of factors contribute to poverty, such as poor nutritional status, poor housing conditions, poor education, lack of basic necessities such as water and electricity [4]. This understanding of poverty is in line with the UN's Human Development Index [5] and moves away from a reductionist definition of poverty as being determined mainly by income level.

Also, many different factors often have an impact on people's health situations, usually in combination and under specific conditions. Stillwaggon (2006) [6] use the phrase 'ecology of poverty' to indicate how factors negatively interact for poor people when they are exposed to HIV/AIDS. How exactly poor conditions interact with HIV/AIDS or other diseases remains largely an empirical question requiring detailed analysis of specific situations [7]. An important element to be considered in such analysis is the fact that people have the capacity to respond to disease challenges themselves. For example, standing water due to poor housing conditions will increase the risk of malaria infection, but these infection risks can be reduced when people engage in regular cleaning of the living space. In this study, we perceive poverty as a general condition that exposes people to a range of stressors. Following the literature on salutogenesis [8 - 10], we use the term 'stressors' for those factors negatively affecting a person's health situation. People's capacity to respond to health challenges that they face, designated as coping, depends on the availability of resources [11- 13] as well as on the person's motivation and understanding of the situation to employ available resources $[14,15]$. This implies that, besides factors from the social and the physical environment, individual factors also play a role in coping [16]. These individual factors may be general demographic features, for example age, sex or education level [13] or specific individual (dispositional) characteristics such, as sense of coherence, self-efficacy, subjective wellbeing and self-rated health. 
Access to appropriate resources will assist in the development of effective coping strategies. Our definition of coping is inspired from its interlinkages with resilience [17-20]. Resilience refers to people's ability to overcome setbacks or catastrophes and to adapt to unforeseen changes $[19,21]$. When facing stressful situations such as job loss, poverty, disease or financial problems, people who are resilient will be better copers [22]. Furthermore, Kitano and Lewis (2005) argue that coping strategies, in addition to personality characteristics and environmental factors, lead to the development of resilience. Some authors see coping as part of resilience, whereas others see resilience as part of coping [20]. Connor and Davidson (2003) indicate that resilience is stress coping ability. In this paper, using different survey instruments, we follow these interlinkages to investigate coping in conditions of poverty and related diseases, and we discuss the data that we have collected about self-reported capacity to overcome setbacks as well as other indicators.

Research on factors that explain coping can offer valuable information for ameliorating and evaluating interventions aimed at fostering health, especially in developing countries. We therefore aim to explore which factors in a set of individual, demographic, social and environmental factors predict coping in people living in conditions of poverty and related diseases.

\section{Methods}

The study presented here is part of a larger project to understand PRDs in Cameroon from a salutogenic perspective.

\section{Settings}

Our study was carried out in 2014, in the Southwest and Centre regions of Cameroon, where two distinct settings were selected: camps housing CDC workers and campuses housing students at University of Buea (UB) and Yaoundé (UNIYAO). CDC is an agro-industrial organisation running banana, rubber and palm-nut plantations. As an organisation, CDC offers its workers free healthcare and free housing in settlements (named camps), usually close to plantations. Most of the CDC workers have a low level of education. Three camps (Limbe, Sonne and Camp7) were selected for our study. The other setting (campuses) refers to neighbourhoods in which university students live. These neighbourhoods are found in the vicinity of the universities. We selected these settings because both are home to a mix of people originally from different parts of Cameroon living in the settings for work (camps) or study (campuses). Also, variations in socio-demographic characteristics, such as age and education level in the different settings, offered an opportunity to explore similarities and 
differences in factors relating to coping with health challenges. To qualify for participation in this study, a respondent had to be living in a CDC camp (as a worker or a worker's dependant) or be a student of UB or UNIYAO.

\section{Selection of respondents}

In the case of Limbe camp, respondents were selected as previously described by [23], whereby for a population of fewer than 1000 inhabitants, one out of every two houses was selected for the research. In Sonne camp and Camp7 however, all houses were visited and a member requested to participate because these were smaller camps with fewer inhabitants. The aim was to get one member to fill out the questionnaire per household visited. The camps where visited at a time when workers had returned from the field/farm, usually after midday. The survey was completed by 509 respondents; the response rate was $93 \%$.

Campus respondents lived in Molyko (UB) and Ngoa-Ekelle (UNIYAO) neighbourhoods and were also selected as previously described by [23]. These neighbourhoods have buildings of varying sizes in which students live. Some have as few as five rooms, whereas others have up to 40 rooms. The buildings are home to students from any degree programme or level. The research team consisted of trained university student assistants and the first author.

\section{Survey instrument}

We investigated factors that are reported in the literature as being associated with coping, summarised under the 'salutogenic umbrella' [10], as well as demographic, social and environmental factors associated with coping.

\section{Coping measurement}

On the basis of the literature outlined in the introduction, we used part of the brief resilience scale (BRS) [24] as our outcome measure for coping. The standardised BRS was used. However, the Cronbach alpha for the scale was low (0.46) and so it was not used as a full scale. We performed factor analysis on the scale and picked out two items that explained most of the variance seen, i.e. questions with high Eigen values. Because these values loaded on different components, they were not combined but used as individual questions to depict coping. The questions were: 'I usually come through difficult times with little trouble' and 'I tend to take a long time to get over setbacks in my life'. Further analysis led us to choose just the latter question as our outcome measure because this was a stronger indicator for coping in terms of the direction of the relationships and the effects seen with the other variables already shown in the literature to be associated with coping. The response to the question was based on a 5-point Likert scale and had options from (1) strongly disagree to (5) strongly agree. The middle point (3) was neutral (neither agree nor disagree). We considered copers as those who strongly disagreed (1) or disagreed (2) with the proposition. In that way, we 
excluded those who were neutral.

\section{Individual factors}

Demographic factors collected from respondents included age, sex, income, employment status, marital status, educational status. Demographic characteristics are conventionally used to describe (lack of) coping strategies [13]. Factors such as sex and education attainment have been shown to influence the kind of coping strategies that people adopt [11 - 13].

Dispositional individual factors included in our study were: sense of coherence (SOC), self-efficacy (SE), subjective wellbeing (SWLS) and self-rated health (SRH). 
Table 6.1: Overview of survey instruments

\begin{tabular}{|c|c|c|c|c|}
\hline $\begin{array}{l}\text { Survey instru- } \\
\text { ment }\end{array}$ & Scale type & Source & $\begin{array}{l}\text { Illustrative ques- } \\
\text { tion }\end{array}$ & $\begin{array}{l}\text { Cronbach's } \alpha \text { (in- } \\
\text { ternal reliability) }\end{array}$ \\
\hline $\begin{array}{l}\text { Sense of coheren- } \\
\text { ce-13 }\end{array}$ & $\begin{array}{l}13 \quad \text { questions, } \\
\text { 7-point Likert } \\
\text { scale: } 1=\text { very } \\
\text { seldom or never, } \\
\text { 7=very often }\end{array}$ & $\begin{array}{l}\text { Antonovsky's 13- } \\
\text { item validated } \\
\text { scale } \\
\text { [9] }\end{array}$ & $\begin{array}{l}\text { 'Do you have the } \\
\text { feeling that you } \\
\text { don't really care } \\
\text { about what goes } \\
\text { on around you?' }\end{array}$ & 0.668 \\
\hline $\begin{array}{l}\text { The general } \\
\text { self-efficacy scale }\end{array}$ & $\begin{array}{l}10 \quad \text { questions, } \\
\text { 4-point Likert } \\
\text { scale with answer } \\
\text { options: } 1=\text { not at } \\
\text { all true, } 2=\text { hardly } \\
\text { true, } 3=\text { =modera- } \\
\text { tely true, } 4=\text { =xact- } \\
\text { ly true }\end{array}$ & $\begin{array}{l}\text { Schwarzer and Je- } \\
\text { rusalem } 10 \text {-item } \\
\text { scale } \\
{[25]}\end{array}$ & $\begin{array}{l}\text { 'I can always ma- } \\
\text { nage to solve dif- } \\
\text { ficult problems if } \\
\text { I try hard enough' }\end{array}$ & 0.732 \\
\hline $\begin{array}{l}\text { Subjective well- } \\
\text { being life scale }\end{array}$ & $\begin{array}{l}5 \quad \text { questions, } \\
\text { 7-point Likert } \\
\text { scale: } 1=\text { strongly } \\
\text { disagree, } 7=\text { =stron- } \\
\text { gly agree }\end{array}$ & [26] & $\begin{array}{l}\text { 'In most ways my } \\
\text { life is close to my } \\
\text { ideal' }\end{array}$ & 0.713 \\
\hline Self-rated health & $\begin{array}{l}\text { Single item health } \\
\text { measure with } \\
4 \text { answer cate- } \\
\text { gories: } 1=\text { poor, } \\
2=\text { fair, } 3=\text { good, } \\
4=\text { excellent }\end{array}$ & [27] & $\begin{array}{l}\text { 'How would you } \\
\text { rate your health } \\
\text { in general?' }\end{array}$ & - \\
\hline $\begin{array}{l}\text { Environmental } \\
\text { factors }\end{array}$ & $\mathrm{No}=1, \mathrm{yes}=2$ & $\begin{array}{l}\text { Not applicable } \\
\text { (NA) }\end{array}$ & $\begin{array}{l}\text { 'Are water cuts } \\
\text { frequent in your } \\
\text { neighbourhood?' }\end{array}$ & (NA) \\
\hline Social factors & $\begin{array}{l}\text { No }=1, \quad \text { yes }=2, \\
3=\text { sometimes }\end{array}$ & (NA) & $\begin{array}{l}\text { 'Is there someone } \\
\text { who provides you } \\
\text { with food when } \\
\text { you are not well?' }\end{array}$ & (NA) \\
\hline
\end{tabular}

SOC was measured using the validated English SOC-13 item scale [8]. SOC was used as both a categorical and a continuous variable in our study. As a categorical variable, SOC was stratified into low and high SOC values based on the 50th median percentile. This stratification has been previously described in other studies $[14,28]$. The median SOC score value was 51.50 . SOC score $\leq 51.50$ was considered as weak SOC ( $n=137$ camps and 99 campuses), SOC score $>51.50$ was considered as strong SOC ( $\mathrm{n}=83$ camps and 153 campuses). As a continuous variable, the 
mean SOC in the camps was 47.02 , whereas on the campuses it was 53.99.

SE was measured by summing the 10 items of the Schwarzer and Jerusalem scale [25]. SE is conceptualised as a person's belief that (s)he is able to cope with many stressors $[29,30]$. People with high SE tend to cope quickly with setbacks and stay motivated regarding their goals. Jex et al. $(2001)[30,31]$ indicate that people with high SE could even employ coping strategies that prevent the occurrence of stressors. Measuring SE provides an indicator for the self-ascribed capacity of people to cope with the variety of stressors they face [32].

SWLS was measured by summing the five items on Diener's SWLS validated scale. Diener et al. (2002:63) define SWLS as 'a person's cognitive and affective evaluations of his/her life'. The concept of subjective wellbeing is broad and includes pleasure feelings as well as feelings indicating how satisfied a person is with life [26]. The more satisfied a person is with his life, the more he is able to cope with challenges [33 - 35].

In this study, SRH was measured using a single item validated scale as previously described [27]. SRH [36, 37] may reveal feelings of ill-health that may not be easily detected medically, and its rating may include all aspects of health (mental, physical, spiritual and so on) which are difficult to capture otherwise. SRH has been shown to be a stronger predictor of mortality than objective health [38]. It is a subjective assessment of a person's health status and has been shown to predict health behaviours and the ability to function properly [37].

Environmental factors were selected on the basis of preliminary observations in the settings and the literature. These were: ease in finding a house, satisfaction with space allocation in the house, satisfaction with the protective ability of the house against mosquitoes and other vermin, satisfaction with the house generally, food availability, food affordability, water accessibility (having a good and permanent water supply).

Social factors were defined as people who support a person in relation to health issues [16]. They were obtained by asking respondents whether they shared their meals and whether they had someone who provided them with food when they were ill.

\section{Procedure}

Questionnaires were dealt with in two ways, either self-completed or assisted, in which case questions and options were read out and the preferred answer selected by the respondent. The latter occurred in situations where respondents were illiterate, hence only in the camps. That notwithstanding, respondents in this case were capable of speaking and understanding the English language. 


\section{Statistical analysis}

The data were analysed using SPSS version 22 for Windows (SPSS, Chicago, IL). Each scale was tested for internal reliability using Cronbach's a reliability coefficient. Chi-square and ANOVA tests were used to investigate bivariate differences in the factors included in the survey. Bivariate differences were investigated between and within the camps and campuses and between non-copers and copers generally and within the two settings. Factors that were significant in the bivariate analysis of non-copers and copers were included in the model for multiple logistic regression analysis. Multiple logistic regression was performed to see which significant survey factors were able to predict coping in the camps and on campuses.

\section{Ethical considerations}

This study was approved by the Wageningen University review board and the Human Resources and Health departments of CDC. The aim and procedure of the study were explained to all respondents who met the inclusion criteria. Respondents were informed of their right to stop at any stage. Respondents were assured of anonymity, and each signed an informed consent form before participating.

\section{Results}

This section starts by highlighting differences in socio-demographic, individual, environmental and social factors between the camps and the campuses (see Table 6.2) and then highlights bivariate differences between non-copers and copers in terms of survey factors. It ends by highlighting factors that predict coping.

\section{Descriptive statistics}

\section{Demographic factors}

In the camps, $56.4 \%$ of the respondents were male and $43.6 \%$ female. On the campuses, $39 \%$ of the respondents where male and $61 \%$ female. Camp respondents were significantly older than campus respondents. The mean age of camp respondents was 36.40 years, whereas the mean age of campus respondents was 23.63 years. About half of the camp respondents were married (50.6\%), whereas most campus respondents were single $(98.9 \%)$. With regard to educational level, camp respondents had mostly a low level of education: $73.2 \%$ had either no formal education or basic primary school education, whereas all the students were studying at university level. Employment status also differed significantly between the settings: $70.0 \%$ of camp respondents were employed for wages, whereas $4.1 \%$ of students were employed besides being students. Most camp-dwellers (58.3\%) had income between 20 and 50 
thousand FCFA (between 33 and 82 US\$) while most students (43.1\%) had income less than 20 thousand FCFA ( less than 33US\$).

\section{Individual factors}

SOC scores were significantly higher on the campuses than in the camps, $p<0.0001$. SOC was significantly stronger in females, in single respondents and in respondents with a high educational level. There was no significant difference in respondents with weak or strong SOC in terms of income. SOC was higher for students than of respondents who were employed for wages.

$\mathrm{SE}$ also differed significantly between the camps and campuses, $\mathrm{p}<0.0001$. The mean $\mathrm{SE}$ score in the camps was 28.15, whereas on the campuses it was 29.94. SWLS differed significantly between the camps and the campuses, $\mathrm{p}<0.0001$. The mean SWLS score was 16.49 in the camps and 19.27 on the campuses. There was a significant difference in SRH between the two settings, $\mathrm{p}<0.05$. More people on the campuses than in the camps rated their health as good, and more people in the camps than on the campuses rated their health as poor.

\section{Environmental factors}

In the camps, $57.4 \%$ of respondents reported that it was easy to find a house. On the campuses, this was reported by $41.3 \%$ of respondents $(\mathrm{p}<0.0001)$. More students $(64.7 \%)$ reported having enough living space than people in the camps $(45.6 \%)(\mathrm{p}<0.0001)$. Regarding the protective ability of houses against mosquitoes and other vermin, $25.7 \%$ in the camps said their house offered protection, whereas $51.5 \%$ of campus respondents said their house offered protection $(\mathrm{p}<0.0001)$. Most respondents were not satisfied with the general status of their houses $(85.1 \%$ in the camps and $75.7 \%$ on the campuses) $(\mathrm{p}<0.05)$. Food availability was significantly different between the two settings $(\mathrm{p}<0.05)$. There was no significant difference between them regarding food affordability. Regarding having a good and permanent supply of water (water accessibility), most respondents in both settings reported that they did not have a good and permanent supply of water. In the camps, the proportion was $96.2 \%$ and in the campuses $74.9 \%$ of respondents $(\mathrm{p}<0.0001)$.

\section{Social factors}

Most respondents in both settings reported that they shared their meals with others and also that they had someone to provide them with food when they were sick (more than $80 \%$ of respondents in both settings). There was no significant difference in these factors between the settings. 
Table 6.2: Bivariate differences in survey factors between camps and campuses

\begin{tabular}{|c|c|c|c|c|c|c|c|}
\hline & & Camps & & Campuses & & & \\
\hline \multirow{4}{*}{ Sex } & & $\begin{array}{l}\% \text { or mean } \\
\quad(\mathrm{SD})\end{array}$ & $\mathrm{n}$ & $\begin{array}{l}\% \text { or mean } \\
\quad(\mathrm{SD})\end{array}$ & $\mathrm{n}$ & $\mathrm{F}$ & $\begin{array}{c}p \text {-va- } \\
\text { lue }\end{array}$ \\
\hline & & & & & & & 0.000 \\
\hline & Female & $43.6 \%$ & 103 & $61.0 \%$ & 166 & & \\
\hline & Male & $56.4 \%$ & 133 & $39.0 \%$ & 106 & & \\
\hline \multirow{2}{*}{$\begin{array}{l}\text { Sense of Cohe- } \\
\text { rence (SOC) }\end{array}$} & Low SOC & $62.3 \%$ & 137 & $39.3 \%$ & 99 & & \\
\hline & High SOC & $37.7 \%$ & 83 & $60.7 \%$ & 153 & & \\
\hline \multicolumn{2}{|l|}{ Total SOC score } & $47.02(11.48)$ & 220 & $53.99(10.40)$ & 252 & 47.905 & 0.000 \\
\hline \multicolumn{2}{|l|}{ Self-efficacy } & $28.15(5.88)$ & 231 & $29.94(4.22)$ & 265 & 15.418 & 0.000 \\
\hline \multicolumn{2}{|c|}{ Self-rated health score } & & & & & & 0.000 \\
\hline & Excellent & $18.1 \%$ & 43 & $13.7 \%$ & 37 & & \\
\hline & Good & $45.6 \%$ & 108 & $62.2 \%$ & 168 & & \\
\hline & Fair & $23.6 \%$ & 56 & $21.9 \%$ & 59 & & \\
\hline & Poor & $12.7 \%$ & 30 & $2.2 \%$ & 6 & & \\
\hline \multicolumn{2}{|c|}{ Subjective wellbeing } & $16.49(6.59)$ & 230 & $19.27(6.47)$ & 264 & 22.337 & 0.000 \\
\hline \multicolumn{8}{|c|}{ Environmental factors } \\
\hline \multicolumn{2}{|c|}{ Easy to find a house } & & & & & & 0.000 \\
\hline & No, not easy & $42.6 \%$ & 100 & $58.7 \%$ & 158 & & \\
\hline & Yes, easy & $57.4 \%$ & 135 & $41.3 \%$ & 111 & & \\
\hline \multicolumn{2}{|c|}{ Enough space for people } & & & & & & 0.000 \\
\hline & No & $54.4 \%$ & 129 & $35.3 \%$ & 96 & & \\
\hline & Yes & $45.6 \%$ & 108 & $64.7 \%$ & 176 & & \\
\hline \multicolumn{2}{|c|}{ House protects from vermin } & & & & & & 0.000 \\
\hline & No & $74.3 \%$ & 176 & $48.5 \%$ & 131 & & \\
\hline & Yes & $25.7 \%$ & 61 & $51.5 \%$ & 139 & & \\
\hline \multicolumn{2}{|c|}{ House needs improvements } & & & & & & 0.006 \\
\hline & No & $14.9 \%$ & 35 & $24.3 \%$ & 64 & & \\
\hline & Yes & $85.1 \%$ & 200 & $75.7 \%$ & 199 & & \\
\hline \multicolumn{2}{|l|}{ Food is available } & & & & & & 0.031 \\
\hline & No & $23.4 \%$ & 55 & $15.5 \%$ & 42 & & \\
\hline
\end{tabular}


Table 6.2: Bivariate differences in survey factors between camps and campuses

\begin{tabular}{|c|c|c|c|c|c|c|c|}
\hline \multicolumn{4}{|c|}{ Camps } & \multicolumn{2}{|l|}{ Campuses } & \multirow[b]{2}{*}{$\mathrm{F}$} & \multirow[b]{2}{*}{$\begin{array}{c}p \text {-va- } \\
\text { lue }\end{array}$} \\
\hline & & $\begin{array}{c}\% \text { or mean } \\
(\mathrm{SD})\end{array}$ & $\mathrm{n}$ & $\begin{array}{c}\% \text { or mean } \\
(\mathrm{SD})\end{array}$ & $\mathrm{n}$ & & \\
\hline & Sometimes & $43.4 \%$ & 102 & $42.1 \%$ & 114 & & \\
\hline & Yes & $33.2 \%$ & 78 & $42.4 \%$ & 115 & & \\
\hline \multicolumn{2}{|c|}{ Food is affordable } & & & & & & ns \\
\hline & No & $27.5 \%$ & 65 & $19.9 \%$ & 54 & & \\
\hline & Sometimes & $40.3 \%$ & 95 & $40.2 \%$ & 109 & & \\
\hline & Yes & $32.2 \%$ & 76 & $39.9 \%$ & 108 & & \\
\hline \multicolumn{3}{|c|}{ Good and permanent water } & & & & & 0.000 \\
\hline & No & $96.2 \%$ & 227 & $74.9 \%$ & 203 & & \\
\hline & Yes & $3.8 \%$ & 9 & $25.1 \%$ & 68 & & \\
\hline \multicolumn{8}{|l|}{ Social resources } \\
\hline \multirow[t]{3}{*}{ Sharing meals } & & & & & & & n.s \\
\hline & No & $13.5 \%$ & 32 & $10.7 \%$ & 29 & & \\
\hline & Yes & $68.5 \%$ & 205 & $89.3 \%$ & 243 & & \\
\hline \multicolumn{4}{|c|}{ Someone provides food when person is ill } & & & & n.s. \\
\hline & No & $14.9 \%$ & 35 & $18.0 \%$ & 49 & & \\
\hline & Yes & $85.1 \%$ & 200 & $82.0 \%$ & 223 & & \\
\hline
\end{tabular}

\section{Bivariate differences in socio-demographic individual and en- vironmental factors between non-copers and copers}

Results of the bivariate analysis on socio-demographic, individual and environmental factors related to coping are shown in Table 6.3. Analysis revealed that age, marital status, education level, employment status and setting were significantly associated with coping. Higher scores in SOC, SWLS and SRH were also significantly associated with coping. The SE score was not significantly different between non-copers and copers. Significant associations with coping were also seen between people who were satisfied with the space allocation in their houses, who reported food was available and affordable for them, and who reportedly had a good and permanent supply of water $(\mathrm{p}<0.05)$. 


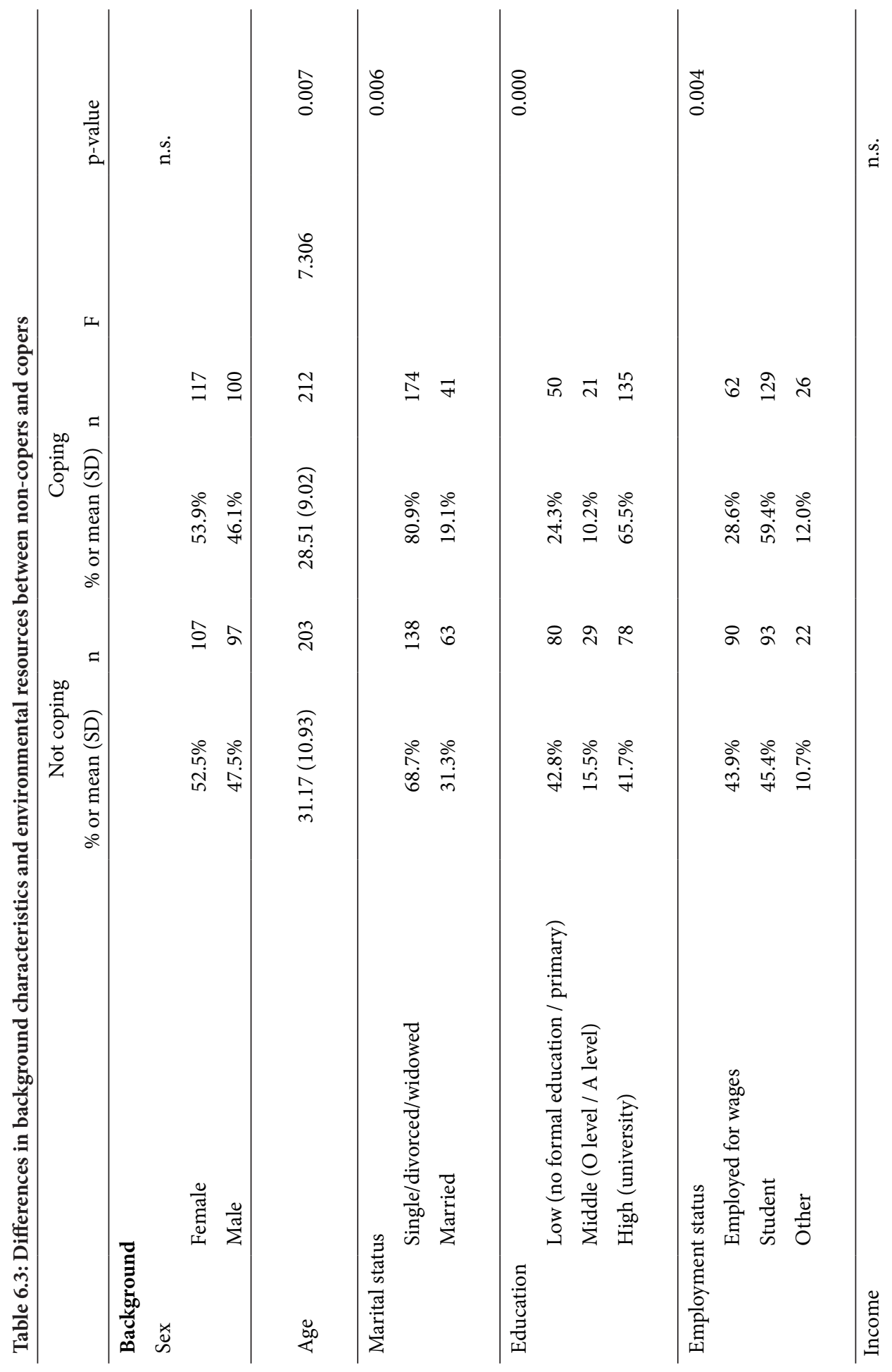




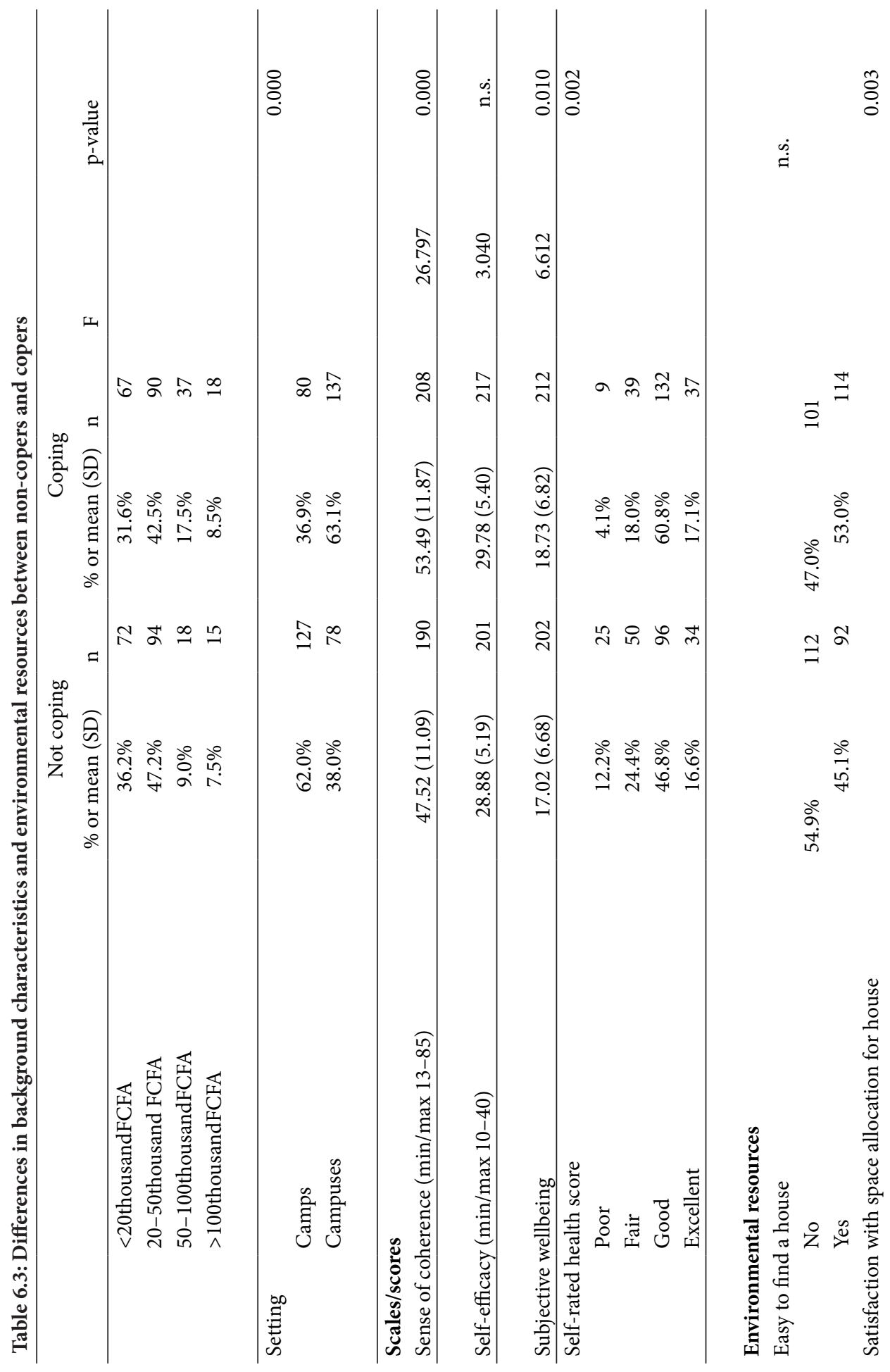




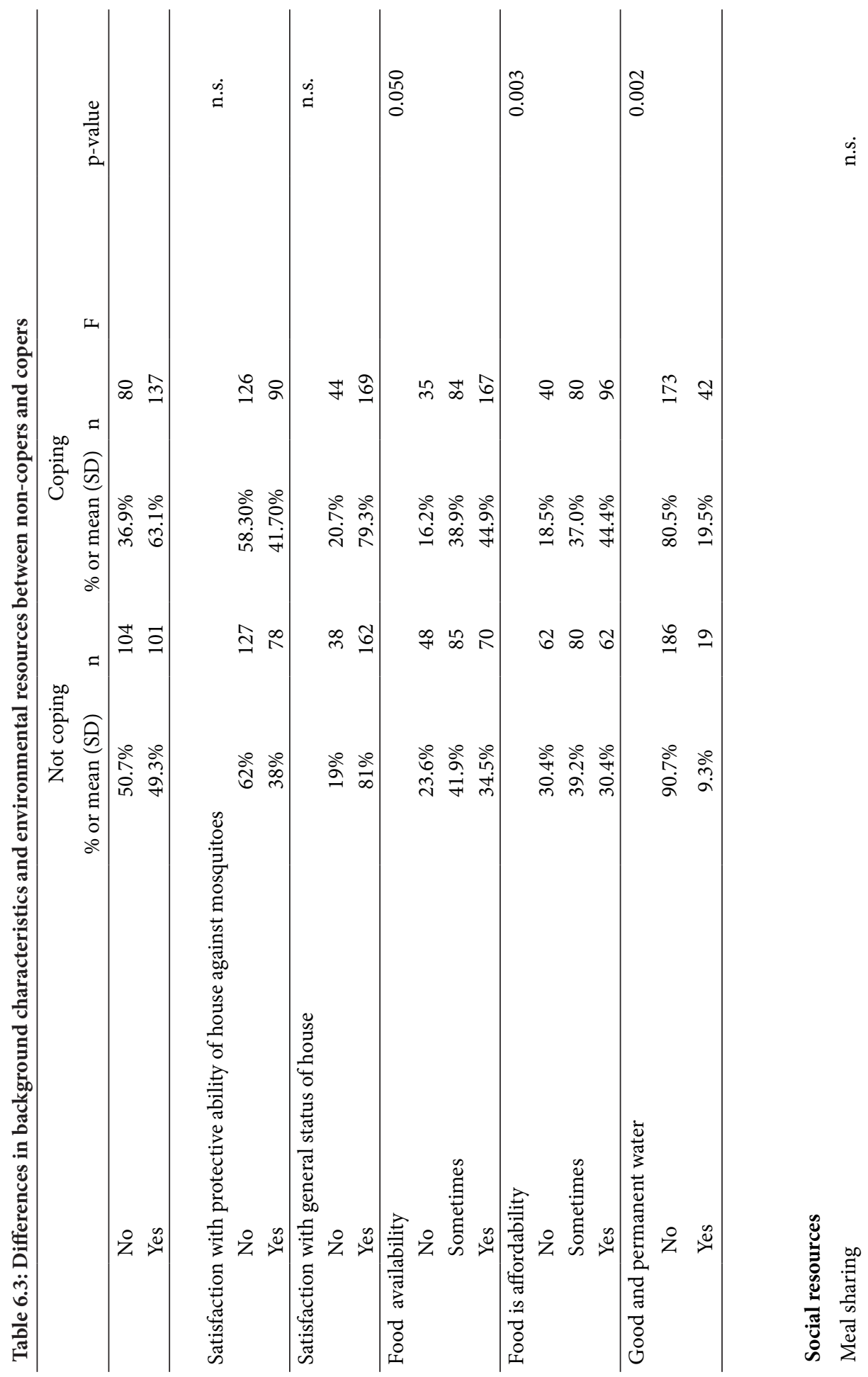




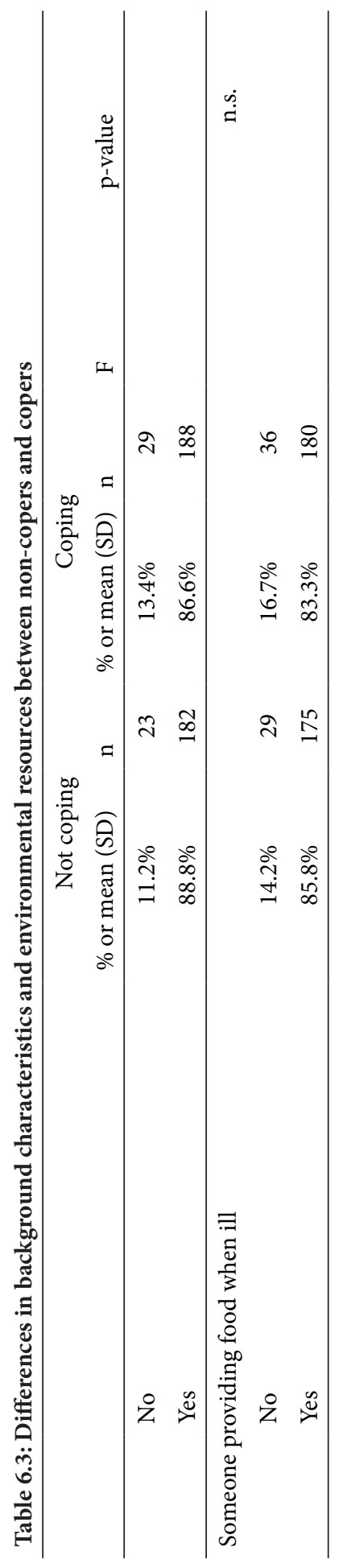


The factors that showed significant differences in the bivariate analysis between non-copers and copers were included in the multiple logistic regression model to identify factors that predict coping (Table 6.4). Two factors emerged as predictors of coping: setting and SOC. The Nagelkerke R-square value was 0.135 . People on campuses had a higher probability than people in camps of being copers, and people with a stronger SOC had a higher probability than people with a weaker SOC of being copers.

Table 6.4: Logistic regression model with coping as dependent variable (coping= I tend to take a long time to get over setbacks in my life)

\begin{tabular}{|c|c|c|c|c|}
\hline & B & S.E. & Sig. & $\operatorname{Exp}(B)$ \\
\hline \multicolumn{5}{|l|}{ Background } \\
\hline Settings (camps vs campuses) & .719 & .232 & .002 & 2.052 \\
\hline \multicolumn{5}{|l|}{ Internal resources } \\
\hline Sense of Coherence & .029 & .010 & .006 & 1.030 \\
\hline Subjective wellbeing & -.006 & .018 & .735 & .994 \\
\hline Self-rated health & -.210 & .144 & .144 & .811 \\
\hline \multicolumn{5}{|l|}{ Environmental resources } \\
\hline Enough space for people & -.028 & .237 & .904 & .972 \\
\hline Food availability & -.048 & .189 & .802 & .954 \\
\hline Food affordability & .266 & .186 & .154 & 1.304 \\
\hline Good and permanent supply of water & .259 & .333 & .438 & 1.295 \\
\hline Constant & -1.888 & .830 & .023 & .151 \\
\hline Nagelkerke R2 & & & & 0.135 \\
\hline
\end{tabular}

Because of the significant contribution of settings, additional bivariate analyses were performed on copers and non-copers in the settings separately. Within camps, copers are less satisfied with the protective ability of their house against mosquitoes and other vermin. Multiple logistic regression using background variables and perceived protective ability of the house as independents, confirmed the protective ability of the houses as the only variable distinguishing copers from non-copers in camps (Table 6.5). Bivariate analyses for campuses revealed more differences. Copers in campuses are more often male, have a higher income, a higher sense of coherence and self-efficacy. Also, copers report different environmental resources than non-copers; they report less difficulties to find a house, are more satisfied with the space allocated for the house, and have fewer complaints about the availability and affordability of food. A multiple logistic regression (Table 6.6), using these variables and relevant background characteristics showed that a higher income and sense of coherence as well as having less difficulties in finding a house predict chances of being someone who copes. 
Table 6.5 Logistic regression model for camps with coping as dependent variable (coping = I tend to take a long time to get over setbacks in my life)

\begin{tabular}{lllll|}
\hline & B & S.E. & Sig. & Exp(B) \\
\hline Background & & & & \\
Sex (female) & .191 & .350 & .585 & 1.211 \\
Age & -.002 & .020 & .930 & .998 \\
Education (ref=low (no formal education / primary)) & & & .573 & \\
middle (O level / A level) & .480 & .457 & .294 & 1.616 \\
high (university) & .408 & 1.348 & .762 & 1.504 \\
Employment status (ref = employed for wages) & & & .259 & \\
Student & -.989 & .690 & .152 & .372 \\
other & .140 & .477 & .769 & 1.150 \\
Marital status (single/divorced/widowed) & .034 & .398 & .931 & 1.035 \\
Income & -.018 & .227 & .936 & .982 \\
Environmental resources & & & & \\
Satisfaction with protective ability house & -.919 & .431 & .033 & .399 \\
Constant & .643 & 1.158 & .579 & 1.902 \\
\hline
\end{tabular}

Table 6.6 Logistic regression model for campuses with coping as dependent variable (coping = I tend to take a long time to get over setbacks in my life)

\begin{tabular}{lllll|}
\hline & B & S.E. & Sig. & Exp(B) \\
\hline Background & & & & \\
Sex (female) & -.474 & .379 & .211 & .623 \\
Age & .007 & .061 & .911 & 1.007 \\
Employment status (ref = employed for wages) & & & .461 & \\
$\quad$ Student & .851 & 1.006 & .397 & 2.342 \\
$\quad$ other & 1.803 & 1.468 & .220 & 6.066 \\
Income & .538 & .245 & .028 & 1.712 \\
Internal resources & & & & \\
Sense of coherence & .051 & .018 & .004 & 1.052 \\
Self-efficacy & .074 & .046 & .107 & 1.076 \\
Environmental resources & & & & \\
Easy to find a house & .856 & .374 & .022 & 2.354 \\
Satisfaction with space allocation for house & -.017 & .380 & .964 & .983 \\
Food availability & .257 & .278 & .355 & 1.293 \\
Food affordability & .371 & .267 & .166 & 1.449 \\
Constant & -8.472 & 2.548 & .001 & .000 \\
\hline
\end{tabular}




\section{Discussion}

Our study explored whether a set of individual, demographic, environmental and social factors predict coping in conditions of poverty and related diseases in camps and on campuses in Cameroon. By analysing data for people in two different settings, we have provided insights on the interactions between poverty and health and on the relative importance of factors in coping. These insights are necessary for improving interventions to promote health.

\section{Predictors of coping}

\section{Setting}

The first predictor of coping in our study was setting. It should be noted that it was not the setting per se, but the characteristics of the people living in the settings that predict coping. For example, younger age, being single and higher educational level were significantly associated with coping, which are typically characteristics of students.

On the campuses, higher income, strong SOC as well as having less difficulty to find a house were predictors of coping whereas in the camps, it was having less satisfaction with the protective ability of one's house.

There were several significant differences between respondents in the camps and on the campuses. As expected, campus respondents were more highly educated than camp respondents. Camp respondents on their part, were mostly married, older and had relatively stable jobs, whereas students had more volatile income sources, mostly receiving money from their parents or guardians. An unexpected difference was that camp respondents reported higher income than students. However, overall, income was not related to coping. Insecurity over income may add to the perception of having low income and influence a person's coping disposition [19]. On the campuses, income was a predictor of coping whereas in the camps, income was not significantly different between copers and non-copers. These results underline the need for a multidimensional perspective on poverty as it suggests that factors other than income may be more relevant for coping in the camps [4]. Despite higher and more secure income, people in camps reported to be living in worse conditions than people on campuses. Evidently, the housing conditions in the camps are largely determined by what CDC provides. Likewise, most students rent rooms from landlords. Both groups therefore have a limited capacity to influence their housing conditions, and income differences then become relatively unrelated to this important aspect of wellbeing especially in the camps.

In other studies as well, both resources at the individual and the environmental level have 
been shown to influence people's coping abilities and optimise coping $[10,19,39,40]$. Volanen et al. [41] indicated that the most important external resources were those linked to education levels, social support, living conditions, and work conditions. Social support in our study, was not significantly different between non-copers and copers, contrary to what other studies have reported [16]. The specific situation of the settings may explain this. Both the workers and the students moved to these settings for work or study, creating a more remote connection with the social networks of family and friends with whom they grew up. Although new relationships are established within camps and campuses, the social support in these settings have no clear effect on coping levels. Another explanation could be the limited number of indicators to show social support in our study.

Unlike social support, certain environmental resources in our study differed significantly between non-copers and copers. Significant associations were seen between coping and people who were satisfied with the space allocation in their houses, who reported food was available and affordable for them, and who reportedly had a good and permanent water supply. These resources probably increased people's potential to cope with stressors. Again, the specific situation of the settings may explain this as our study showed that environmental factors related to different aspects of housing predicted coping within the different settings. Our results therefore highlight the need for the improvement of the living conditions in the settings to enhance coping.

\section{SOC}

The second predictor of coping revealed in our study was having a strong SOC. This was the only individual dispositional factor that emerged as a predictor of coping. Given that respondents had limited capacity to influence certain environmental factors such as housing conditions, individual factors (dispositional) may appear crucial to reveal relevant insights. Bivariate analysis revealed that respondents in the different settings showed significant differences in dispositional - SOC, SWLS, SRH and SE - and environmental factors. SOC, SWLS, SE and SRH scores were significantly higher on the campuses than in the camps. This could be because of the high educational level of campus respondents [13]. Regarding SOC in particular, which facilitates the way people can effectively manage tension in their lives [41], our study also showed that a strong SOC was not associated with income - another indication that income is not related to coping ability. Also, more women than men had a strong SOC. This contradicts many previous studies that have linked a strong SOC to males $[42,43]$ and confirms more recent findings that have linked a strong SOC to females [28, 44]. Further research should examine why this is so. As expected, our results also showed that the individual dispositional factors SOC, SWLS and SRH differed significantly between copers and non-copers. SE, however, did not. This was unexpected and contradicts what has been reported previously in other studies [31,45-46]. The reason for this contradiction is 
unclear, but it could be linked to cultural differences in the populations studied.

Our result, revealing SOC as a predictor of coping, is confirmed by previous studies [47]. A strong SOC was reported mostly on the campuses. This finding is important, because studies have always indicated a need to strengthen SOC. Because these factors have been identified, health promotion interventions can seek to boost observed qualities associated with a strong SOC in people. For example, higher education is positively linked to a stronger SOC, as shown in other studies [46] and as confirmed by our study. People in places such as CDC camps could benefit from adult education classes that could be organised by CDC as this would probably lead to them developing a stronger SOC, with the added benefit of being more able to combat a variety of stressors that they face in their daily lives.

\section{Limitations}

We did not use an actual coping scale in the study but derived our own measure based on observations and the literature. We presume that using an actual coping scale might have elicited more insights than we have now. This can be followed up with further research. Also, the set of environmental and social factors identified through our respondents was limited. We realise therefore that some social factors that could probably predict coping may not have been included in our model. That notwithstanding, our study also had strong points. It examined a large number of variables, using both standardised and un-standardised measurements to explain coping, and therefore enables a better understanding of the interaction between poverty and health. It also used the same instrument in two different settings and in this way revealed new insights that are important for improving designs and assessing interventions aimed at ameliorating health conditions for people living in conditions of poverty and disease.

\section{Conclusion}

We started this paper on the premise that, although poverty is a condition that makes people more susceptible to certain diseases and limits how people can respond to those diseases, it is also a condition that offers an opportunity to identify factors necessary for coping with health challenges. We investigated coping in two different groups of people. We highlighted differences between non-copers and copers based on individual, socio-demographic and environmental factors. Coping was related most strongly to individual factors (SOC, SWLS 
and SRH) and to a lesser extent to environmental factors such as satisfaction with the general status of the house, food availability and affordability, and having a good and permanent source of water. Neither social resources nor income generally related to coping. Our study showed that predictors of coping were linked firstly to setting. More precisely, to characteristics of the people living in the settings such as people who report less satisfaction with the protective ability of houses in camps or higher income, and more ease to find house on campuses.

Having a strong SOC predicts a greater ability to identify and use resources to combat stressors. Our results confirm the inextricable links between people and their environment, support the need to create supportive environments as prescribed by the Ottawa Charter [48] and indicate the need to apply the salutogenic approach in research on PRDs. In particular, the emphasis this approach puts on stressors and the capacity to employ a variety of resources to overcome stressors is a fruitful way to better understand PRDs and the importance of location-specific circumstances for how poverty, health and diseases are connected. Our study makes clear that health as a public concern is not restricted to government health polices but extends to other government responsibilities, in particular education and housing, as well as corporate responsibilities of private enterprises. Given the deplorable state of many of the houses and facilities observed in the camps, we urge the government of Cameroon and the CDC to unite in improving the living conditions for CDC workers in the camps. We also recommend that CDC aspire to organise adult literacy classes for its workers, as this would lead to empowerment and a consequent strengthening of their SOC and probably enable them to cope better with other stressors that they face daily. 


\section{References}

1. Burtscher D, Burza S. Health-seeking behaviour and community perceptions of childhood undernutrition and a community management of acute malnutrition (CMAM) programme in rural Bihar, India: a qualitative study. Public Health Nutr 2015;18(17): 3234-3243. https://doi.org/10.1017/S1368980015000440

2. Stevens P. Diseases of poverty and the 10/90 gap. IPN Working Papers on Intellectual Property, Innovation and Health. London, UK: World Health Organisation; 2004.10/90 Gap. http://sarpn.org/documents/d0002617/6-Disease_Poverty_IPN_2007.pdf (26 May 2016, date last accessed).

3. WHO. Global Report for Research on Infectious Diseases of Poverty. World Health Organisation (2012). http://apps.who.int/iris/bitstream/10665/44850/1/9789241564489_ eng.pdf (17 September 2015, date last accessed).

4. Ningaye P, Alexi TY, Virginie TF. Multi-poverty in Cameroon: A structural equation modeling approach. Social Indicators Research 2013. 113: 159-181.

5. UNDP. Human Development Index. United Nations Development Programme 2015.

6. Stillwaggon E. The ecology of poverty: Nutrition, parasites, and vulnerability to HIV/ AIDS. AIDS, Poverty and Hunger: Challenges and Responses International Food Policy Research Institute, Washington 2006: 167-180.

7. Gillespie S, Kadiyala S, Greener R. Is poverty or wealth driving HIV transmission? Aids. 2007. 21: S5-S16. http://hdr.undp.org/en/content/human-development-index-hdi (2 August 2016, date last accessed)

8. Antonovsky A. Health, stress, and coping. San Francisco, California: Jossey-Bass, San Francisco, CA. 1979.

9. Antonovsky A. Unraveling the mystery of health: How people manage stress and stay well: Jossey-Bass, San Francisco, CA. 1987.

10. Eriksson M, Lindström B. Bringing it all together: the salutogenic response to some of the most pertinent public health dilemmas. Health Assets in a Global Context: Springer, New York. 2010. pp. 339-351. 
11. Njong AM. The effects of educational attainment on poverty reduction in Cameroon. International Journal of Educational Administration and Policy Studies. 2010. 2: 001008 .

12. Gage-Bouchard EA, Devine KA, Heckler CE. The Relationship between Socio-demographic Characteristics, Family Environment, and Caregiver Coping in Families of Children with Cancer. Journal of clinical psychology in medical settings. 2013. 20: doi:10.1007/s10880-10013-19362-10883.

13. Alnazly E. Coping strategies and socio-demographic characteristics among Jordanian caregivers of patients receiving hemodialysis. Saudi Journal of Kidney Diseases and Transplantation. 2016. 27: 101.

14. Eriksson M. Unravelling the mystery of salutogenesis : the evidence base of the salutogenic research as measured by Antonovskys Sense of Coherence Scale doctoral thesis in social policy at ÅAU, 2007. Vasa: Faculty of Social and Caring Science.

15. Lindström B, Eriksson M. From health education to healthy learning: Implementing salutogenesis in educational science. Scandinavian Journal of Public Health. 2011. 39: 85-92.

16. Terry DJ (1991) Coping resources and situational appraisals as predictors of coping behavior. Personality and individual differences 12: 1031-1047.

17. Connor KM, Davidson JR. Development of a new resilience scale: The Connor-Davidson resilience scale (CD-RISC). Depression and anxiety. 2003. 18: 76-82.

18. Folkman S, Moskowitz JT. Coping: Pitfalls and promise. Annual Review of Psychology, 2004. 55, 745-774.

19. Southwick SM, Litz BT, Charney D, Friedman MJ. Resilience and mental health: Challenges across the lifespan. 2011. Cambridge University Press. Cambridge, UK.

20. Rice V, Liu B. Personal resilience and coping with implications for work. 2016. Part I: A review. Work: 1-9.

21. Pearson J, Hall D. Resilience: Coping Effectively with Life's Challenges. Depression 2007. 1: 4, 11-12. 
22. Cherry K. What Is Resilience? Coping With Crisis , 2015. Verywell.com. https://www. verywell.com/what-is-resilience-2795059 (22 July 2016, date last accessed).

23. Moyou-Somo R, Essomba P, Songue E, Tchoubou NN, Ntambo A, et al. A public private partnership to fight against malaria along the Chad-Cameroon pipeline corridor: I. Baseline data on socio-anthropological aspects, knowledge, attitudes and practices of the population concerning malaria. BMC Public Health. 2013. 13: 1-10.

24. Smith BW, Dalen J, Wiggins K, Tooley E, Christopher P, et al. The brief resilience scale: assessing the ability to bounce back. International journal of behavioral medicine. 2008. 15: 194-200.

25. Schwarzer R, Jerusalem M. Generalized Self-Efficacy scale. 1995. Windsor, UK: NFER-NELSON: In J. Weinman, S. Wright, \& M. Johnston. Windsor, UK, pp. 35-37.

26. Diener E, Emmons RA, Larsen RJ, Griffin S. The satisfaction with life scale. Journal of personality assessment. 1985. 49: 71-75.

27. Parker, T. Factors associated with American Indian teens' self-rated health. American Indian and Alaska Native Mental Health Research, 2004. 11, 1. http://dx.doi. org/10.5820/aian.1103.2004.1

28. Swan E, Bouwman L, Hiddink GJ, Aarts N, Koelen M. Profiling healthy eaters. Determining factors that predict healthy eating practices among Dutch adults. Appetite. 2015. 89: 1-9.

29. Bandura A. Self-Efficacy. The Corsini Encyclopedia of Psychology. 2010: John Wiley \& Sons, Inc. Hoboken, NJ.

30. Jerusalem M, Schwarzer R, Schwarzer R. Self-efficacy as a resource factor in stress appraisal processes. Self-efficacy: Thought control of action. 1992: 195-213. Routledge, New York, pp. 195-213.

31. Jex SM, Bliese PD, Buzzell S, Primeau J. The impact of self-efficacy on stressor-strain relations: Coping style as an explanatory mechanism. Journal of applied psychology. 2001. 86: 401.

32. Koelen MA, van den Ban AW, van den Ban A. Health education and health promotion 2004: Wageningen academic publishers, Wageningen. 
33. Headey B, Wearing A. Subjective well-being and coping with adversity. Social Indicators Research. 1990. 22: 327-349.

34. Diener E, Lucas RE, Oishi S. Subjective well-being. Handbook of positive psychology. 2002. Oxford University Press, New York, pp. 63-73.

35. Carmel S, Raveis VH, O’Rourke N, Tovel H. Health, coping and subjective well-being: results of a longitudinal study of elderly Israelis. Aging \& Mental Health 2016: 1-8. http://dx.doi.org/10.1080/13607863.2016.1141285

36. Karademas EC, Zarogiannos A, Karamvakalis N. Cardiac patient-spouse dissimilarities in illness perception: Associations with patient self-rated health and coping strategies. Psychology \& Health. 2010. 25: 451-463.

37. Mauro PM, Canham SL, Martins SS, Spira AP. Substance-use coping and self-rated health among US middle-aged and older adults. Addictive Behaviors. 2015. 42: 96-100.

38. Idler EL, Benyamini Y. Self-rated health and mortality: a review of twenty-seven community studies. Journal of health and social behavior. 1997: 21-37.

39. Kitano MK, Lewis RB. Resilience and coping: Implications for gifted children and youth at risk. Roeper Review. 2005. 27: 200-205.

40. Diehl M, Hay EL, Chui H. Personal risk and resilience factors in the context of daily stress. Annual Review of Gerontology and Geriatrics. 2012. 32: 251-274.

41. Volanen S-M, Lahelma E, Silventoinen K, Suominen S. Factors contributing to sense of coherence among men and women. The European Journal of Public Health. 2004. 14: 322-330.

42. Larsson G, Kallenberg KO. Sense of coherence, socioeconomic conditions and health. The European Journal of Public Health. 1996. 6: 175-180.

43. Anson O, Paran E, Neumann L, Chernichovsky D. Gender differences in health perceptions and their predictors. Social Science \& Medicine. 1993. 36: 419-427.

44. Horiguchi M, Tanaka G, Ogasawara H, Maruyama R. Gender-based relationship between eating behavior and sense of coherence in Japanese young adults. Social Behavior and Personality: an international journal. 2016. 44: 45-58. 
45. Bandura A. Self-efficacy: The exercise of control. American Journal of Health Promotion. 1997. 12: 8-10.

46. Luszczynska A, Scholz U, Schwarzer R. The General Self-Efficacy Scale: Multicultural Validation Studies. The Journal of Psychology. 2005. 139: 439-457.

47. Eriksson M, Lindström B. Life is more than survival: Exploring links between Antonovsky's salutogenic theory and the concept of resilience. Scandinavian journal of public health. 2011. 39: 85-92.

48. WHO. Ottawa charter for health promotion. Health Promotion International, 1986. 1, $3-5$ 


\section{Chapter 7}

General discussion and conclusion 


\section{Introduction}

The link between poverty and health has been widely acknowledged and has given rise to the term poverty-related diseases (PRDs). Undoubtedly, the poor suffer more than other groups in society from diseases and have more difficulty managing them, but nonetheless they play a role in coping with the challenges in their lives. This aspect has been omitted so far in the fight against PRDs, which has been mainly disease-focused. If the social conditions, people's capacities and what people do on their own to manage PRDs are included in an intervention, that intervention is more likely to be successful and sustainable. This study adopted this approach by focusing on the ways two different groups of people (workers of the Cameroon Development Corporation (CDC) and their dependants, and students at the universities of Buea and Yaoundé: Ngoa-Ekelle) cope with conditions that hamper their health and wellbeing, with an emphasis on PRDs. In order to achieve this, we employed the salutogenic model of health (SMH), which underscores the search for the causes of health. We therefore highlighted mechanisms and strategies through which people manage their everyday-life challenges.

This final chapter recapitulates and brings together the results of the previous chapters of this thesis. The overall aim of this thesis was to understand how conditions of poverty impact the health of people and how they manage these challenges. Specifically, the study aimed to unravel the interlinkages between poverty and health by obtaining a deeper understanding of the social and material dynamics that enable people's capacity to preserve health, anticipate health risks, and mitigate or recover from stressors such as PRDs. Also, the study aimed to contribute to sustainable and effective response strategies towards PRDs.

This chapter starts with a summary of the main research findings and how these findings inform the answers to the specific research questions posed in the introduction to this thesis. In the section following the summary, answers to the main research question are discussed in the light of the overall insights they bring and how these relate to the academic literature on poverty and health. Further, methodological considerations are addressed. This chapter ends with a reflection on the implications for policy and further research. 


\section{Summary of the main findings: answering the spe- cific research questions}

A summary of the main findings is presented in Table 7.1.

\section{Research question 1: What factors underlie people's perceptions of PRDs and how do these influence the way people respond to diseases?}

In Chapter 2, we employed the health belief model (HBM) to investigate the perceptions of university students in Cameroon about common diseases and diseases related to poverty, to find out how they respond to diseases, to ascertain the motivations for their responses and, finally, to identify the determinants (perceived benefits and barriers) of the participants' use of formal healthcare services. A total of 272 students took part in this study. Their responses showed that the students were able to differentiate between the diseases that they perceived as common and those that they considered to be PRDs. Malaria was perceived as being both a common disease and a PRD. Even though the students perceived HIV/AIDS to be the third most common disease, it did not fall among the top three PRDs. Cholera was perceived to be a major PRD but not a common disease, whereas typhoid was considered to be a common disease but not a major PRD. With the exception of malaria, respondents' classification of major PRDs did not align with the classification of major PRDs by national and international health governing bodies, e.g. the World Health Organisation. The responses revealed that an important element in disease perception was people's immediate living environment, particularly poor hygiene conditions. This was a major attributed cause for disease presence. Another insight from the chapter was that utilisation of the formal healthcare services was based on a combination of self-diagnosis and available financial means. People weigh up factors such as type of disease, perceived severity and having money before seeking formal healthcare. This comes out most strongly for malaria. Over $85 \%$ of the students said they would use informal healthcare services, including self-medication, to deal with malaria. The responses to malaria show some uniformity across the groups. Socio-demographic status did not predict the use of formal healthcare services in the case of malaria, and neither did the odds change for their use in the presence of challenges in sanitation, food and water.

Chapter 3 presents the results of the same study among CDC camp dwellers. A total of 237 camp dwellers took part in this study. Just as in the students' case, camp dwellers perceived the disease threat posed by the living environment and were also cognisant of the diseases perceived as common or as PRDs. Common diseases perceived by the camp dwellers were 
slightly different from those perceived by the students. For example, camp dwellers did not perceive HIV/AIDS as a common disease, but the students did. The perception of malaria as a common disease and a PRD on the other hand was the same. Typhoid was reported as a common disease as well as diarrhoea. Regarding PRDs, the camp dwellers' classification was the same as that of the students. In both settings therefore, malaria, cholera and diarrhoea were the most prominent diseases perceived to be PRDs. Once again as in the study with the students, poor hygiene was a major reason attributed to disease presence. The ways in which camp dwellers responded to diseases aligned with those of the students. As a general response, free CDC clinics were hailed as the preferred response to illness. However, what stands out from these findings is that, despite the fact that the CDC clinics provide free healthcare, financial means also appeared a factor in the workers' decisions to go to these clinics. The decision to visit a clinic was related to having no drugs at home, perceived severity of the disease as well as how long the illness had lasted. In the case of malaria however, the preferred response changed from the free CDC clinics to mostly informal healthcare providers, indicated as using small pharmacies and street vendors and also practising self-medication. Once again, socio-demographic characteristics did not predict the use of the formal healthcare sector in the case of malaria. The odds of using formal healthcare services for malaria were higher, however, for people who reported having water challenges.

Chapters 2 and 3 show that disease perceptions are formed through an interplay of various factors related partly to general knowledge about diseases and partly to specific knowledge and experiences from the respondents' living environment. This shows most clearly when respondents were asked about what they perceive as PRDs. For them, malaria, cholera and diarrhoea are diseases that have a prominent linkage to poverty, poor living conditions and poor health. In other words, their perception of the interplay between poverty and health represents a combination of a general knowledge about health and a context-specific understanding of linkages between poor social wellbeing and poor health, including judgements about this linkage, i.e. a condition they strongly reject. The response to diseases showed an overall consensus for formal healthcare as a response to diseases in general. This was influenced by different factors related to the disease, to finances and to medication. A discrepancy was observed in relation to responses to malaria, and this was similar for the different groups of respondents, whereby over $80 \%$ of respondents in both settings indicated a preferred reliance on informal medicine and services. This was the case even when free healthcare services were available for CDC workers and their families. It was clear that, no matter what the setting, the favoured response to a suspected malaria attack was to rely on informal medication unless symptoms became very severe. This response to malaria is an insight that may indicate why malaria is still so common, because little is known about the efficacy and long-term effects of informal treatment. Therefore, it is important to include this finding in the rethinking of health promotion strategies and to address, in a constructive 
way, the role of informal healthcare providers in the control of malaria rather than merely dismissing informal medication as ineffective.

\section{Research question 2: What are the health challenges faced by camp dwellers and university students and how do they respond to those challenges?}

In Chapter 4, we qualitatively analysed the health challenges faced by people in the camps and on the campuses and ascertained how they dealt with these challenges. The findings confirm the significant presence of malaria in both settings. The picture with respect to the classification of PRDs is slightly different from that found in Chapters 2 and 3. In this study, we found additional reasons why respondents did not use the (free) health services offered to them. This was because of the poor quality of treatment received as well as the constant shortage of drugs. In other words, health challenges were related not only to exposure to diseases but also to the volatility of the healthcare services. This chapter also revealed that respondents were pro-active towards their health. This was visible in how they engaged in hygiene practices such as the clean-up campaigns observed in the camps or students' cleaning of their individual space as seen on the campuses. The results also showed that both formal and informal sectors were employed. With regard to the informal sector, using the services of small pharmacies and street vendors were favoured options. The students had quasi-formal healthcare providers called quart-doctors. Quart-doctors were students still in medical school or those who had graduated but were not yet legally practicing medicine. Health-seeking behaviour was influenced by three major dynamics, namely: perceived disease severity, local perceptions and financial constraints.

The findings in Chapter 4 thus show a close connection between the perceived challenges and the way people respond to these challenges. An important element in this connection is the finding that, besides disease risks, a major challenge for people is a combination of the affordability, functionality and reliability of existing healthcare services.

\section{Research question 3: How are stressors experienced by camp dwellers and university stu- dents and what coping mechanisms do they use to deal with stressors?}

Chapter 5 focused on stressors as experienced by camp dwellers and university students and the coping mechanisms they use. We followed the SMH, whereby we focused on how respondents advanced towards better health despite the presence of stressors. According to the $\mathrm{SMH}$, stressors are a range of conditions that can negatively affect health, for example work or study conditions, social relationships or a tight financial budget. The identification and use of resources that are available internally or externally to people (GRRs) can help people to cope. Being able to identify and use these resources depends on people's capacities 
to understand and make sense of their conditions. Our results confirmed that stressors were experienced by all respondents. Whereas some stressors were context-specific, others were common to both camp dwellers and students. Common stressors experienced by all respondents were related to their living environment, characterised by insufficient or unreliable water and sanitary conditions, poor work or study conditions, social affiliations, healthcare and finances. The presence of stressors did not prevent the respondents from striving to have meaningful life experiences. Chapter 5 elaborates on coping mechanisms put in place by respondents to meet their challenges. Most prominently, it was seen that respondents' social infrastructure and religious beliefs and activities created a supportive environment around the lives of camp dwellers and students. Furthermore, respondents found ways to make additional money. Also highlighted in this study was the finding that there was a thin line between the stressors experienced and the resources on which people drew to overcome the stressors, as sometimes what people drew on as resources could become what they experienced as stressors, and vice versa. Free healthcare services for the camp dwellers and studies for the students are examples of resource/stressor interchangeability presented in Chapter 5. In such cases, respondents had to find a balance by engaging in constant and timely adjustments in their lives to ensure a reduction in the stressful aspects of a resource and an increased focus on the positive aspects. Chapter 5 also explored the resistance resources (SRRs) in the lives of the respondents. GRRs and SRRs are presented as elements that together with Sense of Coherence (SOC) enable respondents to participate in shaping their lives and to live the lives they want to live.

The answer to research question 3, emerging from the findings presented in Chapter 5, is that respondents identified a range of stressors that they experienced as challenging but overall manageable thanks to a variety of resources at hand. The main sources of stressors are highly similar for both groups. Mechanisms put in place by respondents included developing improvisational capacities and taking preventive action, actively managing social relationships, taking part in religious activities and faith as well as finding alternative ways to make additional money. This study therefore shows clearly that people are active participants in shaping their lives. This aspect offers a promising lens through which PRDs and poverty can be addressed.

\section{Research question 4: Which factors influence effective coping with health challenges in the settings?}

Chapter 6 explored the factors in a set of individual, demographic, social and environmental attributes that predict coping in people living in conditions of poverty and related diseases. Data were collected and analysed for 509 respondents from the camps and the campuses. Individual people's dispositions, measured by standardised surveys, showed that scores 
for SOC, self-efficacy (SE), subjective wellbeing (SWLS) and self-rated health (SRH) were higher on the campuses than in the camps. It was interesting to see that these indicators had a clear relation with people's coping capacity, as copers scored higher than non-copers. Environmental attributes overall scored higher among the people on the campuses than among the people in the camps. In particular, housing conditions appeared a critical factor in the camps. The analysis showed that coping in the camps is primarily related to satisfaction with the protective ability of the houses. Social attributes appeared to be more prominent among the students. In particular, sex (in the biological differentiation sense) came up as a factor because copers on campuses were predominantly male. Environmental resources such as house satisfaction and availability and affordability of food also clearly enhanced coping among students. The results indicate that SOC is a good predictor of coping. The scores also show that living conditions in the camps had a higher impact on coping than living conditions on the campuses. The results from the camp respondents in particular make clear that free healthcare is a positive asset but in itself not enough for people to cope when housing conditions are so bad that people feel unprotected from health challenges.

The findings in Chapter 6 show that factors that influence coping are related to a combination of immediate living environment and individual dispositions. Overall, a strong SOC appears a good predictor of coping in the two settings. The students' scores reveal that a combination of being male, having better housing and having more financial means predicts coping. For the camps, the protective ability of the house appeared a major predictor of coping. The results of this study highlight the need to improve our respondents' living conditions as well as for an increase in factors that can strengthen SOC, as this will make people better able to cope with the challenges that they face in their daily lives. 


\section{Summary of the main findings}

\begin{tabular}{|c|c|}
\hline Thesis chapter & Research objective and main findings \\
\hline \multirow[t]{3}{*}{$\begin{array}{l}\text { Chapter } 2 \\
\text { PRDs: unravelling com- } \\
\text { plexities in disease res- } \\
\text { ponses }\end{array}$} & $\begin{array}{l}\text { Research objective } \\
\text { - To assess the perceptions of university students in Cameroon } \\
\text { about common diseases and diseases related to poverty, to find } \\
\text { out how they respond to diseases, to ascertain the motivations for } \\
\text { their responses and, finally, to identify the determinants (percei- } \\
\text { ved benefits and barriers) of the participants' use of the healthcare } \\
\text { services. }\end{array}$ \\
\hline & $\begin{array}{l}\text { Main research findings } \\
\text { - } \quad \text { Perceived common diseases: malaria, typhoid and HIV/AIDs } \\
\text { - } \quad \text { Perceived major PRDs: malaria, cholera and diarrhoea } \\
\text { - } \quad \text { Response to diseases: generally, the use of formal healthcare ser- } \\
\text { vices was reported; in the case of malaria, informal services were } \\
\text { reported (i.e. the use of small pharmacies, street vendors and } \\
\text { self-medication practices) } \\
\text { Determinants for seeking formal healthcare: having money, seve- } \\
\text { rity of disease and duration of illness }\end{array}$ \\
\hline & $\begin{array}{l}\text { Conclusions } \\
\text { Students have a different classification of PRDs than governing health } \\
\text { bodies } \\
\text { The immediate living environment determines this perception } \\
\text { The use of formal healthcare depends on an interplay of self-diagnosis } \\
\text { and financial means }\end{array}$ \\
\hline \multirow[t]{2}{*}{$\begin{array}{l}\text { Chapter } 3 \\
\text { Poverty and health among } \\
\text { plantation labourers in } \\
\text { Cameroon: an application } \\
\text { of the health belief model }\end{array}$} & $\begin{array}{l}\text { Research objective } \\
\text { - To assess the perceptions about common diseases and PRDs, and } \\
\text { investigate how labourers of the Cameroon Development Cor- } \\
\text { poration manage diseases that adversely affect their health and } \\
\text { well-being }\end{array}$ \\
\hline & $\begin{array}{l}\text { Main research findings } \\
\text { - Perceived common diseases: malaria, typhoid and diarrhoea } \\
\text { - Perceived major PRDs: malaria, cholera and diarrhoea } \\
\text { - } \quad \text { Response to diseases: generally, the use of CDC free clinics repor- } \\
\text { ted and this was determined by having money to seek healthcare } \\
\text { elsewhere, severity of disease and duration of illness } \\
\text { - In the case of malaria, self-medication practices, use of small } \\
\text { pharmacies, street vendors were the favoured options } \\
\text { Having water challenges increased the odds of using formal } \\
\text { healthcare services in the case of malaria }\end{array}$ \\
\hline
\end{tabular}




\begin{tabular}{|c|c|}
\hline & $\begin{array}{l}\text { Conclusions } \\
\text { - Camp dwellers like the students had a different classification of } \\
\text { PRDs than national and international health organisations } \\
\text { - The immediate living environment was pinpointed as a determi- } \\
\text { ning factor for presence of disease } \\
\text { - The use of formal healthcare was determined by an interplay of } \\
\text { self-diagnosis and financial considerations }\end{array}$ \\
\hline \multirow{3}{*}{$\begin{array}{l}\text { Chapter } 4 \\
\text { Health-seeking behavi- } \\
\text { our towards poverty-re- } \\
\text { lated disease (PRDs): a } \\
\text { qualitative study of peop- } \\
\text { le living in camps and on } \\
\text { campuses in Cameroon } \\
\text { In the qualitative study, } \\
\text { findings are in line with } \\
\text { the survey study. Some } \\
\text { additional aspects are pre- } \\
\text { sented here }\end{array}$} & $\begin{array}{l}\text { Research objective } \\
\text { - To identify health challenges and management strategies as well } \\
\text { as the dynamics of HSB in the camps and on the campuses }\end{array}$ \\
\hline & $\begin{array}{l}\text { Main findings } \\
\text { - Poor quality of treatment and frequent shortage of medication } \\
\text { prevented camp dwellers from using the clinics } \\
\text { - Students used quart-doctors as quasi-formal healthcare providers } \\
\text { because of financial constraints } \\
\text { - In both settings, the dynamics of HSB was influenced by local } \\
\text { perceptions, perceived disease severity and financial constraints }\end{array}$ \\
\hline & $\begin{array}{l}\text { Conclusions } \\
\text { - Disease risks and a combination of affordability, functionality and } \\
\text { reliability were major challenges for respondents } \\
\text { - Volatility of the formal healthcare services determined their use } \\
\text { - The versatile response, using a variety of resources in a comple- } \\
\text { mentary way, is the main mechanism associated with HSB in the } \\
\text { camps and on the campuses }\end{array}$ \\
\hline \multirow{3}{*}{$\begin{array}{l}\text { Chapter } 5 \\
\text { Understanding health } \\
\text { and well-being among } \\
\text { camp dwellers and uni- } \\
\text { versity students in Ca- } \\
\text { meroon: a salutogenic } \\
\text { approach }\end{array}$} & . \\
\hline & $\begin{array}{l}\text { To identify how stressors are experienced by camp dwellers and stu- } \\
\text { dents and to uncover the coping mechanisms they put in place to deal } \\
\text { with stressors }\end{array}$ \\
\hline & $\begin{array}{l}\text { Main findings } \\
\text { - Stressors are experienced by all respondents, some specific to } \\
\text { each group and others common to both groups } \\
\text { - Even in the presence of stressors, respondents can have meaning- } \\
\text { ful life experiences and strive to live happy and fulfilled lives } \\
\text { - There is a thin line between the stressors experienced by people } \\
\text { and the resources on which they draw to overcome stressors, as } \\
\text { sometimes what people draw on as resources could become what } \\
\text { they experience as stressors, and vice versa, e.g. free healthcare } \\
\text { services for camp dwellers }\end{array}$ \\
\hline
\end{tabular}




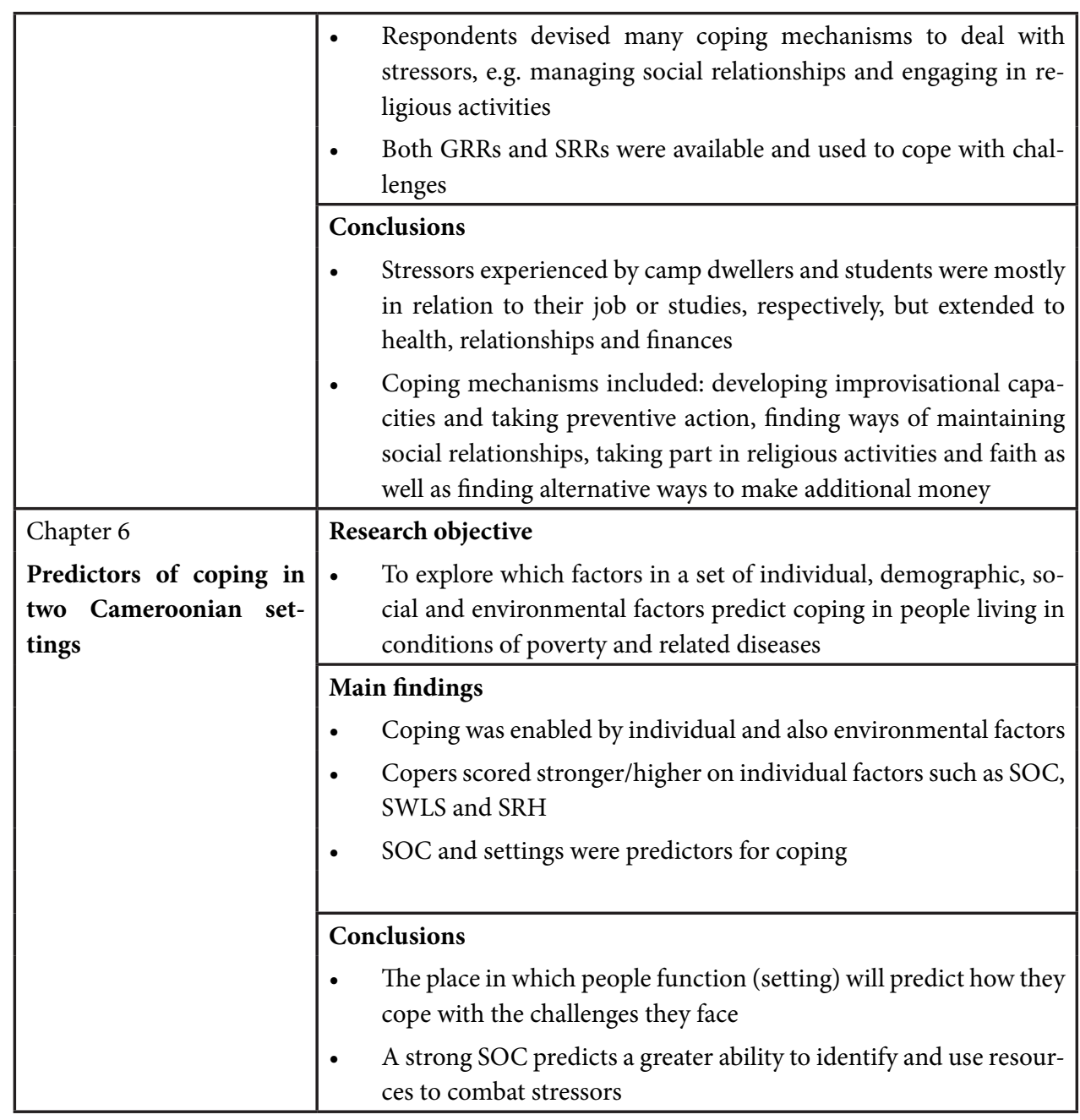




\section{Bringing it all together: including people's percep- tions and capacities for dealing with health challen- ges}

The main research question addressed in this thesis was: What factors underlie the maintenance of good health and overcoming stressors in the face of poverty-related diseases in Cameroon? This question aimed to get the overall picture of the different individual, social, material or environmental factors influencing health in two settings and how people manage.

Bringing the overall findings together: the perceptions of university students and camp dwellers towards PRDs (Chapter 2 and Chapter 3, respectively), their health-seeking behaviour (Chapter 4), the mechanisms they have developed to cope (Chapter 5) and the elements that enable coping (Chapter 6) present a picture of people having clear and articulate perceptions of the challenges they are facing and a rather strong agency or capacity to develop a noticeably diverse set of strategies to deal with their health challenges and shape the course of their lives.

From the findings, it can be concluded that PRDs not only reflect a specific set of diseases but also embody a broader set of issues that have to do with a variety of stressors as potential health challenges, in particular those related to living in conditions of poverty. The results of this thesis reveal that issues of hygiene in people's immediate living environment, the activities in which they are engaged - work on plantations and study for the respective groups that we studied - in combination with irregularity and overall shortage of financial means have the most impact on people's health. Even though this impact is negative in terms of increased disease risk, people do not remain passive but are triggered to respond and find alternative, often cheaper, forms of health support as well as creating a sort of mental immunity towards the many stressors they face.

In the following section, we discuss the main research findings in the light of overall insights and academic literature. Our study has taken up the topic of PRDs from a hitherto unexplored angle, and we present the findings with the aim of contributing towards a holistic or integrated programme to control or eradicate PRDs.

\section{The picture of PRDs and other health challenges in the settings}

Overall, this thesis has shown that most respondents from both settings identified the same three major PRDs - malaria, cholera and diarrhoea (Chapters 2 and 3). It was interesting to see that both groups identified the same diseases as major PRDs and also that the clas- 
sification was different from that identified by major health organisations [1-3]. Diseases considered as major PRDs by health organisations have so far been the focus of interventions with the goal of eradicating PRDs. Vaccine candidates or drug discoveries and other technical solutions have so far targeted malaria, HIV/AIDS and tuberculosis (TB) [4]. Even though malaria is unanimously accepted as a PRD, HIV/AIDS and TB were not perceived to be among the top three PRDs in either setting. In fact, TB was at the lower end of camp dwellers' and university students' ranking of common diseases and PRDs. The other PRDs perceived by our respondents (cholera and diarrhoea) are indeed diseases that cause many deaths in Sub-Saharan Africa especially, but do not receive as much attention as the infamous trio (malaria, HIV/AIDS and TB). Diarrhoea, for example, has been indicated as the cause of death for more children in a year than malaria, HIV/AIDS and TB combined [5]. Cholera is an infection that also has diarrhoea as a symptom and has been responsible for many epidemics in Sub-Saharan Africa [6]. The key to controlling diarrhoeic infections, whether caused by cholera or other microbial pathogens, is hygiene, water and sanitation [5]. These are challenges that were visible in the lives of respondents (Chapters 2, 3, 4, 5, 6). In fact, respondents attributed the presence of diseases primarily to the poor hygiene conditions in their living environments. The predominant linking of PRDs to poor hygiene (Chapters 2, 3, 4, 5, 6) presents an image of a main stressor faced by respondents in their daily lives. This picture is one of respondents' immediate environments being the source of diseases. As long as they live under those conditions, it is likely that the diseases that are common now and that they perceive as PRDs are going to stay. A focus on improving hygiene conditions is reflected in Sustainable Development Goal 6, to ensure the availability and sustainable management of water and sanitation for all [7].

This thesis showed that people living in camps and on campuses in Cameroon were able to manage to some extent in the poor hygiene conditions but had to deal with several aspects over which they had no control. The houses, for example, were provided by CDC in the case of the camp dwellers or by landlords in the case of the students. They therefore had to take what was offered primarily because there was a shortage in both cases. Given the above, the camp dwellers and the students did not have control over the quality standard of the houses in which they lived. On the other hand, regarding the quality of their living environments, the respondents could exercise their agency and make changes. Hygiene practices were reported as a way to prevent diseases. Initiatives such as the clean-up campaign in some camps are an example of camp respondents demonstrating agency. The students showed agency by cleaning their micro-environments. Even though individual hygiene practices are important, they may not be sufficient to arrest the spread of certain infections. In such a case, concerted effort or practice by all those living in the same area is a must. Malaria is an example in point here. To illustrate this, those who mentioned engaging in hygiene practices to stay healthy pointed out that not all of their neighbours did the same (Chapter 4 ). Their 
neighbours' conditions were indicated as reasons why mosquitoes were commonplace; this underscores the need for concerted action towards better sanitary environments.

Apart from the affordability aspects of healthcare services [8-10], few studies have addressed their reliability and functionality. Our study showed that these were crucial aspects determining the use of medical facilities. For example, camp dwellers who had the option of free healthcare services did not always use them because they came with challenges, for example unavailability of medication, poor quality of medication received, distance to the services, poor attitude of hospital staff and so forth (Chapters 4 and 5). These are important issues in addition to access to healthcare in terms of cost.

Beyond healthcare services, health and wellbeing are also determined by factors in people's living environment, their daily activities, their mental states and their relationships [11]. In this thesis, it was shown that all respondents faced one kind of challenge (stressor) or another (Chapter 5). Facing challenges or stressors in life is a given, as people experience the events of their daily lives $[12,13]$. The different challenges faced by respondents were partly context-specific, for example related to studies for the university students (poor study conditions) and job-related for the camp dwellers (poor working conditions). However, challenges were also common to both groups, for example uncertainty over finances and tensions over social relationships (Chapter 5). Overall, the results presented in this thesis indicate the close connection between the biophysical and social determinants of health, including people's agency in terms of perception of health challenges and the scope for action to maintain or improve their health.

\section{The role of perceptions in dealing with PRDs}

Studying agency and perceptions is not common practice in research in support of the fight against PRDs [14-16]. Our findings showed similar trends in perception and agency in both groups. For example, all respondents perceived malaria to be a normal part of everyday life and it was something they handled similarly, most prominently with informal treatments.

The qualitative study on health-seeking behaviour (Chapter 4) indicated the role of local perceptions (i.e. people's cultural beliefs) in determining response to diseases. This aspect has been confirmed in other studies $[17,18]$. Respondents strongly believed that tablets were ineffective in treating diseases such as typhoid and malaria (Chapter 4). Having such beliefs, they are unlikely to seek treatment from places where tablet administration is the modus operandi. Results from the surveys, presented in Chapters 2 and 3, showed that more than $80 \%$ of respondents in both settings reported that they would respond to malaria by using informal healthcare practices. By implication, interventions focusing on anti-malarial drugs are likely to be ineffective without a more thorough understanding of the role of informal 
medicine and mental factors as identified in Chapters 4 and 6. The connection between these factors has been observed in other studies on malaria $[19,20]$.

This thesis showed that the way in which CDC healthcare services were organised led to a deeper implantation of camp dwellers' perceptions of inefficiency. For example, the perception that medication given to labourers was not as good as that given to management staff made labourers reluctant to go to the clinics. Students also reported that tablets were not effective, in particular for malaria and typhoid (Chapter 4). This triggered the use of informal healthcare for malaria and typhoid. Our findings also show that the use of informal medication was complementary to official healthcare. People switched from informal to formal healthcare when perceived severity of disease was high or after unsuccessful attempts to recover by using self-medication and informal healthcare providers like small pharmacies and street vendors. This thesis highlights the fact that understanding or taking into account people's perceptions is a promising avenue through which the potential success of any health promotion intervention against PRDs can be achieved.

\section{Coping with PRDs}

With regard to informal responses to diseases, our findings revealed that people were acquainted with alternative treatments for their diseases. This is indicated by the different recipes for treatment they reported in Chapter 4 of this thesis. Self-medication and other informal healthcare practices such as using small pharmacies or street vendors, common in both settings, were probably based on prior successful experiences with the practice. Informal healthcare practices such as self-medication are not new [21]. They have been reported in studies for example by Osemene and Lamikanra [22] and Ondicho [23]. These practices, however, stand out in our studies because the reasons for their use are more complex than have been reported in other studies so far. These reasons go beyond having money, having free healthcare services, having free medication, to mostly perceptions and beliefs about the healthcare system, about the efficacy of medication, and to the appealing features of the informal health sector such as payment flexibility and proximity of the providers (Chapters $2,3,4,5)$.

It is unlikely that self-medication practices will stop. However, although a practice like self-medication indicates pro-activeness on the part of the respondent on the one hand, on the other hand it is a practice that calls for caution because the consequences can be quite severe [10]. Self-diagnosis could lead to erroneous conclusions, with consequent inappropriate self-medication. This could lead to delay in getting appropriate treatment $[23,24]$, potentially with fatal consequences. It is important to understand people's perceptions and find appropriate strategies to anticipate the high level of self-diagnosis and use of informal treatments. For example, media campaigns could focus more on supporting people in what 
they can do themselves and what alternative options they have for seeking treatment. Moreover, formal health services could learn from street vendors' distribution and sale strategies to improve the distribution of medication, for example by creating more flexibility in payment for malaria treatment [22].

Coping with PRDs and other challenges is also linked to other contextual and environmental factors (Chapter 6). From observations and also based on reported resources available, it can be seen that campus conditions were better than camp conditions. Generally, camps have been linked to high levels of congestion and poor sanitation [5]. A combination of demographic, dispositional and environmental factors associated with the campus context probably enabled better coping (chapter 6). This is in line with other studies [25].

Unlike findings reported in other studies [26-28], this study did not reveal self-efficacy as a predictor of coping. However, our findings did show that SOC, an indicator for a person's ability to respond to stressful situations $[25,29,30]$, was a predictor for coping. The challenges that respondents face in life are stressful. In order to move forward or to live the lives they want to live, they have to be able to manage these stressors [29,31], i.e. be able to identify and use available resources. People with a strong SOC are more able to do so than those with a weak SOC. The average SOC score was higher among the students than among the camp dwellers. The results in Chapter 6 showed that the enabling factors for coping were different between the camps and the campuses. Housing quality appeared a main factor in the camps, whereas for the students sex (in the biological differentiation sense) and overall conditions were more prominent. The overall higher SOC score among students, and the importance of overall conditions for coping, underline the importance of proper education and living conditions for dealing with health challenges. The situation in the camps is in line with this. Free healthcare is important to improve people's health situation but becomes less effective when other important health conditions, most prominently housing, do not offer people sufficient protection. Programmes to foster literacy and improve education in places such as the camps may lead to the development of a strong SOC among camp dwellers. Being able to identify and use resources in the camps and on the campuses is what facilitates successful coping [30], and this is dependent on having a strong SOC.

\section{The salutogenic model of health in the case of PRDs: the added value of our study}

Our study has approached PRDs from a hitherto unexplored angle. Predominantly, the fight against PRDs has been disease-focused and has lacked an integrated perspective, including ignoring social and other determinants of health. The SMH has enabled a holistic and more 
integrated approach to PRDs [32,33]. Internationally, measures have been taken towards advances in technology and medical care $[4,34]$. In Cameroon, the government's response has been specifically towards individual diseases, and research has focused on disease aspects, as outlined in the introduction of this thesis. By using the SMH, we have been able to bring out individual, social and environmental aspects relative to coping with PRDs. These included SOC, social infrastructures and perceived inadequacy of basic necessities (housing, food and water). These findings are important for successful and sustainable health interventions that aim to reduce or eradicate the devastating effects of PRDs. Our study highlights the fact that people are vital instruments to be included in matters that concern them, because they are the ones taking decisions about their health and welfare. The integrated findings indicate that people are active participants in the shaping of their lives, as can be seen by the coping mechanisms revealed in Chapter 4. This is also seen when respondents recognise that diseases are present because of the poor hygiene conditions in their living environment and take preventive measures/initiatives like the clean-up campaigns to ensure a better sanitary environment. Such a concerted action by people towards improving hygiene conditions is essential, but this needs to be supported by health organisations as well.

Instead of focusing only on the causes of diseases, the SMH shifts the focus towards people's agency and capabilities in dealing with health and wellbeing challenges present in their everyday lives. The SMH model enabled the elaboration of the different resistance resources: GRRs and SRRs and experiences that respondents identify and use to deal with PRDs and other stressors. In other words, by using a salutogenic model of health, we have been able to bring out the essential social determinants that enable coping with PRDs. Following the $\mathrm{SMH}$, we can conclude that, apart from individual factors such as perceptions of disease and of disease severity and SOC (Chapters $2,3,4,6$ ), social, traditional, alma mater, neighbourhood and church group membership and activities (Chapter 5) give meaning and create a sense of belonging in the lives of camp dwellers and students, and these are fundamental health-enabling factors that result in people being better able to cope with PRDs and other challenges [35]. Coping mechanisms that move people towards the health end of the ease-disease continuum, as revealed in this thesis, are starting points for the rethinking and re-analysis of measures to control PRDs and other challenges related to poverty.

\section{Methodological considerations}

One of the strengths of this study is that we included two diverse groups of people living in conditions of poverty (students and camp dwellers). By including these two groups, we have been able to show the diversity as well as the similarities in stressors experienced, resources available to respondents and coping mechanism they put in place. By employing the same research methods in each group, we ensured that we explored the same issues in both groups 
and can therefore reflect on the similarities and differences that we see in perceptions and in social and environmental determinants of health and coping mechanisms.

Moreover, by using both interviews and surveys, it was possible to get a fuller picture of what PRDs are and what they mean to two different groups of people. This fuller picture includes disease aspects, living conditions aspects as well as response aspects towards PRDs. Also, mixed methods increased the validity of the research findings and enabled a broader view of PRDs than would have been possible with either only the qualitative or only the quantitative method.

Another strength of this study is that in the survey we used standardised questionnaires to determine SOC, SWLS, SE, resilience and SRH. This means that the internal validity of the instruments was already established. Furthermore, we calculated the Cronbach's alpha for each of the questionnaires to ascertain the reliability of the survey instrument used. A limitation of our study is that the respondents were specific groups in society. This may limit the external validity of our study. However, it is expected that the differences witnessed among respondents in terms of socio-demographic characteristics cover a wide range of groups that can be found in society, and thus this study can be a starting point to explore similar investigations in other groups. One of the questionnaires we used in relation to coping was not standardised. Using a standardised coping questionnaire could have strengthened some of our results. It would be interesting for further research to use a standardised coping questionnaire in a follow-up study, as coping is of particular interest for studying PRDs and increasing our overall understanding of the lives of people living in poor conditions.

Reflection on the different approaches and theories used in this study indicates that these were instrumental in highlighting people's strengths and capacities. The SMH approach is oriented towards life and therefore leads to asking questions that will elucidate answers related to advancing in life. In conditions of poverty in particular, it is easy to focus on poverty or disease aspects as reflected in the dominance of the pathogenic model of health, which has so far been used relative to PRDs, and it is more difficult to highlight health-related aspects. By starting with a focus on what enables health even when it is not obvious, this study identified capacities that would not have been found without the SMH. Also, using the health belief model (HBM) and the health-seeking behaviour (HSB) theory were instrumental in understanding people's perceptions about PRDs and how they acted based on those perceptions. Using other theories alongside the SMH threw more light on many aspects. The HBM, for example, specifically highlighted people's perceptions and their role in disease responses. Also, the HSB theory particularly highlighted health challenges and response dynamics. Each of the approaches has its benefits and limitations, and their combined use, as in this thesis, can bring out the complementary value of these approaches. For 
example, the HBM has been criticised for being too focused on the individual, whereas the $\mathrm{SMH}$ goes beyond the individual to include social dynamics as well.

\section{Recommendations for future research and policy}

The results presented in this thesis provide a basis for rethinking and re-adjusting policies and strategies in the fight against PRDs. The SMH provided a complementary way of addressing PRDs. By using the SMH as a point of departure for this thesis, we are linking to the current debate on addressing poverty and related diseases as outlined in the sustainable development goals scheduled for achievement by 2030. With this thesis, we are revealing promising avenues through which poverty and PRDs can be addressed. A combination of both the pathogenic and the salutogenic models of health will provide a broad-based and potentially sustainable response to PRDs, in which the causes of diseases and risk factors will be known, medical interventions addressing diseases improved, and also people's agency and capacities highlighted and supported. Future research can use the SMH in other contexts of poverty and related diseases to strengthen the case for addressing PRDs with this model. Specific policy-relevant factors are listed below:

- The global interest in PRDs has been widespread, even though the focus for over fifteen years has been primarily on malaria, HIV/AIDS and TB, with limited success in eradicating them. This thesis has shown from both interviews and surveys that people perceive some diseases as common whereas others are more specifically attributed to poverty. Our study calls for health bodies to develop context-specific analysis of the relationship between poverty and diseases and an integrated approach. For the areas studied in this thesis, this implies including cholera and diarrhoea on the focus agenda in addition to malaria, HIV/AIDS and TB.

- People's living and working (study) conditions are instrumental in the shaping of their lives. There is a need for better policies geared towards improving the housing, working and study conditions of people living in conditions of poverty. An improved attitude towards health effects of study pressure on the part of university lecturers is essential for students to have meaningful and motivating learning experiences at the university.

- The quality of services offered by healthcare institutions and the attitude of the healthcare staff influence the utilisation of the facilities. We therefore recommend that a special focus be put on improving the service quality of healthcare facilities and the attitudes of healthcare workers.

- One of the recommendations of the Ottawa Charter for health promotion [36] is to 
strengthen community action. This thesis supports this recommendation. We have shown people's efforts in combatting the stressors they face. What they do on their own has limited effectiveness. By strengthening their initiatives in place - viz. clean-up campaigns, loan schemes like njangi - through participatory processes, the respondents' livelihoods can be improved.

- One of the factors that emerged from this thesis was the need for better health education interventions. It is essential to provide health education on the disadvantages of improperly carried out self-medication practices with respect to treatment failure and drug resistance and on how to effectively carry out diagnosis and treatment of minor conditions, because self-medication is an ongoing practice that is not about to stop. Such interventions would clarify misinformation and misconceptions that the respondents might have and seek to build on people's agency vis-à-vis their health to promote health.

- Small pharmacies and street vendors are ideal entry points to control diseases such as malaria, because the studies carried out in this thesis all pointed to how valuable these vendors are to the different groups of respondents. However, these vendors have limited training, if any, to deliver adequate health-related services. From the results obtained in this thesis, we advocate building the capacity of these vendors and also involving them in the fight against PRDs.

- Our study showed that monetary and other reliability and functionality factors were important elements influencing decisions on how to respond to health challenges. These issues should therefore be addressed in the current fight against PRDs. In addition to improving the quality of, and access to, healthcare services, we recommend health-promotion interventions with a focus on acknowledging the social and environmental determinants of health and their inclusion in intervention strategies. 


\section{References}

1. WHO. Global report for research on infectious diseases of poverty. Geneva: World Health Organisation; 2012.

2. WHO. Poverty and health. Geneva: World Health Organisation; 2016.

3. MINSANTE. Plan strategique nationale de la lutte contre le paludisme au Cameroon, 2007-2010. Yaoundé: Ministère de la Santé Publique; 2007.

4. Radošević K, Rodriguez A, Lemckert A, Goudsmit J. Heterologous prime-boost vaccinations for poverty-related diseases: advantages and future prospects. Expert Rev Vaccines. 2009;8: 577-592.

5. Bartram J, Cairncross S. Hygiene, sanitation, and water: forgotten foundations of health. PLOS Med. 2010;7: e1000367.

6. Talavera A, Perez EM. Is cholera disease associated with poverty? J Infect Dev Ctries. 2009;3: 408-411.

7. Wilkinson D, Gouws E, Sach M, Karim SSA. Effect of removing user fees on attendance for curative and preventive primary health care services in rural South Africa. Bull World Health Organ. 2001;79: 665-671.

8. Falkingham J. Poverty, out-of-pocket payments and access to health care: evidence from Tajikistan. Soc Sci Med. 2004;58: 247-258.

9. Dzator J, Asafu-Adjaye J. A study of malaria care provider choice in Ghana. Health Policy. 2004;69: 389-401.

10. Biswas P, Kabir ZN, Nilsson J, Zaman S. Dynamics of health care seeking behaviour of elderly people in rural Bangladesh. Int J Ageing Later Life. 2006;1: 69-89.

11. Chipwaza B, Mugasa JP, Mayumana I, Amuri M, Makungu C, et al. Self-medication with anti-malarials is a common practice in rural communities of Kilosa district in Tanzania despite the reported decline of malaria. Malar J. 2014;13: 252.

12. Von Bothmer MIK, Fridlund B. Self-rated health among university students in relation to sense of coherence and other personality traits. Scand J Caring Sci. 2003;17: 347-357. 
13. Antonovsky A. Health, stress, and coping. San Francisco CA: Jossey-Bass; 1979.

14. Antonovsky A (1996) The salutogenic model as a theory to guide health promotion. Health Promot Int. 1996;11: 11-18.

15. Pryce H, Metcalfe C, Hall A, Claire LS. Illness perceptions and hearing difficulties in King-Kopetzky syndrome: What determines help seeking? Int J Audiol. 2010;49: 473481.

16. Joshi MS, Lalvani A. 'Home from home': risk perceptions, malaria and the use of chemoprophylaxis among UK South Asians. Ethn Health. 2010;15: 365-375.

17. Schoormans D, Mulder BJ, van Melle JP, Pieper PG, van Dijk AP, et al. Illness perceptions of adults with congenital heart disease and their predictive value for quality of life two years later. Eur J Cardiovasc Nurs. 2014;13: 86-94.

18. Sabuni LP. Dilemma with the local perception of causes of illnesses in Central Africa: muted concept but prevalent in everyday life. Qual Health Res. 2007;17: 1280-1291.

19. Asampong E, Dwuma-Badu K, Stephens J, Srigboh R, Neitzel R, et al. Health seeking behaviours among electronic waste workers in Ghana. BMC Public Health. 2015;15: 1065. doi: 10.1186/s12889-015-2376-Z

20. Muela SH, Ribera JM, Tanner M. Fake malaria and hidden parasites-the ambiguity of malaria. Anthropol Med. 1998;5: 43-61.

21. Okpako DT. Traditional African medicine: theory and pharmacology explored. Trends Pharmacol Sci. 1999;20: 482-485.

22. Osemene K, Lamikanra A. A study of the prevalence of self-medication practice among university students in Southwestern Nigeria. Trop J Pharm Res. 2012;11: 683-689.

23. Ondicho JM. Factors associated with use of herbal medicine among the residents of Gucha sub-county, Kenya. Master's thesis. Jomo Kenyatta University of Agriculture and Technology; 2015.

24. Mackian S, Bedri N, Lovel H. Up the garden path and over the edge: where might health-seeking behaviour take us? Health Pol Plan. 2004;19: 137-146. 
25. Grundy J, Annear P. Health-seeking behaviour studies: a literature review of study design and methods with a focus on Cambodia. Melbourne, Australia: The Nossal Insitute for Global Health; 2010.

26. Eriksson M, Lindström B, Lilja J. A sense of coherence and health. Salutogenesis in a societal context: Åland, a special case? J Epidemiol Community Health. 2007;61: 684-688.

27. Bandura A. Self-efficacy: the exercise of control. Am J Health Promot. 1997;12: 8-10.

28. Jex SM, Bliese PD, Buzzell S, Primeau J. The impact of self-efficacy on stressor-strain relations: coping style as an explanatory mechanism. J Appl Psychol. 2001;86(3): 401-409.

29. Luszczynska A, Scholz U, Schwarzer R. The general self-efficacy scale: multicultural validation studies. J Psychol. 2005;139: 439-457.

30. Lindström B, Eriksson J. The hitchhiker's guide to salutogensis: salutogenic pathways to health promotion. Helsinki: Folkhalsan Research Centre; 2010.

31. Eriksson M, Lindström B. Bringing it all together: the salutogenic response to some of the most pertinent public health dilemmas. In: Morgan A, Ziglio E, Davies M, editors. Health assets in a global context. New York: Springer; 2010, pp. 339-351.

32. Mittelmark MB, Sagy S, Eriksson M, Bauer GF, Pelikan JM, et al. The handbook of salutogenesis. Heidelberg: Springer Open; 2017. doi 10: 978-973

33. Alnazly E. Coping strategies and socio-demographic characteristics among Jordanian caregivers of patients receiving hemodialysis. Saudi J Kidney Dis Transplant, 2016;27(1): 101-106. doi: 10.4103/1319-2442.174088

34. Olesen OF, Hoeveler A. How can the industrial world help to implement new vaccines against poverty-related diseases? In: Kaufmann SHE, Lambert PH, editors. The grand challenge for the future. Basel: Springer; 2005, pp. 37-52.

35. Krause C. Developing sense of coherence in educational contexts: making progress in promoting mental health in children. Int Rev Psychiatry. 2011;23(6): 525-532. doi: $10.3109 / 09540261.2011 .637907$

36. World Health Organisation. Ottawa charter. Geneva: World Health Organisation; 1986. 



\section{Summary}

Ever since the formulation of the Millennium Development Goals in the year 2000, malaria, HIV and tuberculosis (TB) have been prominent on the international health and development agenda. In Cameroon, both the ministry of public health and research ventures have also focused on the infamous trio. Goals to eradicate these diseases have been the main focus of many (inter)national organisations. The approach to meet these goals has focused on diseases and has brought great advances in medical and technological development but has paid less attention to social and other determinants of health or to people's capacities and agency to respond to issues regarding their health. Consequently, very little is known about how people cope with the conditions of poverty and diseases resulting from those conditions. This thesis employs the salutogenic model of health to highlight the capacities of people, living in conditions of poverty and high disease risks, to cope with the challenges that they face. The study was carried out in Cameroon among two different groups: workers of the Cameroon Development Corporation (CDC) and their dependents living in camps, and students from the universities of Buea and Yaoundé living on what we refer to as campuses. The overall aim of this thesis is to understand how conditions of poverty impact people's health and how they manage these challenges. Specifically, the study aims to unravel the interlinkages between poverty and health by creating a deeper understanding of the social and material dynamics that enable people's capacity to preserve health, anticipate health risks, and mitigate or recover from stressors such as poverty-related diseases (PRDs).

The main research question - what factors underlie the maintenance of good health in the face of poverty-related diseases - is addressed by four specific research questions that each cover aspects of how camp dwellers and students understand and cope with PRDs and other challenges. The specific research questions answered in this thesis are:

1. What factors underlie people's perceptions of PRDs and how do these influence the way people respond to diseases?

2. What are the health challenges faced by camp dwellers and university students and how do they respond to those challenges?

3. How are stressors experienced by camp dwellers and university students and what mechanisms do they use to cope with stressors?

4. Which factors influence effective coping with health challenges in the settings? 
These questions are addressed in a cross-sectional methodological design involving two phases of data collection in 2013 and 2014 in Cameroon. In the first phase, observations, preliminary interviews, reading of documents and interviews with 21 camp dwellers and 21 students were carried out. Based on these observations and interviews, a set of situation-specific questions was added to standardised questionnaires that together comprised the second (survey) phase of the study. The questionnaire was filled out by 237 camp dwellers and 272 students. The results of phase one and phase two data collection are presented and discussed in subsequent chapters.

In chapter 2, results are presented of survey data from 272 university students. The objective of the chapter is to investigate respondents' perceptions about common diseases and diseases related to poverty, how students respond to diseases and the motivations for their responses and, finally, to identify the determinants (perceived benefits and barriers) of the participants' use of healthcare services. The conceptual framework for the chapter is based on the health belief model. The results show that malaria was perceived as the most common disease and also a major PRD. Contrary to official rankings of HIV/AIDS and TB, cholera and diarrhoea were considered as other major PRDs. Also, typhoid fever was perceived to be more common and a greater PRD than HIV/AIDS and TB combined. The most prominently attributed cause for diseases was (lack of) hygiene. In response, students deployed formal and/or informal healthcare strategies, depending on factors like available money, perceived severity of the disease and disease type. Discrepancies were observed in respondents' responses to diseases generally and to malaria in particular. Even though respondents predominantly reported a formal healthcare response towards diseases in general, for malaria informal responses dominated. There was an overall strong awareness and (pro)activity among students for dealing with diseases.

Chapter 3 also used the framework of the health belief model, with the objective of understanding camp dwellers' perceptions about common diseases and PRDs, as well as how they managed these. The results show that commonly perceived diseases were malaria, typhoid and diarrhoea. The top three perceived PRDs were malaria, cholera and diarrhoea. Malaria was therefore perceived to be both a common disease and a PRD. Poor hygiene conditions were attributed causes for PRDs and common diseases. As in the case of the students, using formal healthcare services was reported as the means to generally respond to diseases. This was dependent, however, on factors such as having money, perceived severity of illness, duration of illness and availability of drugs at home. The way camp dwellers responded to malaria was similar to the way the students responded. Malaria was perceived a very common disease and a normal occurrence in respondents' daily life. Camp dwellers reported that they mostly used informal healthcare in response to malaria, including self-medication practices, using small pharmacies and street vendors. Further analysis was carried out to reveal which 
factors determine the use of formal healthcare services to treat malaria. The results show that people who face water challenges are more likely to seek formal healthcare for malaria, and broader socio-demographic characteristics did not determine the use of formal healthcare services in the case of malaria.

Using the health-seeking behaviour (HSB) theory, Chapter 4 identifies health challenges faced by camp dwellers and students and how they managed those challenges. Data were collected from interviews among 21 camp dwellers and 21 students. The results show that health challenges in the camps and on the campuses were related not only to the presence of diseases but also to the shortcomings of the health system. The latter includes aspects of affordability, reliability and functionality. The volatile nature of healthcare services was a factor that hindered their use. In order to respond to diseases, respondents utilised formal healthcare services as well as informal medication and treatments, including self-medication practices, using small pharmacies and street vendors. Self-medication practices were reported more on the campuses than in the camps, given that students did not have free healthcare services like the camp dwellers did. Respondents also showed pro-activeness by cleaning up their individual space on the campuses or carrying out clean-up campaigns in some camps as preventive measures to stay healthy. The dynamics of HSB were influenced by local perceptions, perceived disease severity and financial constraints. In both settings, respondents used a variety of means in a complementary way to maintain their health.

Using the salutogenic model of health, Chapter 5 investigates the different types of stressors as experienced by camp dwellers and university students and explores how they were able to find mechanisms to cope with these stressors. The results show that stressors were either specific to each group of respondents (e.g. work or study for the camp dwellers and the students, respectively) or common to both groups (e.g. finances). Even in the presence of stressors, respondents were able to strive for meaningful life experiences. Stressor-resource interchangeability was seen in both settings, especially in the case of free healthcare services for the camp dwellers and of studies for the university students. This chapter reveals several mechanisms through which respondents managed their challenges. The specific mechanisms included alternative ways to earn additional money, maintaining social relationships, taking part in religious activities and faith, preventive action and improvisation.

Using the salutogenic model of health, Chapter 6 explores which individual, demographic, social and environmental factors could predict coping in people living in conditions of poverty and related diseases. The main findings indicate that coping was enabled by individual and also environmental factors. People who coped had higher scores on individual factors such as sense of coherence (SOC), subjective wellbeing (SWLS) and self-rated health (SRH). Two factors stood out as predictors of coping: settings and SOC. The place where people live 
(setting) predicted how these people coped with their challenges. Better coping was found in the camps setting. Also, having a stronger SOC predicted a greater ability to identify and use resources to combat stressors.

Chapter 7 presents the overall conclusion of the thesis. The main research question of this thesis: What factors underlie the maintenance of good health and overcoming stressors in the face of poverty-related diseases in Cameroon? is answered in this chapter. The main findings of the overall research, presented in the empirical chapters, show the picture of PRDs and other health challenges in the settings, the role of perceptions in dealing with PRDs and the coping strategies employed by people to deal with PRDs. From the findings, this thesis concludes that PRDs not only reflect a specific set of diseases but also embody a broader set of issues that have to do with a variety of stressors as potential health challenges, in particular those related to living in conditions of poverty. Specifically, the results of this thesis reveal that issues of hygiene in people's immediate living environment, the activities in which they are engaged - work on plantations and study for the respective groups that we studied - in combination with irregularity and overall shortage of financial means have the most impact on people's health. Even though this impact is negative in terms of increased disease risk, people do not remain passive but are triggered to respond and find alternative, often cheaper, forms of health support as well as creating a sort of mental immunity towards the many stressors that they face. 


\section{Acknowledgements}

When I embarked on this $\mathrm{PhD}$ journey, I was so ready. It was for me an expected continuation of my career goals. There was never a doubt in mind from the time I was a little girl that I would do a $\mathrm{PhD}$. It was in my plans long before I got into a university. I had it all worked out even though it didn't actually follow the timeline I put. For a while it seemed like I was on a journey to do several Masters degrees but that ended when I was able to come back to Wageningen to do a PhD.

I am grateful to Wageningen University and Research for awarding me the scholarship to do a PhD and to the Institute of Medical Research and Medicinal Plants Studies for granting me the permission to embark on this journey.

Many people have been instrumental to the completion of this PhD and as I write this, I am humbled and indeed very grateful.

I would like to offer my sincere thanks to my promotor, Maria Koelen for her patience, support and encouragement, commitment to quality and meticulousness. You patiently went over the papers over and over again with an eye spotted even the tiniest of errors. Thank you. When you were overwhelmed with a million other duties, you still had time for me.

Thank you Lenneke for your support. You were a great asset to the team. Quick to spot inconsistencies and meticulous in your reviews. I am grateful you were so thorough. Thank you.

Harro, what can I say, you are my co-promotor, you are my friend. I have known you and Maria for over 10 years now and always, you have been a great help, a great support. Thank you for always being the one I could run to with all my worries and confusion. Our discussions always brought clarity to previously confusing situations. I am grateful your office was always open for me to come any time. Your patience and dedication, I cannot forget. Thank you.

This research would not have been possible without the cooperation of my respondents and those who facilitated my access to the respondents. I am grateful to the Management of CDC for the permission granted to do this research in the camps. Special thanks to $\mathrm{Mr}$ Foteh Vincent of CDC for helping me get permission from CDC. I benefited from your deep knowledge of how CDC works. Thanks also to Mr Ewane Etape, Mr Ndumbe, Elizabeth Esimboe for their support and facilitation for data collection. 
To my reliable assistants Jerry Junior, Elizabeth Enanga, Vicky, Matilda, Honorine, TP, Nanyongo, Cristal, Golda, Eyole and all the others I have not named, thank you.

I am also grateful to my colleagues of the Health and Society Group. Thanks to Lette, Carlijn, Lisanne, Sabina, Karlijn, Niels, Jeanine, Mariette, Emily, Marion, Kirsten, Franshelis, Laura, Annemarie, Renske and the new comers: Yvette, Kristel and Christianne. Thank you HSO group, I enjoyed every single lunch walk discussion. Thank you Sabina for answering my questions on statistics and to Lette for her invaluable support in statistics. I learnt a lot from you. I am thankful to Lette and Carlijn for being my paranymphs. Thanks also to Jos Hogeling for cover design and inside work of the thesis.

Thanks also to the support staff. Carry, Margaret, Hedy and Sandra. Your support was invaluable. Thanks Carry for being a special problem solver, Dutch letter reader etc. I appreciate all you have done.

Staying in Wageningen was made so much fun because of my special friends of "members only". Big thanks to Daniel, Faith and Aisha. Being part of 'Members only' was such an uplifting experience. You guys made Wageningen so much fun and I appreciate it. Big thanks to my other very caring friends: Gino, Nurudeen, Djalal, Dawit, Rebecca, Inge, Prisca, and Leon Pijnenburg. Thanks also to fellow members of the WASS PhD council Paola, Giacomo, Sanne and Viet. Working with you on the council was much fun and a great learning experience. We made a good team. I will miss our meetings and our event planning sessions. I am thankful to Catherine O'dea for the painstaking editing she so tirelessly did. Catherine, thank you for being so understanding and ready to meet up with my sometimes very urgent requests.

Thank you to Leontine Visser, my mentor, for all advise and productive discussions we had as well as for taking time to read my manuscripts. I am also thankful to my opponents : Paul Richards, Han van Dijk, Meghan Ormond and Bengt Lindstrom who took time to read and appraise this thesis. Thank you also Anna Bonmati for stepping in the role of my opponent.

Special thanks to my small Cameroonian community here in Wageningen. It is so great to be among you guys. Thanks to Caroline for all the 'retouches', meals and support. Thank you Favour for just being you! Thank you Simplice Tagne for being a real "frère". Always helping me with my bicycle troubles and packing. Always available when I call and always saying 'coucou' no matter how many times I said not to :) Merci beaucoup!. Thanks also to you Sammy, my personal person. It was great having you near Wageningen. I appreciate everything. 
To my corridor mates both past and present, I say thanks. Wiebe, Timon, Jesse, Paul, Shi, Mirthe, Abdulai, Vasiliki, Jean, Huang, Thanos, Rebecca, Veronika, Branco, Kirsten, Chrissy, Julia, Sophie, Victor etc. It was a great pleasure living with you guys.

I would also like to say a big thank you to my AGP family. Thank you Pastor Farai and Busi. Thank you Sunday, Maureen, Ijeoma, Ikenna, Pastor Adesoa, Elton, Ednah, Ernest and all the big AGP family. Thanks to all members of the Monday prayer team. Being part of the Amazing grace Parish was such a blessing to my spiritual life.

I say thanks to my colleagues in Cameroon as well. Sincere thanks to my boss, Prof Essame Oyono for all the support. You easily granted me permission to travel each time I had to. Thanks also to Prof Moyou Roger for his support and to all the staff of the 'Centre de Recherches Medicales' in Nkomo- Yaoundé. Many thanks to Lucia, Edward, Rodrigue and Amedée. Thanks also to our good friends in Yaoundé, Bertin and Patricia for being there for us every time.

Heartfelt thanks to my dearest Siny ter Borg. Words are not sufficient to say how much you mean to me. You have been a wonderful mother and friend to me and I am truly grateful. Your concern about my welfare, my studies and the kids has always touched me deeply. You have been there for me for over 10 years now. I feel honoured to have you with me as I celebrate the end of this trajectory. Thank you for all the wonderful times we spent together, for the great people I met through you and for the immense support I received from you. I am truly grateful. Thanks also to Robert and Tineke and all the other wonderful Dutch people I met.

To my dearest father Jerry Makoge and mom Lenore Eposi, I say I feel honoured to be your daughter. I am grateful for the support, prayers and blessings that have come from you both. Darl, before I started this $\mathrm{PhD}$, we discussed and we knew this day would come and that you will be here with me to see me do this. I am grateful because you always believed in me.

To my special siblings: Laura, Tracy, Junior and Golda. Big big thanks. Golda and Junior you helped me at various points in my research and for that, je dis grand merci... Laura and Tracy, you guys are just the best. Being able to talk to you guys or see you, Tracy, in France and meet my namesake was an energy booster.

Thanks to my aunt Gilly Moks for all the weekends you had the kids over when I was absent and for the love you lavished on them. Thanks also to Enanga (Ngongis) for checking out on the kids from time to time. 
My sincere and heartfelt gratitude goes to my mother-in-law. Dorothy Forbin. Mummy, I am truly grateful for the care you took of the kids during my absence. I appreciate the waking up early to get them ready for school, making sure food was ready before they came back, the sleepless nights when they were sick and your total dedication to your grandchildren. Alex and I appreciate everything you have done. Thank you. You are one of a kind. Thanks also to the rest of the Minkan crew: Ernie, Scott, Ilona and Dahlia, Shella and Bih.

To my amazing kiddos, Astera, Bonny and Siny. I am so thankful for the sacrifices you all made. Accepting to be without a mother for many long months. I am very proud of you all and of the wonderful kids you are. Keep on excelling!!! Thank you guys for the cards you wrote to me each time I was leaving and had ready again when I came back. You guys rock!! To Alex, words are not enough to express my gratitude. Thank you so much for being the mother and father many times. Knowing you were there, made me not worry about the kids. Thank you for your support in the pursuit of my studies. I know it has not been easy for you but you held on and I am grateful for the sacrifices. Merci...

Finally, I give thanks to the Lord almighty because without his grace, this would not have been possible. 


\section{About the author}

Valerie Makoge was born on the 13th of February in Buea, Cameroon. As a child, she travelled frequently around Cameroon given her father's official assignments. She obtained her GCE O’ Level certificate in Bilingual Grammar School (BGS) Molyko-Buea and A'L certificate in the Government Bilingual High School Essos- Yaoundé. Valerie then enrolled into the University of Buea, from where she obtained a B.Sc. (Hons) in Biochemistry and an M.Sc. in Zoology (Parasitology). In 2002, she was recruited as a researcher (Attaché de recherche) at the Institute of Medical Research and Medicinal Plant studies (IMPM) of the Ministry of Scientific Research and Innovation (MINRESI) and in 2003, she enrolled into the University of Yaoundé for a DEA in molecular Parasitology. In 2005, Valerie obtained a scholarship from the 'Anne van den Ban fonds' to do another Master's degree in Wageningen University. She enrolled into the Management of Agro-ecological Knowledge and Social change (MAKS) programme which was designed to introduce social sciences to people from a non-social science background. During this programme, she carried out research on communication strategies relative to HIV/AIDS in Cameroon. The title of her thesis was "AIDS fatigue: myth or reality". Also during this programme, Valerie spent three months in Rome-Italy for an internship at the Food and Agricultural Organisation (FAO) of the United Nations. She graduated cum laude from the MAKS program in 2007 and in 2008, she won the Top talent grant for students who excelled at the Masters level and returned to Wageningen. Valerie went back to Cameroon in 2008 and continued working as a researcher in the Medical Research Centre of IMPM, a position she currently holds (now, Chargé de recherche). In 2012, Valerie obtained a scholarship from Wageningen University and started her doctoral studies at the Health and Society group. For Valerie, PhD is not only about research. She gave several guest lectures at the BSc and MSc level (Advances of health promotion) in Wageningen University. In the last year of her PhD trajectory, Valerie joined the WASS PhD council and was also a member of the WASS Education Committee. Her areas of interest include dynamics in malaria and other parasitic diseases, health-seeking behaviour, health communication and health promotion. 


\section{List of publications}

\section{Selected articles in international scientific journals}

1. Makoge V, Vaandrager L, Maat H, Koelen M. Poverty and health among plantation labourers in Cameroon: perceptions, challenges and coping strategies. In press

2. Makoge V, Maat H, Vaandrager L, Koelen M. Poverty-related diseases (PRDs): unravelling complexities in disease responses in Cameroon. Tropical medicine and health. 2017 Jan 14;45(1):2.

3. Makoge V, Maat H, Vaandrager L, Koelen M. Health-Seeking Behaviour towards Poverty-Related Disease (PRDs): A Qualitative Study of People Living in Camps and on Campuses in Cameroon. PLOS Neglected Tropical Diseases. 2017 Jan 4;11(1):e0005218.

4. Makoge V, Maat H, Edward N, Emery J. Knowledge, attitudes and practices towards malaria in Mbonge and Kumba sub-divisions in Cameroon. International Journal of TROPICAL DISEASE and Health. 2016; 15(2):1-3. ISSN: 2278-1005, NLM ID: 101632866.

5. Makoge V, Nkengazong L, Emery J, Moyou RS. Parental response to malaria and other diseases in children in South West region, Cameroon. Annals of Biological Research, 2015, 6 (12) 30-36. ISSN 0976-1233.

6. Zeukeng F, Tchinda VH, Bigoga JD, Seumen CH, Ndzi ES, Abonweh G, Makoge V, Motsebo A, Moyou RS. Co-infections of malaria and geohelminthiasis in two rural communities of Nkassomo and Vian in the Mfou health district, Cameroon. PLoS Neglected Tropical Diseases. 2014 Oct 16;8(10):e3236

7. Makoge V, Ndzi E, Mbah G, Nkengazong L, Matsebo A, Moyou R. Status of malaria-related knowledge in school-going children in Cameroon. Archives of Applied Science Research. 2013; 5(1):105-11.

8. Valerie Dione Makoge, Geraldine Abongwen, Lucia Nkengazong, Ndzi Edward, and Sahfe, Roger Somo Moyou. Falciparum malaria, helminth infection, and anaemia in asymptomatic pupils in four villages in Cameroon. European Journal of Zoological Research 1.2 (2012): 54-59. 
9. Mbacham W.F, Mimche N.P, Masumbe P.N, Evehe M.S, Nji A, Amunom I, Daily J, Makoge V D, Laserson K, Songmbe M.Y, Lomah N, Enyong P, Titanji P.K. and Wirth D. F.(2008) Limited variation of the 5 'cis-control region of the transmission blocking vaccine candidate Pfs 25 amid great genetic diversity of Plasmodium falciparum in Cameroon. pgs 523- 533. African Journal of Biotechnology.

\section{Selected Conference presentations}

1. Makoge VD, Maat H, Koelen M. Understanding Poverty Related Diseases from a Salutogenic perspective. Oral Presentation at the Innovative Alliances for Global Health conference in De Rode Hoed, Amsterdam. September 26, 2012.

2. Makoge VD, Maat H, Koelen M. (2013). Poor health, poor science; poverty-related diseases in Cameroon. October 9th -13th. Oral presentation at the $4 \mathrm{~S}$ annual conference. San Diego, USA 


\section{Completed Training and Supervision Plan Wageningen School of Social Sciences (WASS) Dione Makoge Epse Forbin Valerie}

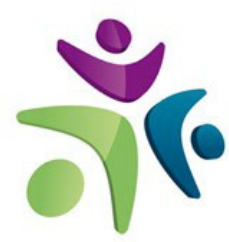

Wageningen School of Social Sciences

\begin{tabular}{|c|c|c|c|}
\hline Name of the learning activity & $\begin{array}{c}\text { Department/ } \\
\text { Institute }\end{array}$ & Year & $\begin{array}{c}\text { ECTS } \\
(1=28 \mathrm{hrs})\end{array}$ \\
\hline
\end{tabular}

\section{A) Project related competences}

Advances in Health promotion, HSO 31806

Qualitative data analysis, YRM 60806

WUR

2012

6

Research Methodology: from topic to proposal

WUR

2013

6

Quantitative Research methods and Statistics,

WASS

2012

4

MAT 22306

Writing Research proposal

WUR

2013

3

Interviewing professionals

WASS

2012

6

Data management

WASS

2012

0.5

B) General research related competences

Information Literacy including EndNote Intro-

WUR Library

2013

0.4

duc-tion

WASS Introduction Course

WUR Library

2013

0.6

"Understanding Poverty related Diseases from

WASS

2013

NVGT/US/AIHGD,

2012

Am-sterdam

a salutogenic perspective"

WGS

2012

tific paper

"Poor Health, Poor Science; Poverty related

4S (USA)

2013

$$
1
$$

Dis-eases in Cameroon"

"Health seeking behaviour towards Poverty

WASS PhD day

2016

re-lated Disease (PRD's): A qualitative study of peo-ple living in camps and campuses in Cameroon"

\section{C) Career related competences}

Mobilising Local health Promotion Systems for Equity

ETC-PHHP SUm-

2014

8

mer Course,

France

Scientific publishing

WGS

2014

0.3

Global Health and Science and Technology

Maastricht

2013 


\begin{tabular}{llcc}
\hline Name of the learning activity & \multicolumn{1}{c}{$\begin{array}{c}\text { Department/ } \\
\text { Institute }\end{array}$} & Year & $\begin{array}{c}\text { ECTS } \\
\text { (1=28 hrs) }\end{array}$ \\
\hline Mental Coaching & WGS & 2013 & \\
Stress Identification and Management & WGS & 2013 & \\
Guest lecture Wageningen University & WUR & 2013,2014 & 2 \\
Doing a Systematic Literature Review & WASS & 2013 & 1.5 \\
Brain Training & WGS & 2015 & 0.3 \\
WASS PhD Council (Member and member of & WASS & 2016 & 2 \\
WASS education committee) & & & 46.8 \\
\hline Total
\end{tabular}


The research described in this thesis as well as printing and other associated costs was financially supported by Wageningen University and Research.

The Institute of Medical Research and Medicinal Plant Studies (IMPM) was a collaborating partner throughout the study.

Cover design and Lay Out by: Jos Hogeling

Printed by: Proefschriftmaken.nl

Published by: Digiforce/ Proefschriftmaken.nl, Vianen 